BEN S. B ER N A N K E

Board of Governors of the Federal Reserve System

VINCENT R. REINHAR T

Board of Governors of the Federal Reserve System

B R I A N P.SA C K

Macroeconomic Advisers, LLC

\title{
Monetary Policy Alternatives at the Zero Bound: An Empirical Assessment
}

THE CONVENTIONAL INSTRUMENT of monetary policy in most major industrial economies is the very short term nominal interest rate, such as the overnight federal funds rate in the case of the United States. The use of this instrument, however, implies a potential problem: Because currency (which pays a nominal interest rate of zero) can be used as a store of value, the short-term nominal interest rate cannot be pushed below zero. Should the nominal rate hit zero, the real short-term interest rate-at that point equal to the negative of prevailing inflation expectations - may be higher than the rate needed to ensure stable prices and the full utilization of resources. Indeed, an unstable dynamic may result if the excessively high real rate leads to downward pressure on costs and prices that, in turn, raises the real short-term interest rate, which depresses activity and prices further, and so on.

Japan has suffered from the problems created by the zero lower bound (ZLB) on the nominal interest rate in recent years, and short-term rates in countries such as the United States and Switzerland have also come uncomfortably close to zero. As a consequence, the problems of conducting monetary policy when interest rates approach zero have elicited considerable attention from the economics profession. Some contributions have framed the

The views expressed are our own and are not necessarily shared by anyone else in the Federal Reserve System. We have benefited from conversations with many colleagues. We also thank Thomas Gallagher of the ISI Group and Jeffrey Young of Nikko/Citigroup for providing data on their real-time interpretations of, respectively, U.S. and Japanese monetary policies. 
problem in a formal general equilibrium setting; another strand of the literature identifies and discusses the policy options available to central banks when the zero bound is binding. ${ }^{1}$

Although there have been quite a few theoretical analyses of alternative monetary policy strategies at the ZLB, systematic empirical evidence on the potential efficacy of alternative policies is scant. Knowing whether the proposed alternative strategies would work in practice is important to central bankers, not only because such knowledge would help guide policymaking in extremis, but also because the central bank's choice of its long-run inflation objective depends importantly on the perceived risks created by the ZLB. The greater the confidence of central bankers that tools exist to help the economy escape the ZLB, the less need there is to maintain an inflation "buffer," and hence the lower the inflation objective can be. ${ }^{2}$

This paper uses the methods of modern empirical finance to assess the potential effectiveness of so-called nonstandard monetary policies at the zero bound. We are interested particularly in whether such policies would work in modern industrial economies (as opposed to, for example, the same economies during the Depression era), and so our focus is on the recent experience of the United States and Japan.

The paper begins by noting that, although the recent improvement in the global economy and the receding of near-term deflation risks may have reduced the salience of the ZLB today, this constraint is likely to continue to trouble central bankers for the foreseeable future. Central banks in the industrial world have exhibited a strong commitment to keeping inflation low, but inflation can be difficult to predict. Although low inflation has many benefits, it also raises the risk that adverse shocks will drive interest rates to the ZLB.

Whether hitting the ZLB presents a minor annoyance or a major risk for monetary policy depends on the effectiveness of the policy alterna-

1. Examples of the first approach include Woodford (2003), Eggertsson and Woodford (2003a, 2003b), Benhabib, Schmitt-Grohé, and Uribe (2002), and Auerbach and Obstfeld (2004); examples of the second include Blinder (2000), Bernanke (2002), Clouse and others (2003), and Bernanke and Reinhart (2004).

2. Phelps (1972), Summers (1991), and Fischer (1996) have noted the relevance of the ZLB to the determination of the optimal inflation rate. Coenen, Orphanides, and Wieland (2004) and Adam and Billi (2004) provide simulation evidence on the link between the ZLB and the optimal inflation rate. 
tives available when prices are declining. Following a recent paper by two of the present authors, ${ }^{3}$ we group these policy alternatives into three classes: using communications policies to shape public expectations about the future course of interest rates; increasing the size of the central bank's balance sheet; and changing the composition of the central bank's balance sheet. We discuss how these policies might work, and we cite existing evidence on their utility from historical episodes and recent empirical research.

The paper's main contribution is to provide new empirical evidence on the possible effectiveness of these alternative policies. We employ two basic approaches. First, we use event-study methods to examine financial market responses to central bank statements and announcements. By using sufficiently narrow event windows, we can get precise estimates of the market's responses to central bank communications and to other types of financial or economic news. Second, we estimate no-arbitrage vector autoregression (VAR) models of the term structure of interest rates for both the United States and Japan. ${ }^{4}$ For any given set of macroeconomic conditions and stance of monetary policy, these models permit us to project the expected level and shape of the term structure. Using the predicted term structure as a benchmark, we are then able to assess whether factors not included in the model-such as quantitative easing in Japan, or changes in the relative supplies of Treasury securities during the recent debt buyback episode in the United States-have economically significant effects on interest rates.

Our results provide some grounds for optimism about the likely efficacy of nonstandard policies. In particular, we confirm a potentially important role for central bank communications to shape public expectations of future policy actions. Our event studies for the United States confirm the result of Refet Gürkaynak, Brian Sack, and Eric Swanson that surprises in the setting of the current policy rate are not sufficient to explain the effect of monetary policy decisions on policy expectations and asset prices. ${ }^{5}$ These effects, however, can be explained by the addition of a second factor that reflects revisions to private sector expectations about the course of the policy rate over the subsequent year. Changes in the second factor appear strongly linked to Federal Reserve policy statements,

3. Bernanke and Reinhart (2004).

4. The VAR-based models we use are similar to that of Ang and Piazzesi (2003).

5. Gürkaynak, Sack, and Swanson (2004). 
providing support to the view that central bank announcements can help to shape market expectations.

The U.S. record also provides encouraging evidence that changes in the relative supplies of securities significantly affect their relative returns. As we know from the classic paper by William Brainard and James Tobin, ${ }^{6}$ if assets are imperfect substitutes for each other, then changes in the composition of the central bank's balance sheet might be an effective nonstandard policy. To assess this possibility, we apply the event-study methodology to three important episodes in which U.S. financial market participants received information that led them to expect large changes in the relative supplies of Treasury securities: the announcement of debt buybacks following the emergence of budget surpluses in the late 1990s, the massive foreign official purchases of U.S. Treasury securities over the past two years, and the "deflation scare" of 2003, during which market participants apparently believed that the Federal Reserve was seriously considering a program of targeted bond purchases. We supplement the event-study evidence with results from our estimated term structure model, which provides a benchmark against which to compare the actual behavior of Treasury yields during the above three episodes. Our evidence generally supports the view that financial assets are not perfect substitutes, implying that relative supplies do matter for asset pricing.

Our analysis of the recent Japanese experience focuses on two nonstandard policies recently employed by the Bank of Japan (BOJ). The first is the BOJ's zero-interest-rate policy (ZIRP), under which the Japanese central bank has committed to keeping its policy rate, the call rate, at zero until deflation has been eliminated; the second is the BOJ's quantitative easing policy, which consists of providing bank reserves at levels much greater than needed to maintain a policy rate of zero. Our evidence for the effectiveness of these policies is more mixed than in the case of the United States. In event-study analyses, which may be less informative in Japan because of small sample sizes and our use of daily rather than intraday data, we find no reliable relationship over the past few years between one-year-ahead policy expectations and policy statements by the BOJ. This result, taken on its own, suggests that the BOJ was either unwilling or unable to influence one-year-ahead expectations during the period considered (but see below).

6. Brainard and Tobin (1968). 
On a more positive note, Japan provides the only evidence of recent vintage bearing on the second type of nonstandard policy, namely, changing the size of the central bank's balance sheet (or quantitative easing). Although the BOJ has used this strategy recently, many consider the manner in which it has done so to have been relatively restrained and limited. Moreover, other forces have no doubt been at work at the same time, making it difficult to parse out the effects of quantitative easing on the economy. Nevertheless, our estimated term structure model for Japan does suggest that yields in Japan were noticeably lower during the quantitative easing period than the model would have predicted-a bit of evidence for the effectiveness of this policy. A similar result emerges for the period when the ZIRP was in effect, suggesting that the event-study analysis may not have captured the full effect of the BOJ's policy commitments on longer-term yields.

Despite our relatively encouraging findings concerning the potential efficacy of nonstandard policies at the ZLB, we remain cautious about making policy prescriptions. Although it appears that nonstandard policy measures may affect asset yields and thus potentially the economy, considerable uncertainty remains about the size and reliability of these effects under the circumstances prevailing near the ZLB. Thus we still believe that the best policy approach is one of avoidance, achieved by maintaining a sufficient inflation buffer and easing preemptively as necessary to minimize the risk of hitting the ZLB. However, should that outcome prove unavoidable, we hope that our research will provide some guidance on the potential of nonstandard policies to lift the economy away from the zero bound.

\section{Monetary Policy Options at the Zero Bound}

It is not without some irony that the resurgence in work on the ZLB, which for a few generations of economists seemed to be a relic of the Depression era, traces to a remarkable achievement by central banks in the major industrial economies. Among those countries, annual consumer price inflation has fallen to around 2 percent, about one-third the pace of twenty years ago. ${ }^{7}$ For instance, as shown in figure 1, the median inflation

7. October of 2004 marked an important turning point in those efforts: Twenty-five years ago, then-Federal Reserve Chairman Paul Volcker and the other members of the Federal Open Market Committee fired the initial salvo in the battle to conquer inflation in the United States. 
Figure 1. Consumer Price Inflation in Advanced Economies, 1980-2005 ${ }^{\mathrm{a}}$

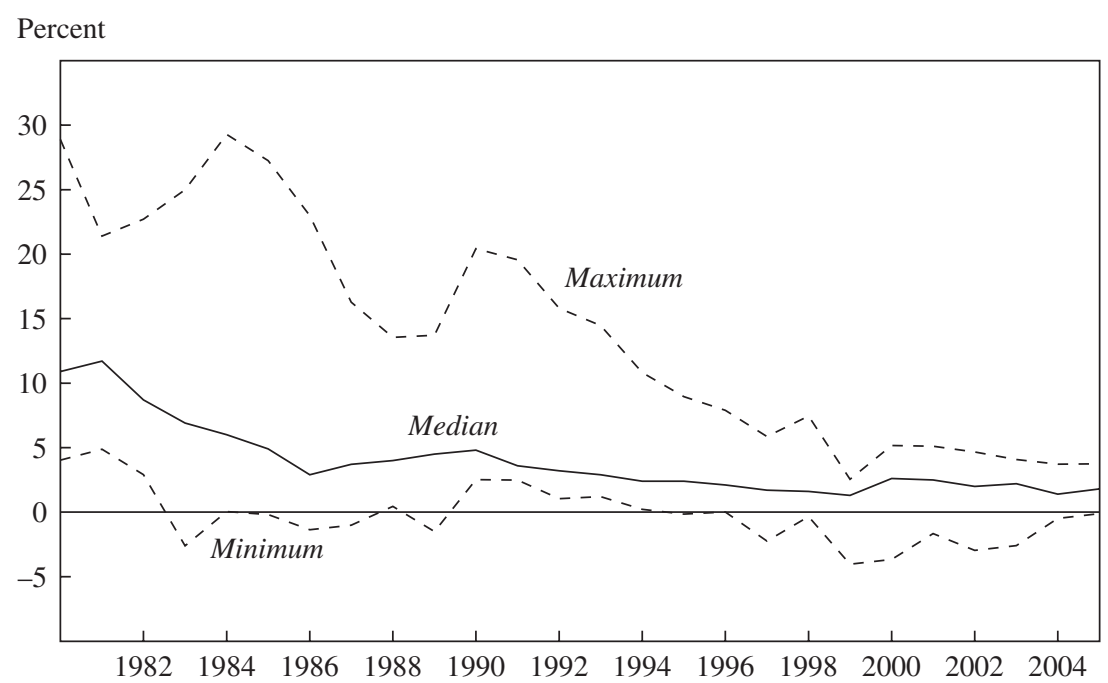

Source: International Monetary Fund, World Economic Outlook (April 2004).

a. International Monetary Fund definition of twenty-eight advanced economies, excluding Iceland and Israel.

rate among twenty-six countries labeled "advanced" in the International Monetary Fund's World Economic Outlook database has moved down steadily since $1980 .{ }^{8}$ This disciplined pursuit of low inflation has no doubt generated macroeconomic benefits and should be considered a singular accomplishment, but it also has been associated with episodes of very low inflation and sometimes outright deflation. ${ }^{9}$ The minimum inflation rate observed among these twenty-six economies has often been negativeand consistently so over the past ten years. In the case of Japan, deflation over the past five years implies that the current level of consumer prices is now slightly lower than in 1995.

With inflation low and likely to remain so, industrial countries are at risk of encountering the ZLB on nominal interest rates periodically in the future. This raises the stakes for answering the question: What options

8. Data from Iceland and Israel, which both experienced bouts of very high inflation, are excluded from the sample because they distort the maximums shown in the figure.

9. Key references on the potential benefits and costs of low inflation include Friedman (1969), Feldstein (1997), and Akerlof, Dickens, and Perry (1996). 
exist for monetary policy when lowering the nominal short-term interest rate, the usual response to a weak economy, is no longer possible? Many previous studies have discussed possible answers to this question, and we will not review this extensive literature in detail. Instead, as background for the empirical results to be presented later, we provide an overview that focuses on some key debates about the effectiveness of alternative nonstandard policies and describes existing empirical evidence bearing on these debates.

Bernanke and Reinhart discuss three alternative, although potentially complementary, strategies when monetary policymakers are confronted with a short-term nominal interest rate that is close to zero. ${ }^{10}$ As discussed in the introduction, these alternatives involve either shaping the expectations of the public about future settings of the policy rate; increasing the size of the central bank's balance sheet beyond the level needed to set the short-term policy rate at zero (quantitative easing); or shifting the composition of the central bank's balance sheet in order to affect the relative supplies of securities held by the public. We use this taxonomy here as well to organize our discussion of nonstandard policy options at or near the ZLB.

\section{Shaping Policy Expectations}

Commentators often describe the stance of a central bank's policy in terms of the level of the short-term nominal interest rate. For example, the very low short-term rates seen in Japan in recent years have led many to refer to the BOJ's monetary policy as "ultra-easy." ${ }^{11}$ However, associating the stance of policy entirely with the level of the short-term nominal interest rate can be seriously misleading. At a minimum, a distinction needs to be drawn between the nominal short-term rate and the real shortterm rate; in a deflationary environment, a nominal interest rate near zero does not preclude the possibility that real interest rates are too high for the health of the economy.

A more subtle reason that the level of the policy rate does not fully describe the stance of monetary policy is that a given policy rate may coexist with widely varying configurations of asset prices and yields, and hence with varying degrees of policy stimulus broadly considered. In the

10. Bernanke and Reinhart (2004).

11. "BOJ Leaves Policy Unchanged, Keeps Ultra-Easy Stance," Japan Policy and Politics, November 5, 2001. 
United States, at least, the short-term policy rate has little direct effect on private sector borrowing and investment decisions. Rather, those decisions respond most sensitively to longer-term yields (such as the yields on mortgages and corporate bonds) and to the prices of long-lived assets (such as housing and equities). A given short-term rate may thus be associated with relatively restrictive financial conditions (for example, if the term structure is sharply upward sloping and equity prices are depressed) or, alternatively, with relatively easy conditions (if the term structure is flat or downward sloping and equity prices are high). Indeed, copious research by financial economists has demonstrated that two and possibly three factors (sometimes referred to as level, slope, and curvature) are needed to describe the term structure of interest rates, implying that the short-term policy rate alone can never be sufficient to fully describe even the term structure, let alone the broad range of financial conditions.

Financial theory also tells us that the prices and yields of long-term assets, which play such an important role in the transmission of monetary policy, depend to a significant extent on financial market participants' expectations about the future path of short-term rates. In particular, with the relevant term, risk, and liquidity premiums held constant, expectations that short-term rates will be kept low will induce financial market participants to bid down long-term bond yields and (for given expectations about future corporate earnings) bid up the prices of equities. Because financial conditions depend on the expected future path of the policy rate as well as (or even more than) its current value, central bankers must be continuously aware of how their actions shape the public's policy expectations. The crucial role of expectations in the making of monetary policy, in normal times as well as when the policy rate is near the ZLB, has recently been stressed in two important papers by Gauti Eggertsson and Michael Woodford (EW). ${ }^{12}$ Indeed, in the context of their theoretical model, EW obtain the strong result that shaping the interest rate expectations of the public is essentially the only tool that central bankers have-not only when the ZLB binds, but under normal conditions as well. We will have several occasions to refer to the EW result below and to suggest that the levers of policy are greater in number than they contend.

12. Eggertsson and Woodford (2003a, 2003b). 
How, then, can a central bank influence private sector expectations? $\mathrm{EW}$, like most of the literature, emphasize the importance of the central bank's committing in advance to a policy rule. Under the assumption that such a commitment is feasible, they focus on the problem of designing policy rules that perform reasonably well both close to and away from the ZLB. EW are surely correct that predictable, rule-like behavior on the part of central banks is an important means of shaping the public's policy expectations. Central banks have generally become more predictable in recent years, reflecting factors such as increased transparency and, in some cases, the adoption of explicit policy frameworks such as inflation targeting. However, there are limits in practice to the ability of central banks to commit "once and for all" to a fully specified policy rule, as envisioned by theoretical analyses of monetary policy under commitment. Although a theoretician might be able to specify the appropriate statecontingent policy plan for a given model, in practice a central bank would likely find it particularly difficult to describe the details of its reactions to highly unusual circumstances, such as those associated with the policy rate being constrained by the ZLB.

Given that their ability to commit to precisely specified rules is limited, central bankers have found it useful in practice to supplement their actions with talk, communicating regularly with the public about the outlook for the economy and for policy. That is not to say that talk is an independent instrument of policy, because statements by a central bank will be believed by the public only if the central bank has a proven track record of delivering on its stated commitments. However, if central banks perceive a sufficient reputational cost to being seen to renege on earlier statements, communication in advance may enhance the central bank's ability to commit to certain policies or courses of action. Moreover, at all times such communication can be helpful in achieving a closer alignment between the policy expectations of the public and the plans of the central bank.

Although communication is always important, its importance may be elevated when the policy rate is constrained by the ZLB. In particular, even with the overnight rate at zero, the central bank may be able to impart additional stimulus to the economy by persuading the public that the policy rate will remain low for a longer period than was previously expected. One means of doing so would be to shade interest rate expectations downward by making a commitment to the public to follow a policy 
of extended monetary ease. This commitment, if credible and not previously expected, should lower longer-term rates, support other asset prices, and boost aggregate demand.

In effect, public statements by the central bank may foster the expectation that it intends to follow what EW refer to as optimal monetary policy under commitment rather than prematurely remove policy accommodation in the future (as happens in EW's no-commitment case).${ }^{13}$ The expectation that the nominal short-term rate will be kept sufficiently low for long enough to ward off deflation should also prevent inflation expectations from falling, which would otherwise raise real interest rates and impose a drag on spending. Because interest rate commitments have implications for inflation expectations in equilibrium, our description of policy in terms of expected interest rate paths is closely related to the types of policies analyzed by Paul Krugman and Lars Svensson. ${ }^{14}$ These authors stress the importance of the central bank committing to generate sufficient future inflation to reduce the expected real interest rate to levels supportive of aggregate spending. Our emphasis, as in EW, is on policies under which the central bank commits to keeping the short-term nominal rate low for long enough to achieve the same results.

Bernanke and Reinhart note that, in principle, such commitments could be unconditional (that is, linked only to the calendar) or conditional (linked to developments in the economy). ${ }^{15}$ Unconditional commitments are rare. The Federal Reserve's commitment to peg short-term and long-term rates during the decade after 1942, discussed below, might be considered an example of an unconditional commitment, in that the pegging operation was open-ended and did not specify an exit strategy. More usually, central bank commitments about future policies are explicitly conditional.

An important recent example of a conditional commitment is the zerointerest-rate policy of the Bank of Japan. The BOJ reduced the call rate to a level "as low as possible" - to zero, for all practical purposes-in February 1999. In April 1999 then-Governor of the BOJ Masaru Hayami announced that the BOJ would keep the policy rate at zero "until defla-

13. Also see Reifschneider and Williams (2000) on the importance of committing to keeping rates low.

14. Krugman (1998); Svensson (2001, 2003).

15. Bernanke and Reinhart (2004). 
tionary concerns are dispelled," clearly indicating that the policy commitment was conditional. ${ }^{16}$ However, in a case of what might be called commitment interruptus, the BOJ then raised the call rate to 25 basis points in August 2000. In February 2001, following a subsequent weakening in economic conditions, the rate increase was partly retracted. The ZIRP was then effectively reinstated in March 2001, when the BOJ announced that it would henceforth target bank reserves at a level well above that needed to bring the call rate to zero (a policy of quantitative easing; see below). Since that time the BOJ has attempted to assure the markets that the reconstituted ZIRP, together with its other extraordinary policy measures, will be maintained as long as deflation persists. Indeed, under Hayami's successor as BOJ governor, Toshihiko Fukui, the BOJ has become more explicit about the conditions required to move the call rate from its zero floor, asserting that the ZIRP will not end until year-overyear core inflation has been positive for several months and is expected to remain positive.

A relevant, although less explicit, example of policy commitment is also available for the United States. From the latter part of 2002 through much of 2003, Federal Reserve officials expressed concerns about what they described as a "remote" possibility of deflation. Subsequently, in late 2003 and early 2004, although the deflation risk had receded, the slow pace of job creation heightened concerns about the sustainability of the economic recovery from the 2001 recession. Although the Federal Reserve's policy rate remained at least 100 basis points above zero throughout this period, policymakers became more specific in communicating their outlook for policy in the attempt to shape expectations. For example, the August 2003 statement of the Federal Open Market Committee (FOMC, the body responsible for the conduct of monetary policy in the United States) that "policy accommodation can be maintained for a considerable period" may be interpreted as an example of conditional commitment. ${ }^{17}$ The conditional nature of the commitment was made clear in the committee's December 2003 policy statement, which explicitly linked continuing policy accommodation to the low level of inflation and slack in resource use. Likewise, the FOMC's stated plan in 2004 to "remove

16. Fujiki and Shiratsuka (2002).

17. The full texts of the FOMC's statements can be found at www.federalreserve. gov/fomc. 
policy accommodation at a pace that is likely to be measured" gave the market information about the likely direction of the policy rate but also emphasized that future actions would be linked explicitly to the condition that inflation remain under control.

Empirical evidence on the ability of central banks to influence policy expectations through statements, speeches, and other forms of talk is relatively limited. For the United States, Donald Kohn and Sack present evidence that the issuance of FOMC statements increases the variability of market interest rates on the day of the statement, suggesting that these statements convey information to financial markets over and above the information in any accompanying policy action. ${ }^{18}$ However, they do not specifically address the ability of the FOMC to influence expectations of future policy in the desired direction or at longer horizons. In the next section we extend the work of Kohn and Sack to provide additional evidence on the effects of FOMC statements on policy expectations and asset prices.

More work has been done on the effects of the BOJ's ZIRP, primarily by researchers at the Bank of Japan and affiliated research institutions. The majority of this research suggests that the ZIRP has been successful at affecting policy expectations, and thus at affecting yields, although the greatest impact is observed at the short end of the maturity spectrum. ${ }^{19}$ Also, studies that include both the early ZIRP period, before August 2000, and the later application of the policy, which commenced in March 2001 with the introduction of the quantitative easing policy, tend to find modestly stronger effects in the latter period. ${ }^{20}$ In an interesting paper, Kohei Marumo and others use an estimated model of the Japanese term structure to back out the evolution of market participants' beliefs about how long the ZIRP would hold. ${ }^{21}$ They find that, over the period from February 1999 to August 2000, the mode of the probability distribution over the expected remaining time of the policy ranged from less than one year to about three years. For the second incarnation of the ZIRP, after March 2001, they find that modal expectations of the time to the end of

18. Kohn and Sack (2003).

19. Fujiki and Shiratsuka (2002); Takeda and Yajima (2002); Okina and Shiratsuka (2004).

20. Nagayasu (2004).

21. Marumo and others (2003). 
the policy varied from approximately two to three years. Kunio Okina and Shigenori Shiratsuka obtained similar results, ultimately concluding that "[t]he policy duration effect was highly effective in stabilizing market expectations regarding the future path of short-term interest rates, thereby bringing longer-term interest rates down to flatten the yield curve." ${ }^{22}$

A shortcoming shared by most of these studies, however, is the absence of an adequate benchmark for the term structure. That is, most existing studies do not effectively answer the question of what yields would have been in the absence of the ZIRP. Hence we really do not know (for example) whether the exceedingly low level of longer-term government bond yields in Japan during recent years primarily reflects expectations of low future policy rates or the belief that Japan faces a protracted period of deflation. In an interesting recent paper, Naohiko Baba and others address the benchmark issue by estimating a "macro-finance," noarbitrage model of the term structure (discussed in more detail in the next section). ${ }^{23}$ They use this model to estimate what yields in Japan would have been at each date, given the state of the economy, under the counterfactual assumption that no ZIRP was in place. A comparison of the actual term structure with the estimated benchmark permits inferences about the effects of the ZIRP. Notably, these authors find somewhat stronger net effects of the ZIRP on long-term yields than does much of the earlier work. We apply a similar strategy in our empirical analysis below.

Our discussion, like much of the literature, has focused on regimes in which the short-term nominal interest rate is the instrument of monetary policy. However, other variables can and have served as a nominal anchor for the system and thus as a target or instrument for the central bank. Svensson has called attention to the nominal exchange rate as an alternative policy instrument when the ZLB binds, noting that monetary policies that can be defined in terms of current and future values of the short-term nominal interest rate can equally well be expressed in terms of paths for the nominal exchange rate. ${ }^{24}$ Switching the policy instrument from the short-term interest rate to the exchange rate does not eliminate

22. Okina and Shiratsuka (2004, p. 75). However, these authors also argue that the ZIRP did not help the economy much, "since [the] transmission channel linking the financial and non-financial sectors has remained blocked."

23. Baba and others (2004).

24. Svensson $(2001,2003)$. 
the constraints imposed by the zero bound: some paths for the nominal exchange rate cannot be engineered by the central bank, because the values of the short-term nominal interest rate implied by interest rate parity would violate the ZLB. Nevertheless, we agree with Svensson that commitments by the central bank to future policies may be more credible when expressed in terms of a planned path for the exchange rate rather than in terms of future values of the short-term nominal interest rate. One obvious benefit of expressing policy commitments in terms of the exchange rate is that such a commitment is verifiable, in that the central bank's announcement can be accompanied by an immediate and visible change in the exchange rate; promises about future values of the shortterm interest rate cannot be accompanied by immediate action, if the current policy rate is at the ZLB. ${ }^{25}$

These considerations suggest that exchange rate-based policies may be the best way for smaller open economies to break the hold of the ZLB. For example, the Swiss National Bank increased its use of the exchange rate as a policy indicator during its recent struggle with the ZLB. Whether large economies like the United States or Japan can have success with exchange rate-based policies is more controversial. Skeptics have argued that the strongest short-term effects of the devaluation suggested by Svensson would be felt on the patterns of trade, raising the possibility that the large country's trading partners would accuse it of following a beggar-thyneighbor policy. Svensson has replied that growth in domestic demand would ultimately raise imports, offsetting the terms-of-trade effects created by the devaluation. Whether these second-round effects would develop quickly enough to help defuse the political problem, however, is difficult to judge, and we have nothing to add to this controversy. Because large industrial countries have traditionally emphasized interest rates and money growth as policy instruments, the remainder of the paper focuses on these variables. That said, we believe that empirical study of the use of the exchange rate as a policy indicator when the ZLB is binding would be highly worthwhile.

25. In principle, a policy that relies on nominal interest rates could be made similarly verifiable by announcing a desired range for an intermediate- or longer-term yield, perhaps in conjunction with central bank purchases in the corresponding segment of the market, a question we discuss below. Up to now the literature has tended to focus on the exchange rate, not a note or bond price, as the intermediate policy target. 


\section{Increasing the Size of the Central Bank's Balance Sheet}

(Quantitative Easing)

Central banks normally lower their policy rate through open-market purchases of bonds or other securities, which have the effect of increasing the supply of bank reserves and putting downward pressure on the rate that clears the reserves market. A sufficient injection of reserves will bring the policy rate arbitrarily close to zero, so that the ZLB rules out further interest rate reduction. However, nothing prevents the central bank from adding liquidity to the system beyond what is needed to achieve a policy rate of zero, in a policy known as quantitative easing. As already noted, Japan has actively pursued this policy approach in recent years. Announced in March 2001, the BOJ's quantitative easing policy might initially have been interpreted as a recommitment to the policy of keeping the short-term rate at zero-that is, of maintaining the ZIRP. However, the BOJ raised its target for current account balances at commercial banks (essentially, bank reserves) a number of times, to the point that reserves substantially exceeded the level needed to pin the call rate at zero. (The BOJ's target for current account balances reached 30-35 trillion yen in January 2004, compared with required reserves of approximately 6 trillion yen, and the monetary base grew by two-thirds in the three years following the initiation of the quantitative easing policy.) ${ }^{26}$ However, as has been frequently noted, growth in bank reserves and base money in Japan has not resulted in comparable growth in broader monetary aggregates. In large part this limited effect stems from the poor condition of banks' and borrowers' balance sheets, which makes profitable lending difficult and induces banks to hold large quantities of idle balances.

Whether quantitative easing can be effective in relieving deflationary pressures and, if so, by what mechanism, remains controversial. As already noted, EW have provided theoretical reasons to doubt the efficacy of quantitative easing as an independent tool of policy. They show that, in a world in which financial frictions are sufficiently minimal to permit full insurance against idiosyncratic consumption risks, and in which effects of monetary policy on the government's budget constraint are ruled out, quantitative easing will have no effect, except perhaps to the extent that the extra money creation can be used to signal the central bank's intentions regarding future

26. As reported in Baba and others (2004). 
values of the short-term interest rate. The assumptions that financial markets are essentially frictionless and that fiscal budget constraints are independent of monetary policy are rather strong. If these assumptions do not hold, we may have some basis for believing that quantitative easing will be effective.

Why might injections of liquidity that go beyond the point necessary to drive the short-term policy rate to zero help the economy? One argument for quantitative easing is what might be called the reduced-form argument. Broadly, those making this argument are agnostic about the precise mechanisms by which quantitative easing may have its effects. Instead, in support of quantitative easing as an anti-deflationary tool, they point to the undeniable fact that, historically, money growth and inflation have tended to be strongly associated. It follows, according to this argument, that money creation will raise prices independent of its effects on the term structure.

Basing policy recommendations on reduced-form evidence of this sort is problematic, however. As the Lucas critique warns us, historical relationships are prone to break down in novel circumstances. In particular, there is no reason to expect the velocity of money to be stable or predictable when the short-term interest rate (the opportunity cost of holding money) is close to zero, and thus no reason to expect a stable relationship between money growth and nominal income under those conditions. To make the case for quantitative easing, we need more explicit descriptions of how additional money growth might stimulate the economy even when the short-term interest rate has reached zero.

At least three channels through which quantitative easing may be effective have been advanced. The first builds from the premise that money and other financial assets are imperfect substitutes. ${ }^{27}$ According to this view, open-market purchases of securities will raise the amount of money relative to nonmoney assets in the public's portfolio. The private sector's collective attempt to rebalance portfolios will tend to raise the prices and lower the yields of nonmoney assets if money and nonmoney assets are imperfect substitutes. Higher asset values and lower yields, in turn, stimulate the economy, according to this view. Recently, Javier Andres, David Lopez-Salido, and Edward Nelson have shown how these

27. This view is associated both with monetarist expositions, such as Meltzer (2001), and with Keynesian classics, such as Brainard and Tobin (1968) and Tobin (1969). 
effects might work in a general equilibrium model that includes sufficient financial market frictions. ${ }^{28}$

So long as technology has not made it possible to pay a grocery bill with a stock certificate or the deed to a home, it is difficult to dispute the premise that, as a general matter, money and nonmoney assets are imperfect substitutes. However, in the special situation of a binding ZLB, large additional injections of liquidity may satiate the public's demand for money, implying that, at the margin, extra cash provides no transactions services to households or firms. If money demand is satiated, money becomes (at the margin) just another financial asset, one that happens to pay a zero nominal rate, to be riskless in nominal terms, and to have an indefinite maturity. In this situation it is no longer obvious that money is a particularly poor substitute for nonmonetary assets. For example, with the important exception of its maturity, money's characteristics are very close to those of short-term Treasury bills paying close to zero interest. Of course, even in this situation there will be assets-real estate, for example - that are not very substitutable with money, implying that the central bank's choice of assets to buy may matter a great deal.

A second possible mechanism for quantitative easing to influence the economy is the fiscal channel. This channel relies on the observation that sufficiently large monetary injections will materially relieve the government's budget constraint, permitting tax reductions or increases in government spending without increasing public holdings of government debt. ${ }^{29}$ Effectively, the fiscal channel is based on the government's substitution of seigniorage (a tax with little or no deadweight loss in a deflationary environment) for direct taxes such as income taxes. Alan Auerbach and Maurice Obstfeld provide a detailed analysis of both the macroeconomic and the welfare effects of the fiscal channel and find that they are potentially quite substantial. ${ }^{30}$ These authors also note, however, that the fiscal effect of quantitative easing will be attenuated or absent if the public expects today's monetary injections to be withdrawn in the future ${ }^{31}$ Broadly, if the public expects quantitative easing to be reversed at the first sign that

28. Andres, Lopez-Salido, and Nelson (2003).

29. Bernanke (2003); Auerbach and Obstfeld (2004).

30. Auerbach and Obstfeld (2004).

31. Their point is closely related to Krugman's (1998) important analysis, which emphasized the crucial role of central bank credibility in most nonconventional monetary policies. 
deflation has ended, they will likewise expect that their money-financed tax cuts will be replaced by future tax increases as money is withdrawn, and this expectation will blunt the initial impact of the policy. Thus it is crucial that the central bank's promises to maintain some part of its quantitative easing as the economy recovers be perceived by the public as credible. Auerbach and Obstfeld show that, if the central bank is known to be willing to tolerate even a very small amount of inflation, the promise to maintain quantitative easing will be credible. A similar result would likely obtain if the central bank associates even a relatively small cost with publicly reneging on its promises. Thus it seems reasonable to expect that the fiscal channel of quantitative easing would work if pursued sufficiently aggressively.

A third potential mechanism of quantitative easing, admittedly harder to pin down than others, might be called the signaling channel. Simply put, quantitative easing may complement the expectations management approach by providing a visible signal to the public about the central bank's intended future policies. For example, if the public believes that the central bank will be hesitant to reverse large amounts of quantitative easing very quickly, perhaps because of the possible shock to money markets, this policy provides a way of underscoring the central bank's commitment to keeping the policy rate at zero for an extended period.

More speculatively, quantitative easing may work through a signaling channel if its implementation marks a general willingness of the central bank to break from the cautious and conventional policies of the past. A historical episode that may illustrate this channel at work (although the policymaker in question was the executive rather than the central bank) was the period following Franklin D. Roosevelt's inauguration as U.S. president in 1933. During 1933 and 1934 the extreme deflation seen earlier in the decade suddenly reversed, stock prices jumped, and the economy grew rapidly. Christina Romer has argued persuasively that this surprisingly sharp recovery was closely associated with the rapid growth in the money supply that arose from Roosevelt's devaluation of the dollar, capital inflows from an increasingly unstable Europe, and other factors. ${ }^{32}$ Because short-term interest rates remained near zero throughout the period, the episode is reasonably characterized as a successful application of quantitative easing. Romer does not explain the mechanism by which quantita- 
tive easing worked in this episode, other than to observe that real interest rates declined as deflation changed to inflation. ${ }^{33}$ Peter Temin and Barrie Wigmore addressed that question, arguing that the key to the sudden reversal was the public's acceptance of the idea that Roosevelt's policies constituted a "regime change." ${ }^{34}$ The policymakers who preceded him had shown little inclination to resist deflation and, indeed, seemed to prefer deflation to even a small probability of future inflation. In contrast, Roosevelt demonstrated clearly through his actions that he was committed to ending deflation and reflating the economy. Although the president could have simply announced his desire to raise prices, his adoption of policies that his predecessors would have considered reckless provided a powerful signal to the public that the economic situation had fundamentally changed. If one accepts the Temin-Wigmore hypothesis, it appears that the signal afforded by Roosevelt's exchange rate and monetary policies was central to the conquest of deflation in 1933-34. ${ }^{35}$

Outside of the suggestive evidence from the interwar period just discussed, there has been little empirical analysis of the quantitative easing channel. The only recent experience to draw upon, of course, is that of Japan since March 2001. Masaaki Shirakawa reviewed the quantitative easing policy after one year and argued that, although the policy may be credited with reducing liquidity premiums in some markets, it did not have discernible effects on the prices of most assets, including government bonds, equities, or foreign currency, nor did it increase bank lending. ${ }^{36}$ Takeshi Kimura and others studied the effects of quantitative easing by vector autoregression methods and by estimating a money demand equation. They concluded that any effects of quantitative easing have been very small and highly uncertain. ${ }^{37}$

33. Dollar devaluation, of course, improved the competitiveness of U.S. exports and raised the prices of imports. But, in an economy that was by this time largely closed, the direct effects of devaluation seem unlikely to have been large enough to account for the sharp turnaround. Eichengreen (1992) argues persuasively that the devaluation stimulated the economy by freeing up the money supply rather than by changing relative prices.

34. Temin and Wigmore (1990).

35. Meltzer (1999) has also drawn on the experience of the first half of the twentieth century, including episodes in 1920-21, 1937-38, and 1947-48, to argue for the potential benefits of quantitative easing.

36. Shirakawa (2002).

37. Kimura and others (2002). 
The recent moderating of deflation in Japan and the signs of recovery there are, of course, a bit of evidence in favor of the effectiveness of the BOJ's quantitative easing policy. Unfortunately, however, they are far from decisive. Other factors have certainly played a role in the recent improvement in the Japanese economy, including structural and banking reforms, a strengthening world economy, and the ZIRP. The quantitative easing policy, although an important departure from the standard policy framework, has in fact been somewhat conservative in its execution. Despite some interesting initiatives intended to promote the development of various financial markets, the BOJ has largely restricted its openmarket purchases to the usual suspects-government securities-thereby inhibiting any effect that might work through imperfect substitutability. Even more important, there has been a notable absence of cooperation between the monetary and the fiscal authorities (indeed, the BOJ has expressed repeated concerns that monetary ease might facilitate fiscal indiscipline), and the communication and signaling aspects of policy have been subdued. We will present some evidence that is consistent with quantitative easing having been effective in Japan, but our findings do not clearly isolate the effects of quantitative easing from other influences. The reality may well be that the Japanese experience does not support strong conclusions about the potential efficacy of this particular nonstandard policy.

\section{Altering the Composition of the Central Bank's Balance Sheet}

The composition of the assets on the central bank's balance sheet offers another potential lever for monetary policy. For example, the Federal Reserve participates in all segments of the Treasury market, including inflation-indexed Treasury debt: its asset holdings of about $\$ 700$ billion are distributed among Treasury securities with original maturities ranging from four weeks to thirty years. Over the past fifty years, the average maturity of the Federal Reserve System's holdings of Treasury debt has varied considerably within a range from one to four years. By buying and selling securities of various maturities or other characteristics in the open market, the Federal Reserve could materially influence the relative supplies of these securities. In a frictionless financial market, as EW point out, these changes in supply would have essentially no effect, because the pricing of any financial asset would depend 
exclusively on its state- and date-contingent payoffs. However, in a world with transactions costs and in which financial markets are incomplete in important ways, the Federal Reserve's action might be able to influence term, risk, and liquidity premiums-and thus overall yields. ${ }^{38}$ The feasibility of this approach is, of course, closely related to the issue of whether different types of assets are imperfect substitutes for each other, as discussed earlier.

The same logic would apply, of course, to other financial and real assets that the central bank might buy or sell. Except under certain emergency provisions dormant since the 1930s, however, the Federal Reserve is restricted to purchasing a limited range of assets outside of Treasury securities, including some foreign government bonds, the debt of governmentsponsored enterprises, and some municipal securities. ${ }^{39}$ Various methods might effectively make these restrictions less binding. For example, the Federal Reserve has the authority to accept a wide range of assets as collateral for loans from its discount window. Some other central banks face fewer restrictions on the assets they can hold; for example, the BOJ's expansionary efforts have involved purchases not only of treasury bills and Japanese government bonds, but also of commercial paper, various asset-backed securities, and equities (from commercial banks).

Perhaps the most extreme example of a policy keyed to the composition of the central bank's balance sheet is the announcement of a ceiling on some longer-term yield that is below the rate then prevailing in the market. Such a policy would entail an essentially unlimited commitment to purchase the targeted security at the announced price. If these purchases were allowed to affect the size of the central bank's balance sheet as well as its composition, ultimately the policy might also involve quantitative easing. A "pure" pegging policy would require the central bank to sell other securities equal in amount to its purchases of the targeted security. A commitment to peg a longer-term yield may also help to convince the public that the central bank intends to keep the short-term rate low for a considerable period; such a policy would thus include an element of expectations shaping as well.

38. In carrying out such a policy, the Federal Reserve would need to coordinate with the Treasury, to ensure that the latter's debt issuance policies did not offset the former's actions. In principle, the Treasury could alter its debt management patterns to achieve the same effect, much along the lines discussed by Tobin (1963).

39. Clouse and others (2003) review the Federal Reserve's legal authority. 
As with quantitative easing, whether policies based on manipulating the composition of the central bank's balance sheet can have significant effects is a contentious issue. A fair characterization of the prevailing view among financial economists is that changes in the relative supplies of assets within the range of U.S. experience are unlikely to have a major impact on these premiums and thus on overall yields. ${ }^{40} \mathrm{We}$ will present new evidence on this issue later in the paper. If the view is correct that financial pricing approximates the frictionless ideal, then attempts to enforce a ceiling on the yields of long-term Treasury securities would be successful only if the targeted yields were broadly consistent with investor expectations about future values of the policy rate. If investors doubted that rates would be kept low, this view would predict that the central bank would end up owning all or most of the targeted security. Moreover, even if large purchases of, say, a long-dated Treasury security were able to affect the yield on that security, the yield on that security might become "disconnected" from the rest of the Treasury term structure and from rates on private sector securities, thus reducing the economic impact of the policy.

Such caveats notwithstanding, history offers a number of examples of rate pegs by central banks. During the twentieth century, central banks in a number of countries successfully pegged (or imposed a ceiling on) long-term government bond rates in order to facilitate the financing of war or postwar reconstruction. In the United States, the Federal Reserve maintained ceilings on Treasury yields at seven different maturities between 1942 and the 1951 Accord; among these were caps of $3 / 8$ percent on ninety-day Treasury bill rates (raised to $3 / 4$ percent in July 1947) and of $2 \frac{1}{2}$ percent on very long term bonds. The peg on bills appeared to be binding, in that for most of the period the rate on bills remained precisely at the announced level, and Federal Reserve holdings of bills grew steadily, exceeding 90 percent of the outstanding stock by $1947 .{ }^{41}$ In contrast, the $2 \frac{1}{2}$ percent cap on very long term bond yields was maintained

40. Reinhart and Sack (2000) show that a simple mean-variance model of portfolio choice predicts that even sizable changes in the composition of the public's asset holdings would have only small effects on yields. However, a number of studies, including Roley (1982) and Friedman and Kuttner (1998), have provided evidence of imperfect substitution among broad asset classes.

41. Toma (1992). 
without active intervention throughout much of the period, suggesting that the cap was not a binding constraint. There were exceptions to this generalization, however: Notably, from the beginning of the regime in April 1942 through December 1944, long-term bond yields fluctuated in a narrow range between 2.43 percent and 2.50 percent, suggesting that the cap had some influence. ${ }^{42}$ Also, between October 1947 and December 1948, the Federal Reserve appears to have intervened actively to keep bond yields just below the peg, in the process raising the central bank's holdings of bonds from near zero to about 13 percent of the outstanding stock. $^{43}$

The relative ease with which the Federal Reserve maintained the ceiling on long-term government bond yields for an entire decade raises intriguing questions. During the early part of the pegging period, memories of the low interest rates of the 1930s and ongoing low inflation (enforced in part by wartime price controls) plausibly implied equilibrium long-term yields either below or not far above the ceiling. After the war and the elimination of wartime controls, however, inflation rose quite sharply. Yet the long-term peg remained intact. Barry Eichengreen and Peter Garber argue that the public was confident that the Federal Reserve would reverse the postwar inflation and hence remained content to hold low-yielding bonds. ${ }^{44}$ Likewise, Mark Toma notes that there is no logical inconsistency in promising a monetary policy that is easy in the short run but anti-inflationary in the long run, as the pegging policy seemed to do. ${ }^{45}$ In this paper we focus our empirical analysis on more recent episodes, and so we confine ourselves here to raising a few questions about the preAccord period that we believe merit further analysis. First, if we accept the Eichengreen-Garber argument that long-term inflation expectations were well behaved during this period, we might still ask how, if at all, the Federal Reserve's pegging policy influenced those expectations. For example, did the pegging policy communicate a commitment to low inflation, perhaps because the public understood that the Federal Reserve would do all it could to avert the capital losses to banks and on its own account that would be suffered if inflation and long-term rates rose

42. Hutchinson and Toma (1991).

43. Toma (1992).

44. Eichengreen and Garber (1991).

45. Toma (1992). 
sharply? Second, did the pegging policy affect term premiums, for example by reducing the perceived risk in holding long-term bonds? Finally, did the Federal Reserve in fact succeed in pegging long-term yields below their equilibrium levels in 1942-44 and 1947-48, and, if so, what were the consequences?

A second well-known historical episode involving the attempted manipulation of the term structure was the so-called Operation Twist. Launched in early 1961 by the incoming Kennedy administration, Operation Twist was intended to raise short-term rates (thereby promoting capital inflows and supporting the dollar) while lowering, or at least not raising, long-term rates. ${ }^{46}$ The two main actions underlying Operation Twist were, first, the use of Federal Reserve open-market operations and Treasury debt management operations to shorten the average maturity of government debt held by the public, and second, some easing of the interest rate restrictions on deposits imposed by Regulation Q. The current view, shaped largely by the classic work by Franco Modigliani and Richard Sutch, ${ }^{47}$ is that Operation Twist was a failure. ${ }^{48}$ Their empirical estimates of the "habitat model" of interest rate determination led them to conclude that Operation Twist narrowed the spread between long-term and short-term yields by amounts that "are most unlikely to exceed some ten to twenty base points - a reduction that can be considered moderate at best." ${ }^{49}$ However, Modigliani and Sutch also noted that Operation Twist was a relatively small operation and, indeed, that over a slightly longer period the maturity of outstanding government debt rose significantly, rather than fell. ${ }^{50}$ Thus Operation Twist does not seem to provide strong evidence in either direction as to the possible effects of changes in the composition of the central bank's balance sheet. In the next section we consider the effects of more significant changes in relative supplies of government bonds of different maturities than were observed during Operation Twist.

46. Modigliani and Sutch (1966).

47. Modigliani and Sutch $(1966,1967)$.

48. The Modigliani-Sutch conclusion was not uncontroversial; see, for example, Holland (1969).

49. Modigliani and Sutch (1966, p. 196)

50. This was also noted by Tobin (1974). 


\section{The Potential Effectiveness of Nonstandard Policies: Evidence from the United States}

Although the federal funds rate declined to 1 percent in 2003, shortterm nominal interest rates in the United States have not been effectively constrained by the ZLB since the 1930s. Nevertheless, the recent experience of the United States provides some opportunities to test the potential effectiveness of nonstandard monetary policies in a modern, financially sophisticated economy.

The previous section classified nonstandard monetary policies under three headings: using communications to shape policy expectations; increasing the size of the central bank's balance sheet beyond what is needed to bring short-term rates to zero (quantitative easing); and changing the composition of the central bank's balance sheet in order to affect the relative supplies, and thus possibly the relative prices, of targeted securities. As far as we can see, the recent experience of the United States does not contain any episodes useful for studying the potential of the second type of nonstandard policy. However, as we discuss in this section, recent U.S. experience does provide valuable evidence, both direct and indirect, on the effectiveness of the first and third types.

We first address the question of whether the recent communication policies of the Federal Open Market Committee have influenced market expectations of future short-term interest rates, as would be required to affect longer-term rates by shaping market expectations (the first class of nonstandard policies). Our principal methodology is event-study analysis; that is, we draw inferences about the impact of FOMC statements from the behavior of market-based indicators of policy expectations in a narrow window surrounding FOMC announcements. We also use the event-study approach to determine whether FOMC statements affect the responsiveness of policy expectations to other types of news, such as employment reports. The event-study analysis shows that FOMC policy statements do in fact have a substantial impact on market expectations of future policy, both directly and indirectly, suggesting that the committee does have some scope to use communication policies to influence the yields and prices of longer-term assets. To assess further the magnitude of these effects, we next estimate a macrofinance model of the term structure of Treasury yields, which links the term structure to macroeconomic conditions and to indicators of monetary policy. Comparison of this benchmark model of the term structure with 
the actual evolution of yields provides additional information on the magnitude and duration of the effects of FOMC "talk" on the term structure.

In the second part of this section, we present evidence that bears on the possibility that changes in the composition of the Federal Reserve's balance sheet might influence asset prices - the third type of nonstandard policy. The key issue here is whether changes in the relative supplies of assets, such as government bonds of different maturities, have significant effects on prices and yields, holding macroeconomic conditions and policy interest rates constant. We address this issue indirectly by considering the market effects of three recent episodes: first, the period of Treasury debt buybacks of the late 1990s, during which the Treasury announced its intention to shorten significantly the maturity structure of U.S. debt; second, the large purchases of U.S. Treasuries by Japan's Ministry of Finance during the period of Japan's exchange rate interventions after 1998; and third, the "deflation scare" episode of 2003, during which bond market participants purportedly saw a significant probability that the Federal Reserve might use securities purchases to try to affect longer-term yields. Using the same two methodologies as applied in the study of FOMC statements- that is, an event-study approach and the use of an estimated model of the term structure as a benchmark for comparison—we find evidence that "supply effects" have at times significantly influenced bond yields, suggesting that targeted purchases of bonds at the ZLB could be effective at lowering the yields on longer-dated securities. However, the duration and magnitude of these effects remain somewhat unclear from our analysis.

\section{Do FOMC Statements Influence Policy Expectations?}

Has the FOMC historically exerted any influence on investors' expectations about the future course of policy? Although members of the FOMC communicate to the public through a variety of channels, including speeches and congressional testimony, official communications from the FOMC as an official body (ex cathedra, one might say) are confined principally to the statements that the FOMC releases with its policy decisions. ${ }^{51}$ In this section we investigate whether FOMC statements have

51. Some testimony, notably the Federal Reserve chairman's semiannual report to Congress, might also be interpreted as reflecting the collective views of the FOMC. Speeches by the chairman are not technically official communications, but, because of the chairman's influence on policy decisions, they are watched carefully by market participants. 
observable effects on financial markets over and above the effects of policy changes themselves. We undertake a similar exercise for the Bank of Japan later in the paper.

The FOMC has moved significantly in the direction of greater transparency over the past decade. Before 1994, no policy statements or descriptions of the target for the federal funds rate were released after FOMC meetings. Instead, except when changes in the federal funds rate coincided with changes in the discount rate (which were announced by a press release of the Federal Reserve Board), the FOMC signaled its policy decisions to the financial markets only indirectly, through open-market operations, typically on the day following the policy decision. In February 1994 the FOMC began to release statements noting changes in its target for the federal funds rate, but it continued to remain silent following meetings where no policy changes occurred. Since May 1999, however, the committee has released a statement after every policy meeting.

The FOMC statements have evolved considerably. In their most recent form they briefly describe the current state of the economy and, in some cases, provide some hints about the near-term outlook for policy. They also contain a formulaic description of the so-called balance of risks with respect to the outlook for output growth and inflation. A consecutive reading of the statements reveals continual tinkering by the committee to improve its communications. For example, the balance-of-risks portion of the statement replaced an earlier formulation, the "policy tilt," which characterized the likely future direction of the federal funds rate. Much like the policy tilt statement, the balance-of-risks statement hints about the likely evolution of policy, but it does so more indirectly by focusing on the committee's assessment of the potential risks to its dual objectives rather than on the policy rate. The relative weights of forward-looking and backward-looking characterizations of the data and of policy have also changed over time, with the FOMC taking a relatively more forwardlooking stance in 2003 and 2004.

Of course, investors read the statements carefully to try to divine the FOMC's views on the economy and its policy inclinations. ${ }^{52}$ This careful

52. It has been said that a mark of great literature is that readers can find meanings in the text that the author did not consciously intend. On this criterion FOMC statements certainly qualify as great literature. 
attention is prima facie evidence that what the committee says, as well as what it does, matters for asset pricing. Here we support this observation with more formal evidence and try to judge the magnitude of the effect.

To measure the influence of these FOMC announcements, we first take an event-study approach. We look at the movements in three marketbased indicators of the private sector's monetary policy expectations during the periods surrounding FOMC decisions-including both decisions made at scheduled FOMC meetings and decisions made between regular meetings - since July $1991 .^{53}$ The first of the three indicators is a nowstandard measure of the surprise component of current policy decisions. This measure, derived from the current-month federal funds futures contract in the manner described by Kenneth Kuttner, ${ }^{54}$ provides a marketbased estimate of the difference between the federal funds rate target set by the FOMC and the value of the funds rate target that market participants expected just before the FOMC's announcement. (Essentially, the change in the near-term federal funds contract in response to the decision, when scaled by the number of days remaining in that month-long contract, provides a measure of the change in expectations.) The second indicator is the rate on the Eurodollar futures contract expiring about a year ahead. Roughly speaking, the change in this rate during the period that spans the announcement of the FOMC's decision is a measure of the change in year-ahead policy expectations (and movements in the term premium associated with those changes) induced by the committee's decisions. Finally, we also consider changes in the yield on Treasury securities of five years' maturity, which provide an indication of changes in market expectations of policy (as well as associated changes in term premiums) at a five-year horizon. To isolate the effects of policy events on these indicators as cleanly as possible, we focus on movements in the three market-based indicators over the one-hour window (from fifteen minutes before to forty-five minutes after) surrounding the policy announcements.

We would like to test whether the private sector's policy expectations over the hour surrounding an FOMC announcement are affected solely by

53. Determining precisely when each decision was conveyed or signaled to the markets is a tedious process. See the text and especially the appendix of Gürkaynak, Sack, and Swanson (2004) for a discussion and a detailed listing of the timing of decisions.

54. Kuttner (2001). 
the unexpected component of the policy action itself, or whether there is room for additional influences on expectations arising from the committee's statement. The earlier literature has mostly considered the effects on asset prices and yields of the current policy surprise only. ${ }^{55}$ If the "onefactor" view of the effects of FOMC decisions implicit in these studies is correct, there can be no independent effect of the committee's statements on policy expectations or asset prices. To investigate this issue, we follow an approach similar to that of Gürkaynak, Sack, and Swanson to determine whether significant factors independent of the current policy surprise are needed to account for the response of policy expectations at the one-year and five-year horizons. ${ }^{56}$ Specifically, we construct a candidate set of factors through a Cholesky decomposition of our three indicators of changes in policy expectations. We assume that the first factor equals the current policy surprise, as inferred from the federal funds futures market, which also affects the year-ahead futures rate and the five-year yield. The second candidate factor equals the portion of the change in year-ahead policy expectations (as measured by the change in the Eurodollar futures contract) not explained by (that is, orthogonal to) the first factor, which is also allowed to influence the five-year yield. As a residual, the third candidate factor is the change in the five-year Treasury yield not explained by (orthogonal to) the first two factors. If the one-factor view of the effects of policy decisions is correct, then the second and third candidate factors should account for only a small portion of the changes in longer-horizon interest rates in the period surrounding FOMC decisions, and they should be unrelated to aspects of the FOMC decision (such as the statement) other than the change in the policy rate.

The loadings of the three market indicators of policy expectations on the three factors, as determined by the Cholesky decomposition, are shown in the top panel of table 1. By construction, each of the diagonal elements of the table is equal to unity. As already mentioned, the first factor has

55. Kuttner (2001); Bernanke and Kuttner (forthcoming).

56. Our analysis extends the work of Gürkaynak, Sack, and Swanson (2004) in two ways. First, we analyze the relationship of the policy factors to FOMC statements in greater detail. Second, as discussed later in the paper, we extend the analysis to the case of Japan. Methodologically, our approach also differs from theirs in some respects. In particular, Gürkaynak, Sack, and Swanson use four futures contracts covering policy expectations out to a year; we use only one contract to measure year-ahead expectations but use a longerterm yield as well. In addition, we use different methods than Gürkaynak, Sack, and Swanson to identify the underlying factors. 
Table 1. Factor Decomposition of Monetary Policy Indicators, United States ${ }^{\mathrm{a}}$

\begin{tabular}{lccc}
\hline Effect or standard deviation & Factor 1 & Factor 2 & Factor 3 \\
\hline Loading of factor on $^{\mathrm{b}}$ & & & \\
$\quad$ Current policy setting & 1.00 & 0.00 & 0.00 \\
$\quad$ Year-ahead futures rate & 0.51 & 1.00 & 0.00 \\
$\quad$ Five-year yield & 0.27 & 0.64 & 1.00 \\
$\quad$ & & \\
Standard deviation of effect of factor on ${ }^{\mathrm{c}}$ & 10.0 & 0 & 0 \\
$\quad$ Current policy setting & 5.1 & 10.1 & 0 \\
$\quad$ Year-ahead futures rate & 2.7 & 6.5 & 3.5 \\
Five-year yield & & & \\
\hline
\end{tabular}

Source: Authors' calculations based on data from the Chicago Board of Trade, the Chicago Mercantile Exchange, and GovPX. a. Factors are constructed by means of a Cholesky decomposition, in which the first factor is the policy surprise contained in a policy statement, as inferred from the federal funds futures market; the second is the portion of the change in year-ahead policy expectations (as measured by the change in the Eurodollar futures contract) not explained by (that is, orthogonal to) the first factor; the third is the change in the five-year Treasury yield not explained by (orthogonal to) the first two factors.

b. Sample period is July 1991 to the present.

c. In basis points. Sample period is April 1998 to the present.

been set equal to the surprise component in the current policy decision, as measured by the method of Kuttner. ${ }^{57}$ Note that the second and third elements of the first column show the effect of a one-unit increase in the current policy surprise on policy expectations one year and five years ahead, respectively. As found by Kuttner, the effects of a current policy surprise on yields diminish as the horizon lengthens. The second factor has (again, by design) a unitary effect on year-ahead policy expectations and a diminishing effect on the five-year yield, whereas the third factor (by design) affects only the five-year yield.

An important finding is that the second factor (defined, again, as the part of the change in the year-ahead rate that is orthogonal to the surprise in the federal funds rate) plays a substantial role in determining policy expectations. This point can be seen in the bottom panel of table 1, which reports the standard deviation of the effect of each factor on the three market indicators of expectations in the period since $1998 .{ }^{58}$ The standard deviation of the component of the year-ahead futures rate accounted for by the second factor (10.1) is twice that of the component accounted for by the first factor (5.1). Putting the results in terms of variances, we can infer from the bottom panel of table 1 that only about one-fifth of the

57. Kuttner (2001).

58. The post-April 1998 subsample in the bottom panel of table 1 is chosen for comparability to the results presented below for the Bank of Japan. The results reported in the table are similar if the full sample is used. 
variance in the year-ahead futures rate in the hour around policy decisions is explained by current policy surprises (the first factor), and that the other four-fifths of the variance is captured by the second factor. This result confirms a primary conclusion of Gürkaynak, Sack, and Swanson, ${ }^{59}$ who argue that two factors are needed to explain the influence of FOMC announcements on monetary policy expectations out to a horizon of a year.

Also significant is the finding that the second factor makes the largest contribution to the variability in the five-year Treasury yield during the hour around FOMC decisions. In terms of standard deviations, the contribution of the second factor to the variation in the five-year yield is about twice that of either the first or the third factor. In terms of variances, the second factor accounts for 68 percent of the variability of the five-year yield during the event window, whereas the first factor explains 12 percent and the third factor 20 percent of the variance.

Having determined that policy expectations are determined to an important degree by a second factor that represents influences on market expectations of policy not captured in the policy decision itself, we next ask whether the second factor is related to the FOMC's communications. ${ }^{60}$ Informal inspection of the historical realizations of the various factors reveals that the second factor has become increasingly important in the latter part of the sample-the period when policy statements came into regular use. Even during the years from 1994 to 1999, when policy statements were used more sporadically, many of the large realizations of the second factor coincided with policy statements. In contrast, larger realizations of the first and third factors do not seem to line up with dates of policy statements.

To investigate more formally the link between FOMC statements and the three factors, we follow an approach similar to that employed by Kohn and Sack. ${ }^{61}$ As described in the previous section, Kohn and Sack showed that, for given values of the policy surprise, the issuance of statements by the FOMC increases the variability of market interest rates, suggesting that statements contain information relevant to financial markets. Here we extend their approach in several ways, in part by examining the effects on

59. Gürkaynak, Sack, and Swanson (2004).

60. Gürkaynak, Sack, and Swanson (2004) also address this issue and conclude that the second factor is indeed related to FOMC statements.

61. Kohn and Sack (2003). 
expectations of different types of statements (including "anticipated" and "unanticipated" statements), by linking statements to policy expectations at differing horizons (as summarized by the three factors), and by checking whether the directional effects of policy statements on policy expectations seem reasonable. ${ }^{62}$

As a first step, and in a manner analogous to Kohn and Sack's approach, we regress the squared values of each of the factors on several dummy variables related to policy statements, to determine whether statements "matter" for policy expectations at different horizons, as summarized by the three factors, without having to quantify the statements. We define the first dummy, which we call STATEMENT, to equal 1 on any date on which the FOMC released a policy statement following its meeting, and zero otherwise. A positive estimated coefficient on STATEMENT implies that this particular factor tends to be larger in magnitude on dates on which a statement is released. Of the 116 policy decisions in our sample, 56 were accompanied by statements.

Of course, a statement that market participants fully anticipated would not be expected to generate a market reaction. With this in mind, we define a second dummy variable (called STATEMENT SURPRISE) that equals 1 on dates when the issued statement included important information about the state of the economy or the path of monetary policy that a substantial portion of market participants did not expect.

Obviously, assigning values to STATEMENT SURPRISE involves some subjectivity, because investors' expectations about statements cannot be quantified as easily as their expectations for settings of the policy rate. To construct this dummy variable, we read a set of commentaries written before and after each statement was released, to determine whether the statement was substantially as expected by market participants or instead surprised the markets. After-the-fact commentaries that we examined included internal staff analyses from both the Federal Reserve Bank of New York and the Board of Governors of market reactions to the policy decision and the statement, as well as next-day articles about the FOMC's decision from the Wall Street Journal. A drawback of relying on after-the-fact analyses to determine which statements were surprises, of course, is that the authors' interpretations may have been infludata.

62. Also, unlike Kohn and Sack (2003), who use daily data, we continue to use intraday 
enced, consciously or unconsciously, by the observed market responses. ${ }^{63}$ To guard against this source of bias, we also used several before-the-fact sources, including a pre-FOMC-meeting survey of expectations for the balance-of-risks (or policy bias) part of the statement, conducted by Money Market Services and its successor Action Economics; commentaries put out just before each meeting by the ISI Group, a leading financial firm that specializes in monitoring FOMC action; and the results of a survey conducted by the Federal Reserve Bank of New York that asks primary dealers about their expectations for the statement. We took all occasions when the policy bias or the balance of risks differed from the median survey response as surprises. Using these materials, we identified thirty-one of the fifty-six statements in our sample period as involving some nonnegligible surprise. ${ }^{64}$

Table 2 presents the regression results; we focus first on the odd-numbered columns. Column 2-1 shows the results from regressing the square of the first factor (the current policy surprise) against a constant term and the two dummy variables. The first dummy, which indicates the presence of any statement accompanying an FOMC policy decision, enters the regression with a positive and significant coefficient. The most likely explanation for this result is that, for much of the sample period, statements were released only on days on which the federal funds rate was changed; not surprisingly, policy rate surprises tend to be larger on days when the federal funds rate target was changed than on days when no change in the target was made. The coefficient on the second dummy variable, STATEMENT SURPRISE, is negative and significant, which suggests that the FOMC views surprises in the policy rate and in the statement as substitutes, or possibly that the FOMC was simply reluctant to issue surprising statements at the same time that it was also surprising the markets with its policy action.

The regression reported in column 2-3 shows that the squared second factor, by contrast, appears to be driven entirely by statement surprises. The coefficient on STATEMENT SURPRISE is both highly statistically significant and economically important; the regression results imply that,

63. Although written after the fact, the Federal Reserve staff analyses not infrequently reported that the market's reaction was different from their ex ante assessment of the likely response, suggesting that the retrospective bias may not have been severe.

64. The breakdown of statements into surprises and nonsurprises, together with a brief commentary, is available from the authors on request. 
Table 2. Regressions of Squared Factors on Dummy Variables for Federal Reserve Policy Statements ${ }^{\mathrm{a}}$

\begin{tabular}{|c|c|c|c|c|c|c|}
\hline \multirow[b]{3}{*}{ Independent variable } & \multicolumn{6}{|c|}{ Dependent variable } \\
\hline & \multicolumn{2}{|c|}{ Factor 1} & \multicolumn{2}{|c|}{ Factor 2} & \multicolumn{2}{|c|}{ Factor 3} \\
\hline & $2-1$ & $2-2$ & $2-3$ & $2-4$ & $2-5$ & $2-6$ \\
\hline Constant & $\begin{array}{l}64.7 \\
(1.85)\end{array}$ & $\begin{array}{l}64.7 \\
(1.82)\end{array}$ & $\begin{array}{l}24.1 \\
(1.48)\end{array}$ & $\begin{array}{l}24.1 \\
(1.51)\end{array}$ & $\begin{array}{l}3.2 \\
(1.10)\end{array}$ & $\begin{array}{l}3.2 \\
(1.10)\end{array}$ \\
\hline STATEMENT $^{\mathrm{b}}$ & $\begin{array}{c}131.6 * * \\
(2.04)\end{array}$ & $\begin{array}{c}131.6^{* *} \\
(2.03)\end{array}$ & $\begin{array}{l}18.3 \\
(0.61)\end{array}$ & $\begin{array}{l}18.3 \\
(0.63)\end{array}$ & $\begin{array}{l}6.3 \\
(1.18)\end{array}$ & $\begin{array}{l}6.3 \\
(1.17)\end{array}$ \\
\hline $\begin{array}{l}\text { STATEMENT } \\
\text { SURPRISE }^{\mathrm{c}}\end{array}$ & $\begin{array}{c}-149.4 * * \\
(-2.05)\end{array}$ & $\begin{array}{l}-139.5 \\
(-1.75)\end{array}$ & $\begin{array}{c}153.3 * * \\
(4.54)\end{array}$ & $\begin{array}{c}120.7 * * \\
(3.35)\end{array}$ & $\begin{array}{l}8.1 \\
(1.33)\end{array}$ & $\begin{array}{l}7.9 \\
(1.19)\end{array}$ \\
\hline PATH SURPRISE $^{\mathrm{d}}$ & & $\begin{array}{l}-34.2 \\
(-0.32)\end{array}$ & & $\begin{array}{c}112.5^{* *} \\
(2.31)\end{array}$ & & $\begin{array}{l}0.6 \\
(0.07)\end{array}$ \\
\hline Adjusted $R^{2}$ & .04 & .04 & .26 & .30 & .07 & .07 \\
\hline $\begin{array}{l}\text { Source: Authors' regression } \\
\text { a. Numbers in parentheses a } \\
\text { table } 1 \text {. } \\
\text { b. Dummy variable set equ } \\
\text { otherwise. } \\
\text { c. Dummy variable set equa } \\
\text { state of the economy or the pa } \\
\text { otherwise. } \\
\text { d. Dummy variable set equa }\end{array}$ & $\begin{array}{l}1 \text { on dates } w \\
1 \text { on dates whe } \\
\text { f monetary po }\end{array}$ & $\begin{array}{l}\text { en the FOMC } \mathrm{r} \\
\text { the FOMC issu } \\
\text { y that a substar }\end{array}$ & $\begin{array}{l}\text { ased a policy } \\
\text { a statement th } \\
\text { l portion of } n\end{array}$ & $\begin{array}{l}95 \text { percent le } \\
\text { atement follc } \\
\text { included imp } \\
\text { ket participa }\end{array}$ & $\begin{array}{l}\text { Factors are } \\
\text { g its meeti } \\
\text { nt informat } \\
\text { lid not exp }\end{array}$ & $\begin{array}{l}\text { defined in } \\
\text { and zero } \\
\text { about the } \\
\text {, and zero } \\
\text { about the }\end{array}$ \\
\hline
\end{tabular}

on average, the variance of the second factor during the one-hour window surrounding the release of the statement is about 196 basis points (the sum of the constant term and both regression coefficients) when the statement is surprising, but only about 42 basis points (the constant term plus the first coefficient) when the statement is as expected. Moreover, the variance of the second factor is not significantly different from zero on days when no statement is released or when the statement is as anticipated. This result suggests that surprise statements have a major impact on policy expectations a year ahead.

The magnitude of the third factor seems unrelated to policy statements, because neither dummy variable enters significantly into the regression for the square of that factor (column 2-5). In other words, we find no evidence that FOMC statements affect the five-year Treasury yield independent of their effect on year-ahead expectations. (However, recall from table 1 that independent variation in year-ahead policy expectations - the second factor-accounts for the bulk of the variance of the five-year Treasury yield during the periods surrounding FOMC decisions. Thus, holding the current policy decision constant, a surprising statement has an impor- 
tant effect on yields at the five-year horizon, albeit indirectly through its effects on one-year-ahead policy expectations.) As we saw above, the third factor is quite small and may simply reflect residual noise in the fiveyear yield.

Investors are most interested in statements that provide hints about the FOMC's inclinations regarding future policy actions (as opposed to, for example, statements that describe past economic developments). From the committee's point of view, the effects on market expectations of statements bearing on the future course of policy should also be of particular interest, since this is the type of statement that theory suggests should be most useful when the policy rate is near the zero bound. To examine whether statements that provide new information about the likely future path of monetary policy are particularly influential, we used the sources noted above to identify nine statements among the thirty-one surprise statements that seemed most explicitly focused on the likely future path of policy. The dummy variable PATH SURPRISE takes a value of 1 on the dates of these statements.

A number of these statements occurred recently, in a period when the FOMC was attempting to provide additional stimulus to the economy despite the fact that the federal funds rate had already been reduced to as little as 100 basis points. For example, in August 2003 the FOMC stated that "policy accommodation can be maintained for a considerable period," marking the first time that the FOMC statement discussed an extended outlook for its policy path. ${ }^{65}$ This phrase was repeated in FOMC statements following the September, October, and December meetings. At its January 2004 meeting the FOMC replaced the "considerable period" phrase with the assertion that "the Committee believes that it can be patient in removing its policy accommodation." This substitution caused long-dated Treasury yields to jump 15 to 25 basis points, a clear indication that the committee's language was important in shaping longer-term policy expectations. Policymaking by thesaurus continued through 2004. After repeating the "patient" language after its March meeting, the FOMC in its May statement replaced this phrase with the statement that it "believes that policy accommodation can be removed at

65. The "policy bias" that was part of the statement for the brief period from May 1999 to December 1999 was usually interpreted as pertaining to a much shorter time frame, such as the period between FOMC meetings. 
a pace that is likely to be measured," and it maintained that assessment through the end of our sample. These statements, because they are so explicitly focused on the policy path, may provide the best natural experiments for assessing what could be accomplished at the zero bound.

As can be seen in the even-numbered columns in table 2, the PATH SURPRISE dummy enters significantly only in the regression explaining the square of the second factor, further confirming the association of this factor with policy statements. Relative to a situation in which an unsurprising statement is issued, a surprise statement about the likely future course of policy increases the variance of the second factor during the event window by 233 basis points (the sum of the coefficients on surprise statements and policy path surprise statements), indicating that statements providing new information about the prospective path of policy have a powerful effect on year-ahead policy expectations and, hence, indirectly on the five-year Treasury yield as well.

So far we have shown that year-ahead policy expectations react strongly to unexpected changes in the FOMC's statement, in the sense that the absolute change in year-ahead expectations tends to be much larger when the content of the statement is unexpected. We have not yet shown that the change in expectations is in the predicted direction, for example that unexpectedly "hawkish" statements cause expectations to shift toward a greater degree of policy tightening. To take this additional step, while recognizing once again that the quantification of purely qualitative statements is necessarily hazardous, we used the source materials described earlier to "sign" the thirty-one surprise statements in terms of their apparent implications for subsequent monetary policy actions. We summarized this information in a dummy variable, SIGNED STATEMENT, which is assigned the value of +1 for surprise "hawkish" statements (those that implied a higher future path of the federal funds rate than previously expected), -1 for surprise "dovish" statements, and zero for all other observations, including those with nonsurprising statements or no statements at all. We then regressed the levels (not the squares) of each of the three factors on the signed dummy variable. We also tried regressing the levels of the factors on the signed values of statements corresponding to policy path surprises (SIGNED PATH, defined as the product of the SIGNED STATEMENT and PATH SURPRISE dummies.)

The results, shown in table 3 , further strengthen our findings. Columns 3-1, 3-2, 3-5, and 3-6 show that no significant relationship exists between 
Table 3. Regressions of Factors on Signed Dummy Variables for Federal Reserve Policy Statements ${ }^{\mathrm{a}}$

\begin{tabular}{|c|c|c|c|c|c|c|}
\hline \multirow[b]{3}{*}{ Independent variable } & \multicolumn{6}{|c|}{ Dependent variable } \\
\hline & \multicolumn{2}{|c|}{ Factor 1} & \multicolumn{2}{|c|}{ Factor 2} & \multicolumn{2}{|c|}{ Factor 3} \\
\hline & $3-1$ & $3-2$ & $3-3$ & $3-4$ & $3-5$ & $3-6$ \\
\hline $\begin{array}{l}\text { SIGNED STATEMENT } \\
\text { SURPRISE }^{\mathrm{b}}\end{array}$ & $\begin{array}{l}1.4 \\
(0.83)\end{array}$ & & $\begin{array}{c}11.5^{* *} \\
(10.21)\end{array}$ & & $\begin{array}{l}-0.4 \\
(-0.68)\end{array}$ & \\
\hline $\begin{array}{l}\text { SIGNED PATH } \\
\text { SURPRISE }^{c}\end{array}$ & & $\begin{array}{l}-1.5 \\
(-0.49)\end{array}$ & & $\begin{array}{l}15.8 * * \\
(6.38)\end{array}$ & & $\begin{array}{l}1.3 \\
(1.37)\end{array}$ \\
\hline Adjusted $R^{2}$ & -.03 & -.03 & .47 & .26 & -.02 & -.01 \\
\hline
\end{tabular}

the signed statement surprises and either the first or the third factor. In contrast, signed surprises have a large and highly statistically significant effect on the second factor, with hawkish statements raising and dovish statements lowering year-ahead policy expectations by 12 basis points on average (column 3-3). The effects are even larger (16 basis points) when we restrict our attention to the nine policy path surprises (column 3-4). Recalling from table 1 that the loading of the five-year yield on the second factor is 0.64 , we can also estimate that, with the current policy surprise held constant, a surprisingly hawkish statement raises the five-year yield by about 8 basis points and a hawkish statement about the policy path raises the yield by about 10 basis points.

\section{Conditioning Effects of Policy Statements}

The immediate effects of official FOMC statements on policy expectations likely underestimate the overall impact of FOMC communications on expectations; for example, our focus on statements alone ignores the potential effects of speeches and testimony by FOMC members. Also, beyond their immediate effects, FOMC statements may affect the formation of policy expectations by influencing how those expectations respond to various sorts of incoming data. In particular, to the extent that FOMC policy commitments are conditional, that is, tied to specific economic developments, policy expectations should react more strongly to macroeconomic news that bears on those developments. 
A leading example is the market's responsiveness to monthly reports on payroll employment. ${ }^{66}$ Throughout the recent period, the FOMC was concerned about the "jobless" nature of the economic recovery and repeatedly pointed to weakness in the labor market as a key factor shaping the outlook for policy. When Federal Reserve Chairman Alan Greenspan introduced the phrase "considerable period" in his semiannual report to Congress in July 2003, he indicated the Federal Reserve's concerns about resource utilization and "unwelcome disinflation." (On several occasions in congressional testimony, Greenspan has also indicated his preference for the payroll employment series over the household employment series as a measure of current conditions in the labor market.) Each FOMC statement that used the "considerable period" language also discussed labor market conditions, and the December 2003 statement tied the "considerable period" outlook for policy closely to slack in resource use. Statements since December 2003 have continued both to place substantial weight on labor market conditions (as well as inflation) and to provide information about the FOMC's policy expectations.

With this background, if FOMC communication is effective, one might expect to find that financial markets have become more sensitive to news about payroll employment. Figure 2 confirms this hypothesis: it shows the responsiveness, over a thirty-minute window, of the ten-year Treasury yield to surprises in monthly payrolls, where the surprise is defined as the reported payroll number less the median survey expectation as reported by Money Market Services. The sample is divided into the period through August 2003, just before the meeting when the "considerable period" language was introduced, and the period from September 2003 to the present. In the earlier period, as indicated by the thin regression line in figure 2 , a positive surprise of 100,000 payroll jobs translated into a 4-basis-point increase in ten-year Treasury yields during the thirty-minute window. Since September 2003 this responsiveness has strengthened, as is visible from the larger data points. The regression line for the recent subsample shows that ten-year Treasury yields increased by 11 basis points for every surprise of 100,000 jobs above the consensus expectation. The difference in coefficients is statistically significant.

66. A second important example, not pursued here, is the responsiveness of the market to data on core inflation. 
Figure 2. Response of Ten-Year Treasury Yields to Surprises in Monthly Employment Reports, 1991-2004

Change in yield (basis points) ${ }^{\mathrm{a}}$

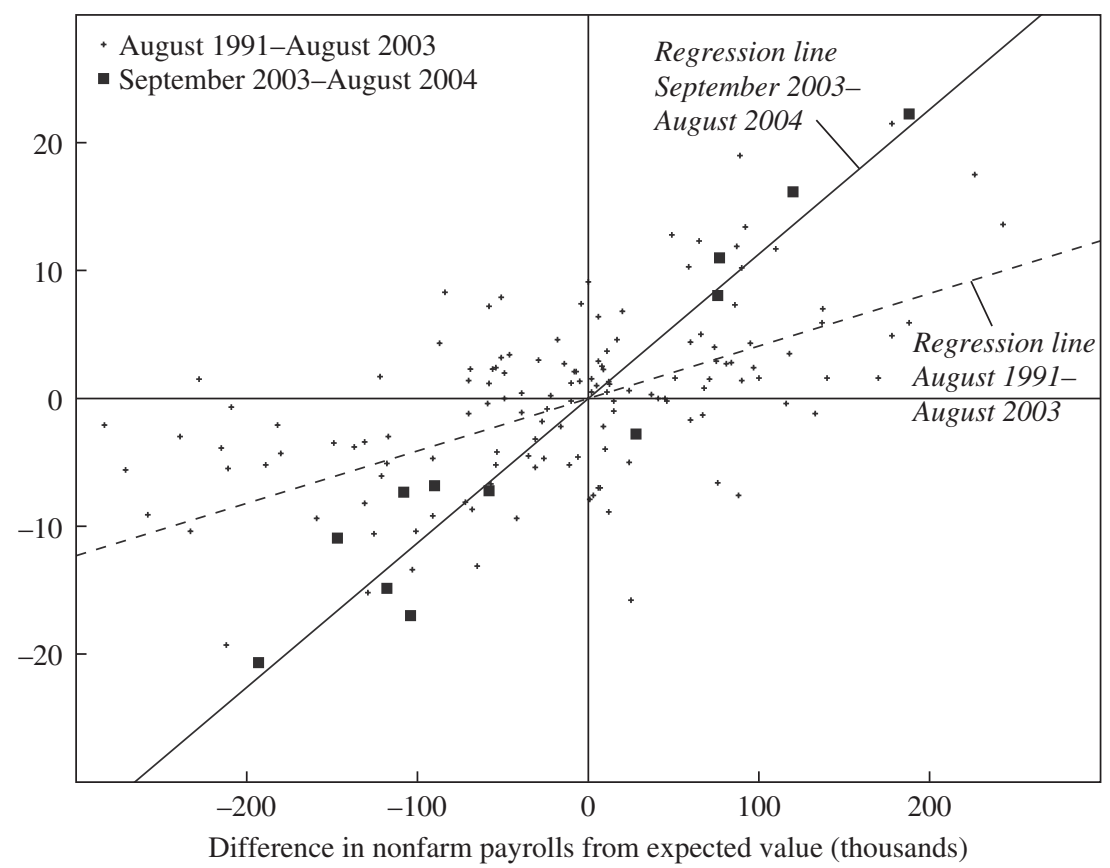

Sources: GovPX, Bloomberg, and Money Market Services.

a. Change in market yield from 8:25 a.m. to 8:55 a.m. on the days of employment reports (released at 8:30 a.m.). A few large observations are excluded from the graph but included in the regression estimation.

If FOMC communications are responsible for the increased responsiveness of yields (and the associated policy expectations) to unexpected changes in payroll employment, it should also be the case that markets have responded less to macroeconomic developments not flagged by the committee as likely to have a strong bearing on policy decisions. This should especially be the case over the period when, conditioned on the ongoing sluggishness of hiring, the FOMC indicated that policy would remain highly accommodative. That this latter conjecture is likely to be true is shown by figure 3 , which reports implied volatility measures derived from options on Eurodollar futures. These measures are market-based estimates of the expected volatility of short-term interest rates over two horizons: four months and one year. As the figure shows, the short-horizon volatility 
Figure 3. Implied Volatility of the Federal Funds Rate, 1990-2004

Percentage points

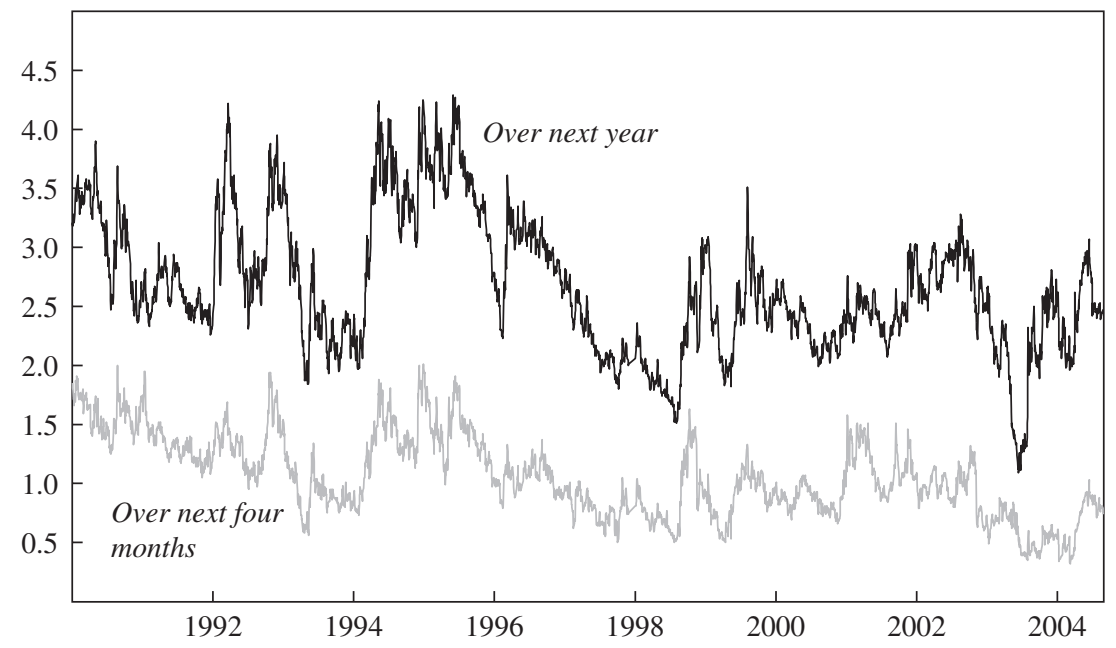

Source: Authors' calculations based on data from the Chicago Mercantile Exchange.

a. Data are widths of a 90 percent confidence interval for the federal funds rate over the indicated horizon, derived from the volatility of the three-month Eurodollar rate implied by options on Eurodollar futures.

measure fell to historic lows during the second half of 2003, but the same result does not hold at the longer horizon. These data provide a bit of evidence that the FOMC's communications in the second half of 2003 reduced the volatility of (or "anchored") near-term policy expectations. Since we have seen that policy expectations simultaneously became more sensitive to certain types of macroeconomic news, such as the payroll report, the decline in overall volatility suggests that the responsiveness of markets to other types of news declined.

\section{Shaping Policy Expectations: Evidence from a Macrofinance Model of the Term Structure}

Our event studies confirm that FOMC statements have important influences, both direct and indirect, on private sector policy expectations. Event studies have the drawback, however, of showing only very short term effects. They may overstate the more important longer-term effects, if, for example, yields tend to overreact in the period just around announcements; or they may understate the longer-term effects, for example by not account- 
ing for types of communication other than statements. In this section we address this issue by developing a benchmark macrofinance model of the term structure. Here and in additional exercises in the remainder of the paper, our model provides estimates of what the term structure would have been on a given date, given the state of the economy and the stance of monetary policy but excluding other factors. By comparing this benchmark estimate of the term structure with the actual term structure at crucial junctures, we may be able to get a sense of the quantitative impacts of these other factors on the maturity structure of interest rates.

To develop a baseline model of the Treasury yield curve, we estimate an affine term structure model (that is, a model that is linear in the factors) ${ }^{67}$ The affine term structure model imposes a no-arbitrage condition that links yields at every maturity of the term structure, thereby increasing the efficiency of estimation and allowing us to forecast the entire yield curve as a function of the variables designated as underlying factors. We differ from most of the previous literature in identifying the underlying factors that determine the term structure by means of observable indicators of macroeconomic conditions and the stance of monetary policy, and not relying on unobserved factors or longer-term yields as the assumed drivers of term structure dynamics.

As to the dynamics of the underlying factors, we employ a vector autoregression (VAR) in five observable variables: a measure of the employment gap (payroll employment, detrended by a Hodrick-Prescott filter); inflation over the past year, as measured by the deflator for personal consumption expenditures, excluding food and energy; expected inflation over the subsequent year, taken from the Blue Chip survey and with inflation defined in terms of the GDP deflator (the Blue Chip survey does not forecast core inflation); the federal funds rate; and the year-ahead Eurodollar futures rate. Together these variables should provide a reasonable summary of economic conditions, including the current setting of monetary policy (as reflected in the federal funds rate) and the expected path of policy over the near term (as captured by the Eurodollar futures rate). The data are monthly from June 1982 (when the Eurodollar data

67. Affine term structure models were popularized by Duffie and Kan (1996), whose formalization encompasses earlier models due to Vasicek (1977), Cox, Ingersoll, and Ross (1985), and Longstaff and Schwartz (1992), among others. Bolder (2001) provides a useful introduction to these models. 
first became available) to the present, and four lags of each variable are included in the VAR.

As already noted, to measure the influence of these observed indicators on the Treasury yield curve, we construct a no-arbitrage term structure model in which the five economic and monetary indicators are treated as factors. In general, Treasury yields are determined by two components: the expected future path of one-period interest rates, and the excess returns that investors demand as compensation for the risk of holding longer-term instruments. The estimated VAR can be iterated to provide forecasts for the one-period interest rate at each horizon (where we treat the monthly average federal funds rate as the "one-period interest rate"). In addition, we make a standard assumption of affine models of the term structure, namely, that equilibrium prices of risk are linear functions of the factors (the variables in the VAR). With that assumption, the entire Treasury yield curve can be priced from the VAR estimates.

To be more specific, suppose we write the estimated VAR in the following form:

$$
\mathbf{X}_{t}=\mu+\Phi \mathbf{X}_{t-1}+\Sigma \varepsilon_{t},
$$

where $\mathbf{X}_{t}$ is the vector of state variables. To develop the no-arbitrage part of the model below, it will be convenient for the state variables to follow a first-order autoregressive process. Thus in equation 1 we have stacked the VAR variables so that the state vector $\mathbf{X}_{t}$ includes the contemporaneous values of the five variables and three lags of the variables (hence $\mathbf{X}_{t}$ is a $20 \times 1$ column vector) ${ }^{68}$

We assume that there is no arbitrage in the bond market, implying that a single pricing kernel determines the values of all fixed-income securities. The pricing kernel is determined by investors' preferences for statedependent payouts. Specifically, the value of an asset at time $t$ equals $E_{t}\left[m_{t+1} Y_{t+1}\right]$, where $Y_{t+1}$ is the asset's gross return in period $t+1$, and $m_{t+1}$ is the one-period pricing kernel. Because we will be considering zerocoupon bonds, the payout from the bonds is simply their value in the following period, so that the following recursive relationship holds:

$$
P_{t}^{n}=E_{t}\left[m_{t+1} P_{t+1}^{n-1}\right]
$$

68. Thus the first five rows of the matrix $\boldsymbol{\Phi}$ include the VAR estimates, and the rest of the matrix contains zeros and ones at the appropriate locations. 
where $n$ is the remaining life of the bond, and the terminal value of the bond, $P_{t+n}^{0}$, is normalized to equal 1 .

Following the approach of Andrew Ang, Monika Piazzesi, and Min Wei, ${ }^{69}$ we assume that the pricing kernel is conditionally log-normal, as follows:

$$
m_{t+1}=\exp \left(-y_{t}^{(1)}-1 / 2 \lambda_{t}^{\prime} \lambda_{t}-\lambda_{t}^{\prime} \varepsilon_{t+1}\right)
$$

where the $\lambda_{t}$ are the market prices of risk associated with the VAR innovations (the source of uncertainty in the model), and $y_{t}^{(1)}$ is the one-period interest rate expressed on a continuously compounded basis. As already noted, we assume that the prices of risk are linear in the state variables:

$$
\lambda_{t}=\lambda_{0}+\lambda_{1} \mathbf{X}_{t} .
$$

We restrict the prices of risk to be zero for all but the first five elements of $\lambda_{t}$, and we assume that those prices of risk depend only on the contemporaneous values of the VAR. (Recall that the final fifteen elements of the stacked column vector $\mathbf{X}_{t}$ are lags of the five factors.) These assumptions imply that only thirty parameters must be estimated in this block of the model, a manageable number while still allowing the model the flexibility needed to provide a good empirical fit of the term structure data.

Manipulation of equations 1 through 3 shows that the zero-coupon yields can be written as linear functions of the state variables, as follows:

$$
y_{t}^{(n)}=a_{n}+b_{n}^{\prime} \mathbf{X}_{t},
$$

where $a_{n}=-\mathbf{A}_{n} / n$ and $b_{n}=-\mathbf{B}_{n} / n$, and the vectors $\mathbf{A}_{n}$ and $\mathbf{B}_{n}$ are determined by the following recursive formulas:

$$
\begin{gathered}
\mathbf{A}_{n+1}=\mathbf{A}_{n}+\mathbf{B}_{n}^{\prime}\left(\mu-\Sigma \lambda_{0}\right)+1 / 2 \mathbf{B}_{n}^{\prime} \Sigma \Sigma^{\prime} \mathbf{B}_{n}-\delta_{0} \\
\mathbf{B}_{n+1}=\left(\Phi-\Sigma \lambda_{1}\right)^{\prime} \mathbf{B}_{n}-\delta_{1} .
\end{gathered}
$$

The starting values for these equations are $\mathbf{A}_{1}=-\delta_{0}$ and $\mathbf{B}_{1}=-\delta_{1}$, and the parameters $\delta_{0}$ and $\delta_{1}$ describe the relationship of the one-period yield to

69. Ang and Piazzesi (2003); Ang, Piazzesi, and Wei (2003). 
the state vector, that is, $y_{t}^{(1)}=\delta_{0}+\delta_{1}^{\prime} \mathbf{X}_{t}$. In our application, because the one-period yield (the federal funds rate) is included in the state variable, this relationship is trivial: All elements of $\delta_{0}$ and $\delta_{1}$ are zero except for the element of $\delta_{1}$ that picks out the current value of the federal funds rate, which is set to unity.

Given a set of prices of risk, the entire Treasury yield curve can be derived using equation 5 . We estimate the prices of risk by minimizing the sum of squared prediction errors for zero-coupon Treasury yields at maturities of six months and one, two, three, four, five, seven, and ten years. Our data are zero-coupon Treasury yields, based on the FisherNychka-Zervos yield curve for the period 1982 to 1987 and on the zerocoupon yield curve constructed at the Board of Governors for the period since $1987 .{ }^{70}$ Note that to some extent we are explaining one set of interest rates by another, since the federal funds rate and the year-ahead Eurodollar rate are included in the VAR and thus serve as factors. As already mentioned, however, including the latter indicators in the VAR serves the important function of capturing the effects of current and expected monetary policy actions on the Treasury term structure; this will be important later when we use the model to isolate relative supply effects on Treasury yields. Moreover, our procedure implies no internal inconsistency, because both indicators of monetary policy differ in substantive respects (for example, in credit risk, liquidity, and maturity) from the Treasury rates that they are being used to model.

Our model contributes to the growing literature that includes macroeconomic variables in no-arbitrage term structure models. An appealing feature of our framework is the substantial simplification in estimation and analysis achieved by our assumption that all the factors driving the term structure are observable economic and monetary variables. As noted earlier, related models typically include unobserved factors as determinants of the term structure and even of the observed economic variables in the system. ${ }^{71}$ The use of unobserved factors has advantages in some applications, but it greatly complicates estimation and may make the economic

70. Fisher, Nychka, and Zervos (1995).

71. Related models include those of Ang and Piazzesi (2003) and Rudebusch and Wu (2003). 
interpretation of the results more difficult. ${ }^{72}$ Our approach instead directly links the term structure to observable economic conditions, thereby providing us with an easily interpretable benchmark for gauging the potential effects of unusual monetary policy strategies.

The estimated model does a quite creditable job of explaining the behavior of the term structure over time. Figure 4 compares the fitted and actual time series for the two-year and ten-year Treasury yields. The model predicts Treasury yields reasonably well at all maturities: as reported in the first column of table 4 , the standard deviation of the model's prediction error is 33 basis points at the six-month maturity and increases to around 80 basis points for longer maturities. Also shown in figure 4 are the two-year and ten-year "risk-neutral" yields. These are derived by setting the prices of risk equal to zero-that is, they are the rates that investors would demand if they were risk neutral. The differences between these lines and the predicted yields, then, are estimated term premiums. Figure 4 shows that estimated term premiums for longerdated securities have declined over time, presumably reflecting greater stability in the economy and in policy, but they remain fairly large. Of particular note is that variations in the term premium are estimated to account for a significant portion of the variation in long-term yields; part of the reason is likely to be that the forecasting model does a better job capturing low-frequency movements in the data than high-frequency ones. Those residuals in predicting high-frequency movements, then, are imputed to the term premium.

In the event-study analysis described earlier, we found that an important part of the effect of a monetary policy decision is transmitted through its impact on year-ahead policy expectations, but that expectations also depend importantly on FOMC statements. The importance of year-ahead policy expectations for longer-dated yields is generally confirmed by our term structure fitting exercise. We can assess the importance of innovations of the futures rate by ordering it last in a Cholesky decomposition. In doing so, we are attributing as much as possible of the movements in futures rates to the other variables. Even so, innovations to the futures rate

72. Ang, Piazzesi, and Wei (2003) employ a model in which, as in our analysis, the pricing kernel is assumed to be a function of observable variables. However, the only macroeconomic variable in their model is GDP growth, and they do not focus on the properties of the term structure model itself but rather on the implications of their framework for predicting GDP growth. 
Figure 4. Actual and Predicted Zero-Coupon Treasury Yields, 1982-2004 ${ }^{\mathrm{a}}$

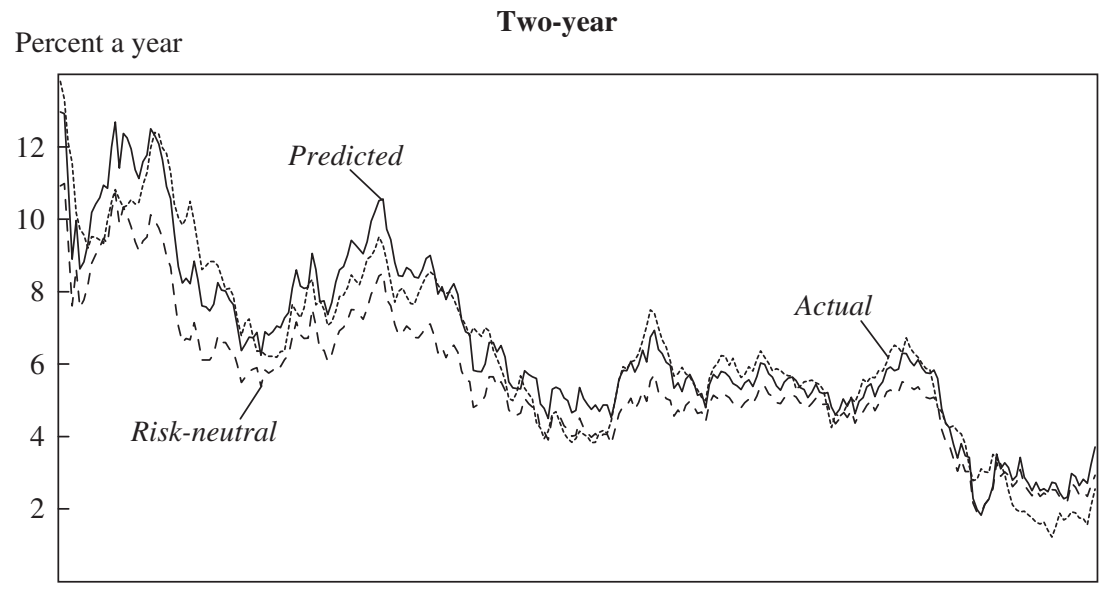

Ten-year

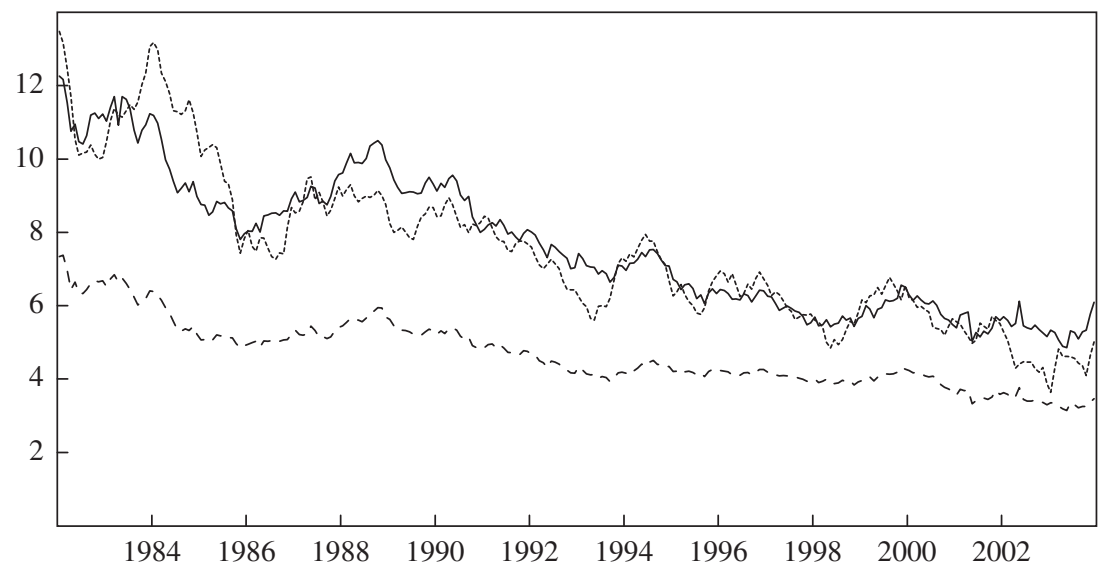

Source: Authors' calculations based on data from the Bureau of Labor Statistics, the Bureau of Economic Analysis, Blue Chip Financial Forecasts, the Chicago Mercantile Exchange, and the Federal Reserve.

a. The predicted Treasury yields are generated by the term structure model, as described in the text. The risk-neutral Treasury yields are generated by the same model, but with the prices of risk set equal to zero. 
Table 4. Prediction Errors for Treasury Yields in the Term Structure Model Basis points

\begin{tabular}{lcc}
\hline & \multicolumn{2}{c}{ Standard deviation of predicted yield } \\
\cline { 2 - 3 } Maturity & $\begin{array}{c}\text { VAR with } \\
\text { Eurodollar shocks }\end{array}$ & $\begin{array}{c}\text { VAR without } \\
\text { Eurodollar shocks }\end{array}$ \\
\hline 6 months & 33.0 & 62.1 \\
1 year & 50.3 & 78.9 \\
2 years & 73.3 & 97.4 \\
3 years & 81.2 & 100.7 \\
4 years & 82.5 & 98.3 \\
5 years & 81.5 & 95.0 \\
7 years & 83.3 & 93.3 \\
10 years & 80.8 & 87.8 \\
\hline
\end{tabular}

Source: Authors' calculations based on data from the Bureau of Labor Statistics, the Bureau of Economic Analysis, Blue Chip Financial Forecasts, the Chicago Mercantile Exchange, and the Federal Reserve.

are important for explaining movements in the yield curve. As can be seen in the second column of table 4, excluding the year-ahead futures rate innovations from the VAR causes a significant deterioration in the fit of the estimated model, particularly at shorter horizons. For example, doing so raises the standard deviation of the prediction error for the two-year Treasury yield from 73 basis points to 97 basis points. The inclusion of a variable such as the year-ahead futures rate, and to a lesser extent the survey measure of inflation looking one year ahead, has the advantage of improving the fit of the model. But it also implies that some of the influence of policy in shaping expectations will be captured by those variables in the forecasting model. If so, our later attempt to interpret deviations of actual yields from those predicted by the model will tend to be conservative, in that the macrofinance model may well capture some expectations effects.

It is tempting to combine the result of the event study (that FOMC statements have a substantial influence on year-ahead policy expectations) with the result from the term structure fitting exercise (that year-ahead policy expectations are important determinants of Treasury yields) to conclude that FOMC statements have an important influence on the term structure. That conclusion may be a bit premature. Notably, the innovations to the Eurodollar futures rate obtained from the VAR need not correspond closely to the innovations to the same variable obtained from the highfrequency event study. To illustrate this point, table 5 compares, for various 
Table 5. Year-Ahead Futures Shocks in Vector Autoregression and in Event Study Basis points

\begin{tabular}{lcc}
\hline & \multicolumn{2}{c}{$\begin{array}{c}\text { Standard deviation of innovations to the } \\
\text { year-ahead Eurodollar futures rate }\end{array}$} \\
\cline { 2 - 3 } Sample period $^{\text {a }}$ & VAR shock & Event-study shock $^{\mathrm{b}}$ \\
\hline July 1991 to January 1994 & 35.9 & 4.2 \\
February 1994 to April 1999 & 35.2 & 6.8 \\
May 1999 to July 2003 & 40.1 & 8.2 \\
August 2003 to May 2004 & 25.2 & 11.7 \\
\hline
\end{tabular}

Source: Authors' calculations based on data from sources listed in tables 1 and 4

a. Overall period begins in July 1991, the earliest date covered by the event study. Break dates include the date at which the FOMC began announcing interest rate decisions (February 1994), the date at which the FOMC began issuing statements after every meeting (May 1999), and the date at which the FOMC adopted the "considerable period" language (August 2003).

b. Aggregated to a monthly variable for comparability with the VAR shock.

subsamples, the monthly standard deviation of innovations to the yearahead Eurodollar futures rate, as calculated from the VAR (first column) and by summing the changes in the Eurodollar rate around FOMC decisions (second column). In general, the variance of the VAR innovations to the Eurodollar rate is significantly greater than the variance of innovations to the Eurodollar rate directly associated with FOMC decisions. Several plausible explanations for this difference come to mind: First, the movements of the Eurodollar rate in the hour around FOMC decisions certainly do not capture all of the effects of FOMC communications, including the effects of speeches and testimonies and the point, demonstrated earlier, that FOMC statements can affect the responsiveness of policy expectations to various kinds of macroeconomic news. Indeed, as table 5 illustrates, as the FOMC has made greater use of communications strategies, particularly since mid-2003, the variation of the Eurodollar rate around FOMC decisions has risen, while the variation in the corresponding VAR innovation has actually fallen, possibly reflecting better anchoring of short-term policy expectations. That said, it seems clear that not all of the VAR innovation represents unmeasured communication effects; certainly, some part of the VAR innovations to the Eurodollar futures rate reflects responses of policy expectations to developments in the economy unrelated to FOMC communications (and not captured by the economic variables included in the VAR).

As a simple case study, we considered in more detail the VAR innovations and the event-study innovations during the period in which the FOMC 
Figure 5. Effects of Unexpected Futures Rate Outcomes on Treasury Zero-Coupon Yield Curve, August-December 2003 ${ }^{\mathrm{a}}$

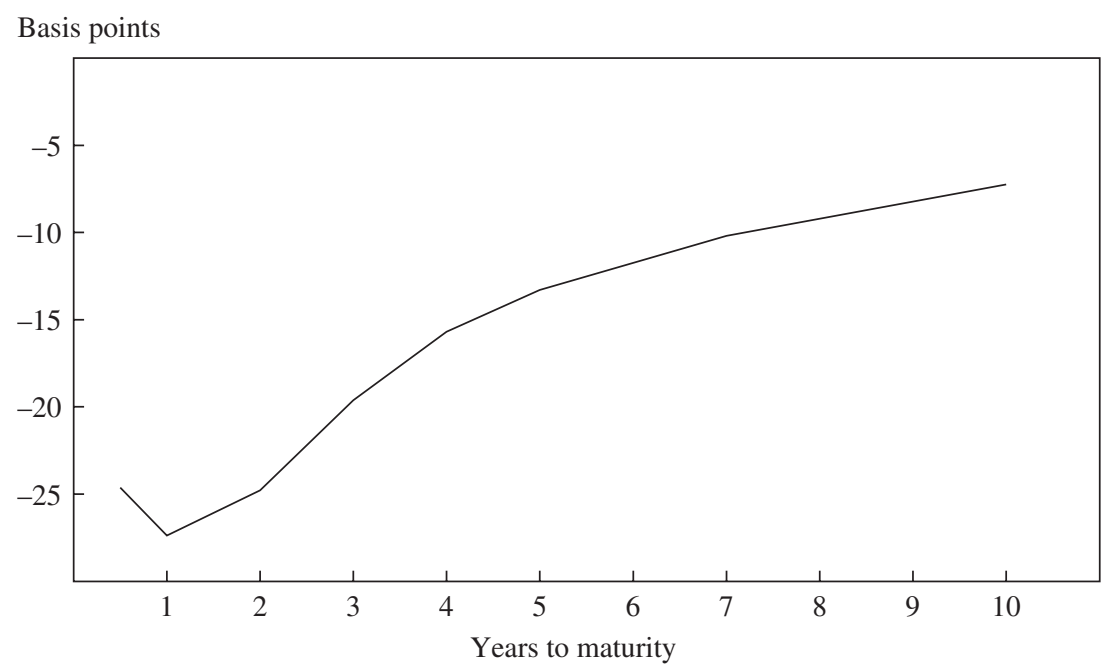

Source: Authors' calculations based on data from the sources listed in figure 4 .

a. Cumulative shift in Treasury yields of the indicated maturity predicted by the futures rate shocks from the VAR described in the text.

introduced the "considerable period" language (August to December 2003). During that period, according to the event study, FOMC communications pushed down the Eurodollar futures rate by a cumulative 19 basis points, whereas the VAR shocks lowered the future rate by 63 basis points. ${ }^{73}$ As an upper bound on the effect of the "considerable period" language on the term structure, figure 5 uses our estimated model of the term structure to show the effect on the yield curve associated with a 63-basis-point decline in the Eurodollar futures rate. The model predicts an effect of the "considerable period" language ranging from about 25 basis points at the two-year horizon to about 7 basis points at the ten-year horizon. ${ }^{74}$

73. Because the VAR models month-average variables, we sum the realization through January 2004, because the "considerable period" language was not removed until the end of that month.

74. Note that an innovation to the Eurodollar futures rate has an effect on Treasury yields that is less than one for one at all maturities, suggesting that the futures rate measured here has excess variation relative to Treasury yields. This could reflect the (presumably small) credit risk premium embedded in the futures rate, premiums for the relative liquidity of the two instruments, or simply measurement noise. 
Overall, the evidence suggests that FOMC statements have importantly shaped the policy expectations of investors, particularly over the past five years. Indeed, yield curve movements around FOMC decisions cannot be adequately described by the unexpected component of policy decisions, but are instead influenced to a greater extent by a second factor, which appears to be associated with surprises in the policy statements. These findings suggest that policymakers may have some scope for influencing investors' expectations if the federal funds rate were to fall to the zero bound.

\section{The Effects of Changing the Supply of Assets}

We turn now to evidence bearing on the third type of nonstandard policy, namely, changes in the composition of the central bank's balance sheet or targeted asset purchases. The question is whether substitution among assets is sufficiently imperfect so that large purchases of a specific class of asset might affect its yield, over and above any influence those purchases might have on investors' expectations about the future course of the short-term interest rate. Of course, the Federal Reserve has not undertaken any such actions in recent years. However, it still may be possible to learn about the effects of such actions by looking at the effects on yields of other actual or expected changes in the relative supplies of assets.

We identified three episodes in the past five years in which market participants in the United States came to anticipate significant changes in the relative supplies of different Treasury securities. These three natural experiments are, first, the Treasury's announcement in 1999 of a plan to buy back government debt in the face of prospective budget surpluses; second, the investment in Treasury securities by Asian official institutions of the proceeds of their foreign exchange market interventions since 2002; and third, the emerging belief on the part of some financial market participants in the spring of 2003 that the Federal Reserve might resort to targeted purchases of long-term Treasury securities in order to combat incipient deflation.

We look at each episode through two prisms. First, we consider the movement in a number of yields in narrow windows surrounding important announcements-in essence relying on an event-study methodology to isolate the market response to news. Then we apply our no-arbitrage 
model of the U.S. term structure to provide a benchmark estimate of the pattern of yields, attributing residual movements to relative supply effects.

THE PAYDOWN OF TREASURY BONDS. We begin with "the case of the disappearing Treasury bonds," that is, the debt buyback episode of 1999-2000. In the mid-1990s a confluence of economic forces and policy changes turned federal budget deficits into surpluses. By the end of the decade, extrapolation of those trends led to forecasts that Treasury debt would disappear by $2010 .{ }^{75}$ The Treasury dealt with that windfall in three stages. Initially, it cut the issuance of Treasury bills as the deficit shrank, which reportedly led to some deterioration of liquidity in that segment of the market and a shift toward three-month Eurodollar instruments as the hedging vehicles of choice. Next, the Treasury trimmed the issuance of longer-term securities by eliminating a few maturities and scaling back the volume of the remainder. Third, the Treasury announced in August 1999 that it was considering buying back some older, off-the-run issues, so that its remaining auctions would remain sizable enough to retain investors' interest.

Developments in the market for Treasury bonds are most interesting for our purposes because the expected supply of those securities changed abruptly. Two events stand out as marking a significant shift in investors' view of the prospects for Treasury bond issuance, namely, the midquarter refunding announcements of February 2000 and November 2001. At the 2000 refunding, the under secretary of the Treasury for domestic finance, Gary Gensler, made a comment suggesting that the ten-year note would replace the thirty-year bond as the benchmark long-term security, triggering speculation that the issuance of thirty-year bonds would be discontinued. At the November 2001 refunding announcement, the Treasury confirmed that it would stop selling the long-term bond.

The supply of bonds was also being reduced by Treasury debt buybacks. Actual market repurchases began in March 2000 and had cumulated to $\$ 67$ billion when the repurchases ended in 2002 . Only bonds were purchased, the bulk of which matured beyond 2015. These debt buybacks represented a significant relative supply shock, as they were

75. Reinhart and Sack (2000) review the economic consequences of such an outcome. Auerbach and Gale (2000) provided a real-time reminder of the fickleness of far-ahead fiscal forecasts. 
Table 6. Changes in Treasury Yields around Quarterly Refunding Announcements ${ }^{a}$ Basis points

\begin{tabular}{lcc}
\hline & \multicolumn{2}{c}{ Date of quarterly refunding } \\
\cline { 2 - 3 } Maturity & February 2000 & November 2001 \\
\hline 2 years & -5 & 1 \\
5 years & -13 & -9 \\
10 years & -13 & -20 \\
30 years & -27 & -43 \\
\hline
\end{tabular}

Source: GovPX.

a. Changes in the yields of on-the-run issues from the day before the announcement to the day after.

concentrated in one maturity segment and amounted to about one-tenth of the outstanding stock of bonds (as of the beginning of 2000). Moreover, the buybacks were widely expected to be much larger than they were, with some dealers in early 2000 estimating that they would reach $\$ 100$ billion a year soon thereafter. Thus, in terms of anticipated supply, the shock was much larger.

Views about the magnitude of debt buybacks seem to evolve over time and thus do not lend themselves easily to event-study analysis. However, we can look at the immediate market impact of the two quarterly refunding announcements, identified above, that provided information about the discontinuation of bond issuance. The news from these announcements bore primarily on the pattern of sales rather than on the outlook for net issuance of government debt. Even so, as shown in table 6, the Treasury yield curve rotated down dramatically in both cases when investors learned that the managers of the government debt would shy away from longer-maturity securities.

The market's reaction is seen more starkly in the movement in yields across the maturity spectrum in the month bracketing the February announcement, as plotted in figure $6 .^{76}$ No doubt, macroeconomic news relevant to interest rate expectations and risk attitudes and perceptions also came out during that month. But the fact that yields on bonds as opposed to notes declined sharply over a month in which important infor-

76. For the past three decades, the longest-maturity security the Treasury issued has been either the ten-year or the thirty-year bond. Points on the yield curve beyond the tenyear maturity, accordingly, come from thirty-year securities of varying issue dates. The four-year gap in the figure corresponds to a gap in Treasury issuance. 
Figure 6. Treasury Yield Curve before and after Announcement of the Debt Buyback Program ${ }^{\mathrm{a}}$

Percent a year

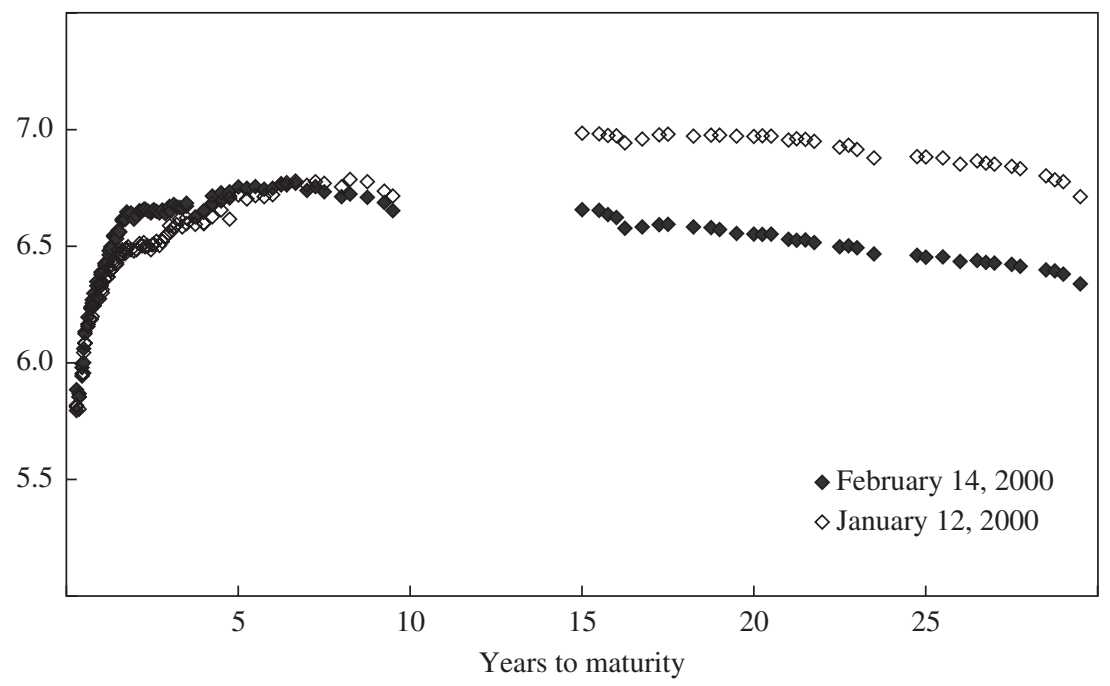

Source: Federal Reserve data.

a. Yields are for all outstanding Treasury notes and bonds, excluding callable issues.

mation about the elimination of the issuance of long-term securities was released seems suggestive of the possibility that relative supplies matter.

We can also look at this episode using our estimated term structure model to control for variations in the economy and monetary policy over the period surrounding the buyback news. Figure 7 shows the prediction error of the model for the twenty-year Treasury yield in the period around the debt buyback..$^{77}$ We see that yields during this period dropped from about 20 basis points above to about 80 basis points below the prediction of the model (which, again, controls for the effects of current and expected monetary policy).

The decline in bond yields during the buyback period is significant in economic terms. To make a rough assessment of their statistical significance, we performed a simple bootstrapping exercise with the model by first forecasting the yield curve for January and February 2000 (about the

77. In order to include the twenty-year Treasury yield in the model, we reestimated the prices of risk. The predicted yields at other maturities did not change materially. 
Figure 7. Prediction Errors of the Term Structure Model for Twenty-Year Zero-Coupon Treasury Yields, 1993-2002 ${ }^{\mathrm{a}}$

Basis points

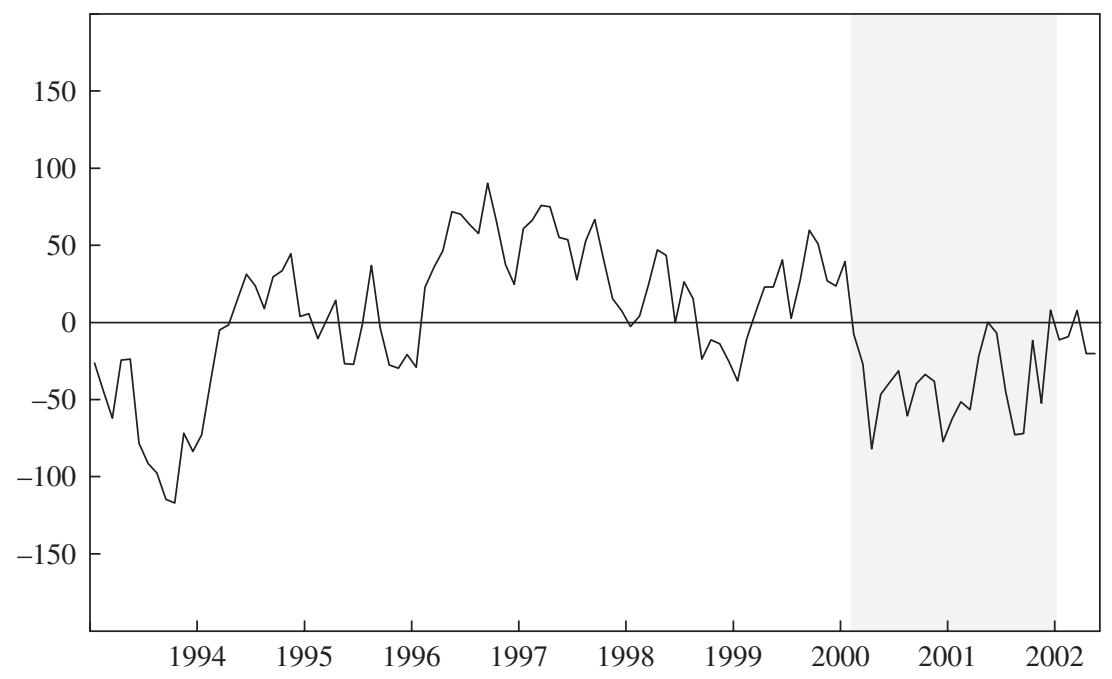

Source: Authors' calculations based on data from the sources listed in figure 4.

a. Figure shows difference between actual and predicted Treasury yields. Shading indicates bond paydown period.

middle of the episode), conditional on economic and yield curve data observed just before the start of the period. We then added shocks by randomly drawing observations from the set of historical errors of both the macroeconomic and yield curve variables over the entire period. By repeating this process 10,000 times, we were able to get some sense of whether the observed errors were outside standard confidence bands. In fact, conditional on our model, the fall in the twenty-year Treasury yield early in 2000 had an ex ante probability of occurring of less than 10 percent - that is, the observed decline in the twenty-year yield appears to be statistically significant. The ex post errors observed along the yield curve at shorter maturities, however, were much more likely to have occurred by chance. These results support the intuition derived from the marked shift in the yield curve already shown in figure 6: the buybacks significantly altered the shape of the long end of the Treasury yield curve and had no material effects on shorter maturities, supporting the view that relative supplies matter. 
Figure 8. Interest Rate Swap Spreads, 1997-2004a

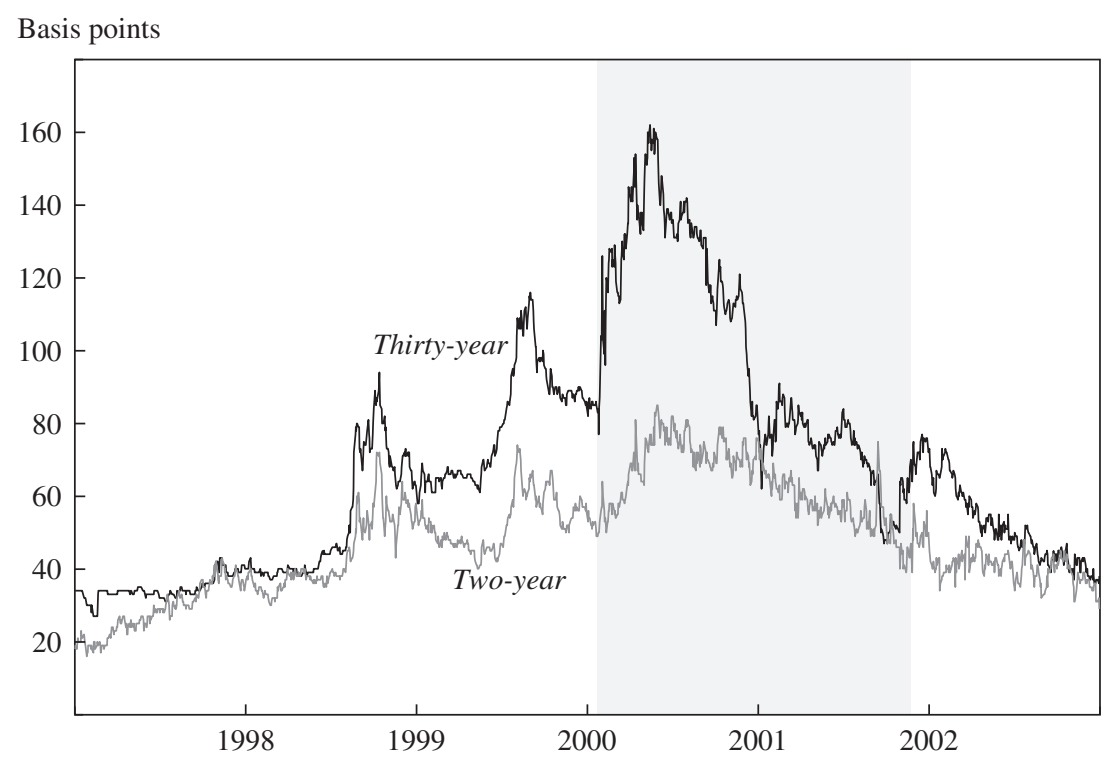

Source: Bloomberg.

a. Shading indicates bond paydown period.

These results are only suggestive, of course, in that the term structure model is unlikely to capture all the determinants of yields or to control adequately for shifts in expectations. In addition, the precise magnitude of the effects is not clear: the size of the shock is hard to determine because we do not know the probability that investors were attaching to a sizable paydown. Moreover, we cannot be sure that the effects shown here are scalable in a predictable manner; hence these results give little quantitative information to policymakers contemplating targeted asset purchases. Finally, as discussed earlier, movements in Treasury yields arising from targeted purchases need not pass through to the interest rates on private transactions that presumably influence spending decisions. As a bit of evidence on this last point, swap spreads - a good indicator of risk premiums on private sector securities - widened noticeably at the thirty-year maturity (but not at the two-year maturity) during the period when long-dated Treasury yields declined (figure 8). The sharp increase in long-term swap spreads and its subsequent unwinding coincide closely with the dip in prediction errors in 
figure 7. Thus private sector interest rates apparently did not follow the long end of the Treasury curve down as investor concerns regarding the availability of certain maturity classes of Treasuries mounted.

FOREIGN OFFICIAL PURCHASES OF U.S. TREASURY SECURITIES. In the wake of the Asian currency crisis in 1998, policymakers in many Asian economies apparently decided that it was desirable to limit fluctuations of their currencies against the dollar. The result has been a steady accumulation of dollar reserves, often in the form of Treasury securities. For instance, securities held in custody at the Federal Reserve Bank of New York on behalf of foreign official institutions now total about $\$ 1 \frac{1}{4}$ trillion, about double the amount at the end of 1998. Japanese authorities, in particular, intervened heavily in foreign exchange markets from 2003 to the first quarter of 2004 in an effort to counter or slow the yen's appreciation against the dollar. Japanese intervention purchases totaled $\$ 177$ billion in 2003 and $\$ 138$ billion in the first quarter of 2004. The Japanese Ministry of Finance holds the proceeds of its intervention activities as either bank deposits or Treasury securities, and its deposit holdings generally are reinvested in Treasuries over time. According to market reports, those purchases have tended to be concentrated in maturities of no more than ten years. The Japanese interventions in the five quarters ending in 2004:1 cumulated to about $\$ 300$ billion, which bond market participants anticipated would be invested in Treasury securities. Since the Japanese interventions were presumably only weakly linked at best to expectations about future U.S. monetary policy, these purchases provide the basis for a second natural experiment for testing the relationship between relative asset supplies and yields.

The simplest exercise is to regress the change in various Treasury yields on the dollar volume of intervention. ${ }^{78}$ Although the interventions were not publicly announced, an examination of newspaper articles indicates that operations were immediately recognized by market participants, who also generally appeared to have an accurate understanding of the scale as well. Thus, even though foreign exchange market transactions settle two days after the transaction $(t+2)$, the effects on Treasury yields should occur at date $t$, as market participants anticipate near-term purchases of Treasury securities. However, to allow for the possibility that in

78. We have benefited from discussions with Alain Chaboud and Jonathan Wright on this topic. 
Table 7. Response of Treasury Yields to Japanese Foreign Exchange Intervention ${ }^{a}$ Basis points per $\$ 1$ billion

\begin{tabular}{lcc}
\hline Maturity & $\begin{array}{c}\text { All days in } \\
\text { sample period }\end{array}$ & $\begin{array}{c}\text { Excluding days of } \\
\text { major U.S. data } \\
\text { releases }^{\mathrm{b}}\end{array}$ \\
\hline 3 months & -0.18 & -0.18 \\
2 years & $(-1.16)$ & $(-0.80)$ \\
5 years & $-0.78^{* *}$ & $-0.55^{* *}$ \\
10 years & $(-3.00)$ & $(-1.99)$ \\
& $-0.83^{* *}$ & $-0.66^{* *}$ \\
No. of observations & $(-2.37)$ & $(-1.98)$ \\
No. of interventions & $-0.73^{* *}$ & $-0.66^{* *}$ \\
\hline
\end{tabular}

Source: Authors' regressions.

a. Table reports coefficients from a regression of the change in the yield of off-the-run issues from the day before an intervention to the day of settlement (two days later) on the size of the intervention; the sample period is January 2000 to March 2004. Numbers in parentheses are $t$ statistics, where standard errors are adjusted for autocorrelation and heteroskedasticity using the approach of Hodrick (1992).

b. Days excluded are those of the release of reports on employment, GDP, business activity (ISM), retail sales, or consumer confidence.

this case the market did not recognize the interventions until the date of settlement, we looked at changes in yields from day $t-1$ to day $t+2$. The sample includes all Japanese interventions from January 3, 2000, to March 3, 2004. As can be seen in the first column of table 7, two-, five-, and ten-year Treasury yields all fell sharply on dates around Japanese interventions, and the estimated coefficients are highly statistically significant. Treasury bill yields did not react to the interventions, however, perhaps because they are pinned down by the current and near-term expected path of the federal funds rate.

Returning to figure 8 , swap spreads did not move materially in the period of heavy Japanese intervention, suggesting that any effects on benchmark Treasury yields were transmitted to yields on private securities. This contrasts with the experience during the bond paydown episode and may be due to the fact that the Treasury buybacks were concentrated exclusively at the long end of the yield curve, whereas Japanese purchases probably spanned a wider band of the maturity spectrum, in which both the Treasury and private markets are deeper.

Although these results are suggestive of an important role for relative asset supplies in the determination of yields, they suffer from potential problems of joint endogeneity. For example, weak economic data could 
cause Treasury yields to fall and the dollar to weaken, with the latter prompting foreign exchange intervention by the Japanese finance ministry. To try to address this problem, we excluded from the sample all days with major U.S. data releases (see the notes to table 7). Their exclusion produced smaller and less statistically significant coefficients (shown in the second column of table 7), but the results remain broadly unchanged.

This episode provides us another opportunity to apply the no-arbitrage term structure model to control for a changing macroeconomic environment. The results, shown in figure 9, indicate that both five-year and tenyear Treasury yields remained below the model's predictions by an average of 50 to 100 basis points over the period January 2000 to March 2004. This suggests that some force not captured in the model was exerting downward pressure on yields over this period. But although the evidence is suggestive of effects from Ministry of Finance purchases, it is not conclusive. Indeed, yields moved down to those levels in advance of the sizable Japanese intervention (but of course did not move back). Moreover, as table 4 indicated, prediction errors of this magnitude are not uncommon.

To assess the statistical significance of these findings, we repeated the bootstrapping procedure described earlier, this time with the goal of putting confidence bands around yield predictions from May 2002 to April 2003. Those results suggest that the underprediction of yields of Treasury securities with maturities from one to ten years was quite unlikely given the structure of the model, as the observed errors differed significantly from zero at better than the 10 percent confidence level. We would hesitate, however, to ascribe this effect exclusively to foreign purchases of Treasury securities because, as we discuss next, other important events were leaving their imprint on yields at about the same time.

THE 2003 DEFLATION SCARE. From the fall of 2002 through the summer of 2003, with the economy remaining weak, inflation low and apparently falling, and the federal funds rate quite low, FOMC members began to talk about the risks of deflation in the United States and the possible responses of monetary policy if the federal funds rate were to hit its lower bound. Table 8 provides a brief chronology of relevant speeches and testimonies by Federal Reserve officials during this period.

Although Federal Reserve officials consistently referred to the risk of deflation as "remote" and the FOMC's planning for the contingency of 
Figure 9. Prediction Errors of the Term Structure Model for Five- and Ten-Year Zero-Coupon Treasury Yields, 1995-2004a

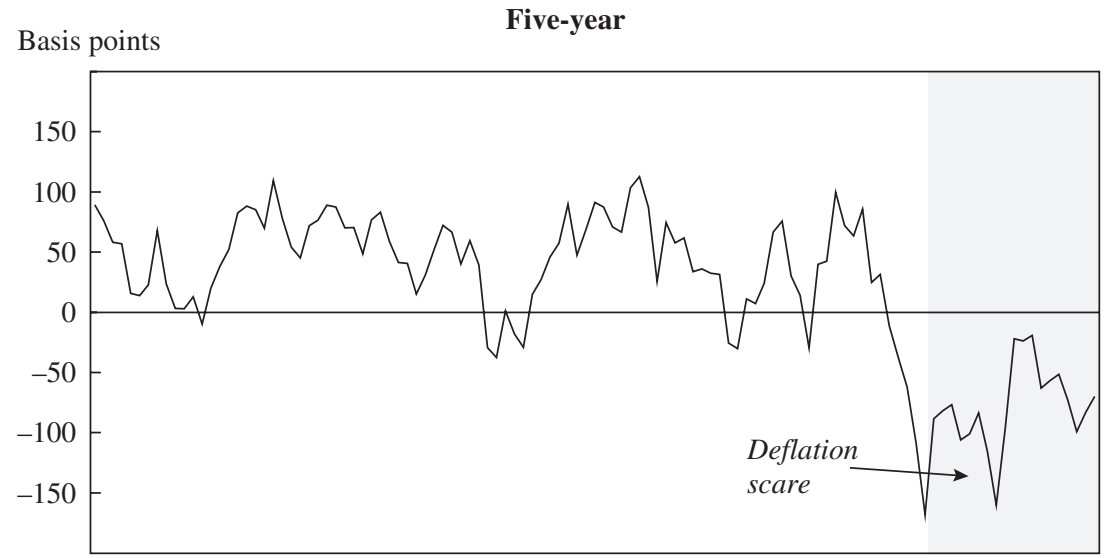

Ten-year

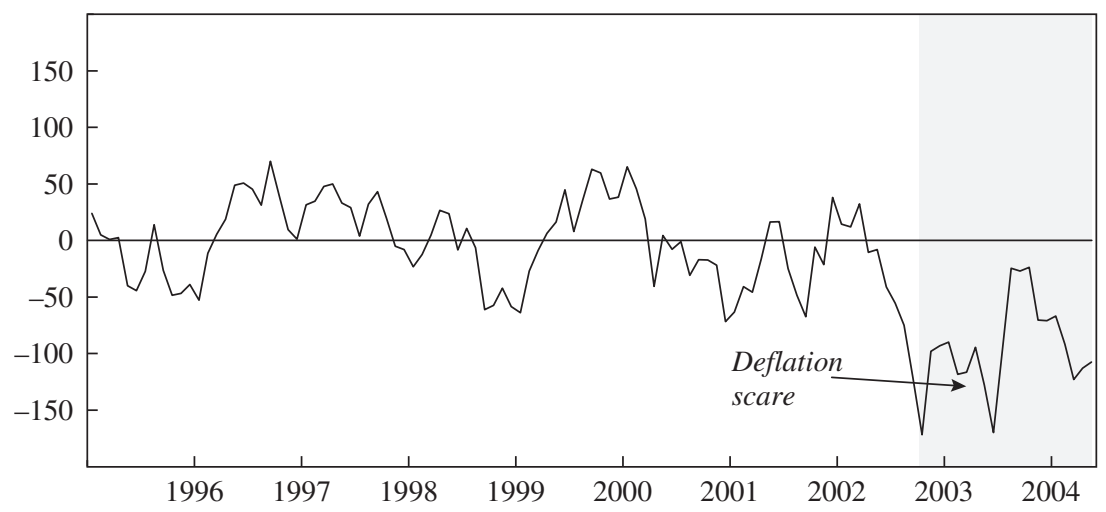

Source: Authors' calculations based on data from the sources listed in figure 4 . a. Shading indicates period of Japanese Ministry of Finance purchases.

hitting the ZLB as purely precautionary in nature, some market participants apparently interpreted these and other public comments as indicating that the Federal Reserve was seriously considering "unconventional" policy measures-in particular, purchasing large amounts of longer-term Treasuries. The perceived likelihood of such actions seemed to peak after the May FOMC meeting, when the committee pointed to the (remote) risk of 
a substantial decline in inflation. The possibility of direct purchases of longer-term Treasuries was seen to be taken off the table when the June FOMC statement did not mention it, and when Chairman Greenspan testified to Congress in July that "situations requiring special policy actions are most unlikely to arise." ${ }^{\prime 79}$ Again, large movements in Treasury yields were observed on many of those days, with little alternative explanation. ${ }^{80}$ Most notably, the ten-year Treasury yield fell sharply on the May FOMC statement (20 basis points) and after the chairman's speech in early June (10 basis points), and then rose abruptly following the June FOMC statement ( 26 basis points) and the chairman's testimony in July (20 basis points).

Of course, the FOMC never undertook targeted purchases of Treasury securities, but in an efficient market even the incorrect anticipation of such an event should affect yields. Figure 9 shows a sharp downward spike in the model errors in May and June 2003, which is reversed in July. These findings, taken at face value, suggest that the perceived possibility of Treasury purchases had an impact on the order of 50 basis points or more. The unexplained dip in yields in May and June is highly statistically significant, based on a bootstrapping exercise similar to that described above. Once again, however, one must be particularly wary of identification issues. The events that conveyed information about the possibility of Federal Reserve purchases of Treasuries most likely also conveyed information to the public about the risk of deflation. Changes in the perceived risk of deflation would affect long-term yields independent of supply effects. Moreover, some overlap exists between this episode and the period of Ministry of Finance purchases, discussed earlier.

If the Federal Reserve were willing to purchase an unlimited amount of a particular asset—say, a Treasury security—at a fixed price, there is little doubt that it could establish that asset's price. Presumably, this would be true even if the Federal Reserve's commitment to purchase the long-lived asset were promised for a future date.

79. Board of Governors of the Federal Reserve System, "Testimony of Chairman Alan Greenspan: Federal Reserve Board's Semiannual Monetary Policy Report to the Congress," July 15, 2003 (www.federalreserve.gov/boarddocs/hh/2003/july/testimony.htm).

80. The fact that rates did not uniformly change by large amounts on all the dates listed is not surprising, because other, unrelated news important to financial markets may have been released on some days and because the events themselves varied in the extent they provided new information. 
Table 8. Notable Events and Changes in Treasury Yields during the 2003 Deflation Scare

\begin{tabular}{|c|c|c|c|c|}
\hline \multirow[b]{2}{*}{ Date } & \multirow[b]{2}{*}{ Event } & \multirow[b]{2}{*}{ Content } & \multicolumn{2}{|c|}{ Change in yield } \\
\hline & & & 2-year & 10-year \\
\hline November 21, 2002 & Bernanke speech & $\begin{array}{l}\text { Presents arguments for } \\
\text { making sure "it" } \\
\text { (deflation) doesn't } \\
\text { happen in United States }\end{array}$ & 7 & 6 \\
\hline December 19, 2002 & Greenspan speech & $\begin{array}{l}\text { Says United States is } \\
\text { nowhere close to sliding } \\
\text { into a "pernicious" } \\
\text { deflation }\end{array}$ & -7 & -10 \\
\hline March 30, 2003 & Reinhart speech & $\begin{array}{l}\text { Discusses policy options } \\
\text { at the zero bound }\end{array}$ & -5 & -9 \\
\hline May 6, 2003 & FOMC statement & $\begin{array}{l}\text { Points to risk of an } \\
\text { "unwelcome substantial } \\
\text { fall in inflation" }\end{array}$ & -9 & -20 \\
\hline May 22, 2003 & $\begin{array}{l}\text { Greenspan } \\
\text { testimony }\end{array}$ & $\begin{array}{l}\text { Argues deflation is a } \\
\text { "serious" issue but the } \\
\text { risks are "minor" }\end{array}$ & -1 & -5 \\
\hline May 31, 2003 & Reinhart speech & $\begin{array}{l}\text { Emphasizes importance } \\
\text { of shaping expectations }\end{array}$ & 7 & 2 \\
\hline June 3, 2003 & Greenspan speech & $\begin{array}{l}\text { Mentions continued risk } \\
\text { of declining inflation, } \\
\text { need for a "firebreak" }\end{array}$ & -13 & -10 \\
\hline June $25,2003^{\mathrm{b}}$ & $\begin{array}{l}\text { FOMC eases, issues } \\
\text { statement }\end{array}$ & $\begin{array}{l}\text { Smaller-than-expected } \\
\text { easing; statement does } \\
\text { not mention unconven- } \\
\text { tional policy measures }\end{array}$ & 29 & 26 \\
\hline July 15, 2003 & $\begin{array}{l}\text { Greenspan } \\
\text { testimony }\end{array}$ & $\begin{array}{l}\text { "Situations requiring } \\
\text { special policy actions are } \\
\text { most unlikely to arise" }\end{array}$ & 9 & 20 \\
\hline July 23, 2003 & Bernanke speech & $\begin{array}{l}\text { FOMC should be willing } \\
\text { to cut the federal funds } \\
\text { rate to zero if necessary }\end{array}$ & -4 & -4 \\
\hline August 12, 2003 & FOMC statement & $\begin{array}{l}\text { Drops "substantial" } \\
\text { from statement on risk } \\
\text { of "unwelcome fall in } \\
\text { inflation" }\end{array}$ & 5 & 20 \\
\hline
\end{tabular}

Source: GovPX.

a. Except where noted otherwise, changes are daily changes in on-the-run Treasury yields. Dates of changes that were strongly associated with the event listed are in italics.

b. Changes in yields are two-day changes, since the market continued to respond on the day after the FOMC meeting. 
Conceptually, it is useful to think of the Federal Reserve as providing investors in that security with a put option allowing them to sell back their holdings to the central bank at an established price. We can use our term structure model to price that option. As a purely illustrative example, suppose the Federal Reserve announced its willingness to purchase the current ten-year, zero-coupon Treasury security one year hence at a yield of $5 \frac{1}{2}$ percent. We will consider the value of this option, jumping off from the last observation used in estimating our model, that of May 2004. (We assume that the rate in May 2004 equals the value predicted by our model rather than the actual rate prevailing in that month.) Without this commitment, according to our model, the yield on that security would be expected to be 5.67 percent one year hence, implying that the put option has a 58 percent chance of ending up in the money. (The yield is given by $y_{t+12}^{(9)}=a_{9}+b_{9} X_{t+12}$.) The strike price of the option will be $K=$ $\exp (-9 \times$ cap $)$, where in our example cap $=0.055$.

The price of the put option is

$$
\text { put }=E_{t}\left\{m_{t+1} m_{t+2} m_{t+3} \ldots m_{t+12}\left[K-\exp \left(-a_{9}-b_{9}^{\prime} X_{t+12}\right)\right]^{+}\right\} .
$$

We can compute this expectation by doing 10,000 simulations of the model. Note that the simulations determine the correlation between the payouts on the option and the value that risk-averse investors place on those payouts (which depends on the evolution of the state variables on the path to the payout). The results indicate that this option would lower today's tenyear rate by 34 basis points, or more than the 17 basis points by which the option is in the money because the convexity of the option gives it value.

Thinking of a pegging strategy in terms of options also highlights the potential that the pass-through to private securities of such a strategy might be limited. In this case, those investors holding a ten-year Treasury security receive the put option, but the holder of, say, a ten-year highgrade corporate bond does not. Thus the value of the put option would be reflected in the price of the corporate bond only to the extent that the marginal investor viewed Treasury and corporate securities as close substitutes. As shown in figure 8, and in contrast to the prediction of theory, swap spreads actually narrowed in the first half of 2003, when deflationary fears were building, and widened after those fears lifted later in the year. The range of variation, however, is quite narrow and so may relate to other macroeconomic and idiosyncratic developments. 


\section{Japan: A Modern Industrial Economy at the Zero Bound}

So far we have made use of a variety of natural experiments from recent U.S. experience to try to gauge the potential effectiveness of policy tools at or near the ZLB. In particular, we have analyzed the effects on market expectations of FOMC statements (relevant for strategies that involve the shaping of policy expectations) and considered how the net supply of various Treasury securities influences the yield curve (relevant for strategies that involve the size or composition of the central bank's balance sheet). The possible effectiveness of such policies in the U.S. context is of great interest, but of course the inferences made are necessarily somewhat indirect, because the policy rate in the United States has remained at least 100 basis points above zero. In contrast, Japan is a modern industrial economy that has actually grappled with the ZLB for some seven years now; and although the Japanese economy differs from that of the United States in many ways (notably in its financial structure), its experience still should provide useful lessons for the United States and other industrial countries. In this section we apply some of the same methods used in the U.S. analysis toward understanding the experience of Japan.

\section{An Event Study of Policies of the Bank of Japan}

We begin our analysis of Japanese monetary policy by conducting an event study analogous to the one we conducted for the United States. As in the U.S. case, the objective is to analyze how monetary policy expectations at different horizons (as measured in financial markets) respond to central bank statements. Because the Bank of Japan in recent years has used its statements not only to try to shape expectations, but also to provide information regarding its programs of quantitative easing and targeted asset purchases, in principle the event study should cast light on the effectiveness of all three types of nonstandard policy options available to an economy at or near the ZLB. In practice, the relatively small number of BOJ policy statements in our sample leads to results that are less sharp than we would like. In the latter part of this section, therefore, we report results based on estimation of the term structure model for Japan.

Two preliminary issues must be addressed before proceeding to the details of the event study. First, the BOJ did not gain its independence 
until April 1998, which shortens the available sample considerably. (Before the BOJ became independent, monetary policy in Japan was largely controlled by the Ministry of Finance.) We include in our sample all policy meetings and dates of policy decisions by the BOJ since independence, which gives us 110 observations. Note that, during most of the sample period, the overnight interest rate was very close to zero. Second, intraday financial data are difficult to obtain for Japan, and so we are forced to rely on daily data. To complicate matters further, on some occasions BOJ statements have been released just before the close of Japanese financial markets, whereas at other times they were released just after the close. Because we could not easily ascertain the exact timing of all releases, to avoid contamination of the results we examine two-day changes in the financial market variables considered, from the day before each policy meeting to the day after. The use of a considerably longer event window than in the U.S. analysis increases the scope for factors other than policy actions or announcements to influence the financial variables. The extra noise will reduce the efficiency of our estimates but should not bias the results.

As in the event study for the United States, we employ three marketbased measures of policy expectations at various horizons. The first is intended to capture the unexpected component of changes in the policy interest rate, the (overnight) call rate. Unfortunately, we cannot measure these surprises in exactly the same way as we do for the FOMC, because there is not an active futures market on the call rate in Japan. Instead we measure current policy surprises as the change during the event window in the first Euroyen futures contract to expire, which reflects unexpected changes in the policy rate over a slightly longer horizon. ${ }^{81}$ Innovations to policy expectations at the one-year and the five-year horizons are measured as changes during the event window in the year-ahead Euroyen futures rate and in the five-year zero-coupon Japanese government bond (JGB) yield. These two indicators of policy expectations are essentially

81. These contracts are written on the three-month Euroyen deposit rate at the time of expiration; in practice, the ease with which investors can switch among money-market assets ensures that this rate will be closely tied to the average policy rate expected to prevail over that interval. The Euroyen futures contract expires $1 \frac{1}{2}$ months ahead on average, implying that the futures rate corresponds approximately to the expected call rate from $1 \frac{1}{2}$ to $4 \frac{1}{2}$ months ahead. 
Table 9. Factor Decomposition of Monetary Policy Indicators, Japan ${ }^{\mathbf{a}}$

\begin{tabular}{|c|c|c|c|}
\hline Effect or standard deviation & Factor 1 & Factor 2 & Factor 3 \\
\hline \multicolumn{4}{|l|}{ Loading of factor on } \\
\hline Current policy setting & 1.00 & 0.00 & 0.00 \\
\hline Year-ahead futures rate & 0.55 & 1.00 & 0.00 \\
\hline Five-year yield & 0.32 & 0.64 & 1.00 \\
\hline \multicolumn{4}{|c|}{ Standard deviation of effect of factor on ${ }^{\mathrm{b}}$} \\
\hline Current policy setting & 3.4 & 0 & 0 \\
\hline Year-ahead futures rate & 1.9 & 3.0 & 0 \\
\hline Five-year yield & 1.1 & 1.9 & 3.5 \\
\hline \multicolumn{4}{|c|}{$\begin{array}{l}\text { Source: Authors' calculations based on data from Bloomberg, the Chicago Mercantile Exchange, and the Bank of Japan. } \\
\text { a. Factors are constructed by means of a Cholesky decomposition, in which the first factor is the policy surprise contained in a } \\
\text { policy statement, as inferred from the nearest Euroyen futures contract, the second is the portion of the change in year-ahead pol- } \\
\text { icy expectations (as measured by the change in the year-ahead futures contract) not explained by (that is, orthogonal to) the first } \\
\text { factor; and the third is the change in the five-year zero-coupon JGB yield not explained by (orthogonal to) the first two factors. } \\
\text { Sample period is April } 1998 \text { to the present. } \\
\text { b. In basis points. }\end{array}$} \\
\hline
\end{tabular}

identical in concept to the analogous rates in our event study for the United States. ${ }^{82}$

As in the U.S. event study, we apply a Cholesky decomposition to derive three candidate factors to explain the movements in the marketbased policy indicators in the period around BOJ decisions. By construction, the first factor corresponds to unexpected changes in the current policy setting during the period around BOJ decisions, as measured by the change in the nearest Euroyen futures contract. The second factor, equal to the part of the change in the year-ahead futures contract that is orthogonal to the first factor, is intended to represent year-ahead policy expectations not explained by changes in the current policy setting. Finally, the third factor equals the change in the five-year zero-coupon JGB yield not explained by the first two factors.

The links between these factors and the policy indicators, shown in the top panel of table 9, are remarkably similar to those found for the FOMC (top panel of table 1). Notably, as in the U.S. event study, we find in the case of Japan that the first factor has an effect on longer-term interest rates that diminishes with maturity, and that the loading of the five-year yield on the second factor is significantly greater than that on the first factor.

82. The Euroyen futures contracts trade on the Chicago Mercantile Exchange. Data for the zero-coupon five-year JGB yield were taken from Bloomberg. 
However, the magnitudes of the three factors, shown in the bottom panel of table 9, differ from the U.S. case. In particular, the first and second factors are much smaller (as measured by their standard deviations, the diagonal elements in the table) than in the U.S. event study (bottom panel of table 1). That is, changes in both current and year-ahead policy expectations in periods around BOJ decisions have been more subdued than in the U.S. case. However, the standard deviation of the third factor, which reflects longer-horizon policy expectations, is about the same, at 3.5 basis points, in the Japanese and the U.S. cases. The influence of the ZLB may explain the limited variation in the first two factors: both current and year-ahead futures rates were near zero over much of the sample, which restricted changes in policy expectations and rates in the downward direction at least. However, the ZLB is not the whole story; even in the period before 2001, when the year-ahead futures rate was generally above 50 basis points, the standard deviation of the second factor was only slightly higher (3.9 basis points) than in the sample as a whole (results not shown). Overall, it appears that the scope for the Bank of Japan to "use" the second factor, or its willingness to do so, was less than in the case of the Federal Reserve over the same period. ${ }^{83}$

As in the U.S. event study, we are interested in examining the relationship between the three factors describing changes in policy expectations and the statements issued by the central bank. We again define a dummy variable, STATEMENT, that equals 1 on dates when the BOJ released policy statements and zero otherwise. As in the U.S. analysis, we also define a dummy variable, STATEMENT SURPRISE, that indicates statements deemed to be surprising in significant aspects to market participants. To determine which statements were surprises, we again relied on several after-the-fact documents, including internal write-ups prepared by the staff of the Federal Reserve Bank of New York and articles in the Wall Street Journal, and one before-the-fact source, a series of commentaries prepared by Nikko/Citigroup just before each BOJ meeting.

Of the 110 observations in our sample, 19 involved the release of statements about the economy or monetary policy; we exclude 10 statements concerned only with various technical aspects of monetary policy opera-

83. An institutional explanation for the smaller second factor in Japan is the BOJ's practice of releasing policy statements only in conjunction with policy actions, rather than after every scheduled meeting. 
tions without implications for the economic or policy outlook. Of these 19 statements, 10 were identified by our methods as surprises. ${ }^{84}$

As in the U.S. event study, we proceeded by regressing the squared factors on the dummy variables indicating statements and surprising statements. Again, following Kohn and Sack, ${ }^{85}$ the use of the squared factors as dependent variables allows us to determine whether statements were associated with large changes in policy expectations (large realizations of the factors), without requiring us to specify the "direction" of the statements.

The regression results, shown in table 10, differ considerably from those found for the Federal Reserve (table 2). First, we find that the square of the first factor has a statistically significant relationship to STATEMENT SURPRISE but not to STATEMENT. One interpretation is that, unlike the FOMC, which appears reluctant to surprise the market in terms of both the policy setting and the statement at the same meeting, the BOJ often did so. Indeed, a review of the record shows that the BOJ on several occasions combined announcements of major policy innovations with unexpected changes in the setting of the interest rate. Notably, the announcement of the adoption of the zero-interest-rate policy on February 12, 1999, coincided with a 9-basis-point policy rate surprise by our measure, as the call rate was reduced from 25 basis points to a value "as low as possible," initially 15 basis points; and the introduction of quantitative easing on March 19, 2001, coincided with an 11basis-point policy surprise, as the call rate was reduced from 12.5 basis points to essentially zero.

Second, and in striking contrast with the results for the FOMC, we find no evident relationship between the second factor and the BOJ's release of statements, whether surprising or not. This result, together with the small magnitude of the second factor already reported, suggests again that the BOJ was either unable or unwilling to influence year-ahead policy expectations with its statements. (In making this interpretation, however, we again note that the Japanese sample is much smaller and that a coarser two-day window was used rather than the one-hour time span in the U.S. case.)

84. A description of all statements over the period and our method of coding them is available from the authors on request.

85. Kohn and Sack (2003). 
Table 10. Regressions of Squared Factors on Dummy Variables for Bank of Japan Policy Statements ${ }^{\mathrm{a}}$

\begin{tabular}{lccc}
\hline & \multicolumn{3}{c}{ Dependent variable } \\
\cline { 2 - 4 } Independent variable & Factor 1 & Factor 2 & Factor 3 \\
\hline Constant & 7.4 & $8.2^{* *}$ & $10.9^{* *}$ \\
STATEMENT & $(1.79)$ & $(2.78)$ & $(4.18)$ \\
STATEMENT SURPRISE & -1.2 & -1.2 & -5.7 \\
& $(-0.09)$ & $(-0.12)$ & $(-0.66)$ \\
Adjusted $R^{2}$ & $50.5^{* *}$ & 10.4 & $25.8^{* *}$ \\
\hline
\end{tabular}

Source: Authors' regressions.

a. Numbers in parentheses are $t$ statistics. ** indicates statistical significance at the 95 percent level. Factors are as defined in table 9. Independent variables are defined in a manner analogous to the definitions in table 2 for the United States.

Third, in Japan, unlike in the United States, the magnitude of the realization of the third factor is linked to the issuance of surprising statements by the central bank. However, this finding is largely the product of a single observation, the February 12, 1999, statement announcing the introduction of the ZIRP. Standard reasoning suggests that the announcement of the ZIRP should have influenced the third factor by leading to a drop in long-term bond yields; surprisingly, the third factor actually rose by 14 basis points that day. Our reading suggests that market participants were disappointed that the statement did not announce large-scale BOJ purchases of JGBs, as had been rumored. Perhaps, then, we should think of this important observation as consisting of two surprises working in opposite directions.

To examine the effects of BOJ statements further, we categorized the surprising statements into three types: statements providing new information about the likely path of policy (PATH SURPRISE, analogous to the variable of that name in the event study for the Federal Reserve); statements announcing an unexpected change in the BOJ's target for purchases of JGBs (JGB SURPRISE); and statements announcing unexpected changes in the BOJ's target for commercial banks' current account balances, in the period following the introduction of quantitative easing (CAB SURPRISE). In principle, this categorization should provide information on the relative effects of changes in policy expectations, targeted purchases of securities, and quantitative easing. Statements were allowed to fall into more than one category, if appropriate. 
Again, the problems arising from a small sample are apparent, as the number of statements in each category is relatively small. We identified only two statements as potential path surprises: the introduction of the ZIRP in February 1999 and the introduction of quantitative easing in March 2001. These, of course, represented major shifts in policy strategy, and thus their effects may differ from those of the policy path surprises identified in the U.S. event study. Five BOJ statements announced changes in the target for JGB purchases (including the implementation of the quantitative easing program), three of which we identified as surprises to the market. Ten statements during the sample period announced changes in the target for banks' current account balances (including the statement that initiated the program), of which six were identified as surprises to the market.

Because the direction as well as the magnitude of statement effects is important, we report here results based on the "signed" dummy variable approach introduced in the earlier section. ${ }^{86}$ Specifically, for each dummy variable corresponding to a surprising statement, we assigned a value of 1 for statements that would be expected to increase interest rates and a value of -1 for statements that would be expected to lower interest rates. Nonsurprising statements were coded as zeros. We then regressed the levels of each of the three factors on the signed dummy variables, allowing us to judge not only whether statements influenced expectations but also whether expectations were influenced in the expected direction.

We added one further innovation to the analysis at this point. Our focus thus far has been on the link at various horizons between central bank policy actions and statements, on the one hand, and interest rates, on the other. However, the logic of quantitative easing and targeted asset purchases implies that the most important effects of these policies may be felt on the prices of assets other than government bonds. To investigate this possibility, we included a fourth candidate factor in this event study, defined as the portion of the change in the Nikkei 500 stock index during the event window that is orthogonal to the other three factors. That is, the fourth factor reflects the impact of the BOJ's action and statement on prices of Japanese equities (an important alternative class of asset), holding

86. We also tried regressing the squared values of the factors on the various dummies; this exercise did not add much information to that already reported in table 11. 
market expectations about current and future interest rates constant. ${ }^{87}$ If BOJ policy decisions are influencing asset prices other than through expectational channels, this factor should pick that up.

The results, shown in table 11, amplify but also generally confirm the results discussed earlier in this section. We saw earlier that surprises in the policy setting (the first factor) and in the statement tend to be associated in Japan. Column 11-1 of table 11 shows that these surprises tend to be in the same direction (that is, both toward tightening or both toward ease), consistent with the earlier discussion. Further, as column 11-2 shows, unanticipated changes in the policy setting also seemed to be associated with statements that provide information on the future path of policy (that is, the PATH SURPRISE dummy accounts for the entire relationship between the first factor and statement surprises). This result is driven primarily by the announcements of the ZIRP and the quantitative easing program, which, as already mentioned, were associated with surprises in the policy setting as well.

We continue to find no significant relationship between the second factor (the innovation in year-ahead policy expectations) and BOJ statements, even with this finer categorization of statements (columns 11-3 and 11-4). This result is the strongest and most important contrast between the findings for the BOJ and for the Federal Reserve.

The level of the third factor (which, again, corresponds to the fluctuation in the yield on JGBs during the event window that is not explained by current or year-ahead policy expectations) appears to be linked with certain types of statements. As column 11-6 shows, a statement that surprises the market in suggesting that policy will be tighter in the future (that is, a positive path surprise) causes five-year yields to fall; the effect is statistically significant. This finding can be rationalized by the argument that a near-term tightening lowers inflation expectations and thus nominal interest rates at long horizons. Perhaps more interesting, the third factor also has a statistically significant link to JGB surprises; that is, BOJ statements announcing unexpectedly large targets for JGB purchases (an easing move, therefore coded as -1) are associated with declines in the yield on five-year JGBs, as should be the case if targeted bond purchases by the

87. It turns out that 99.2 percent of the variance of stock prices during the event window is orthogonal to the first three factors; that is, almost all of the change in stock prices is explained by the fourth factor, unrelated to interest rates. 
Table 11. Regressions of Factors on Signed Dummy Variables for Bank of Japan Policy Statements ${ }^{\mathrm{a}}$

\begin{tabular}{|c|c|c|c|c|c|c|c|c|}
\hline \multirow[b]{3}{*}{$\begin{array}{l}\text { Independent } \\
\text { variable }\end{array}$} & \multicolumn{8}{|c|}{ Dependent variable } \\
\hline & \multicolumn{2}{|c|}{ Factor 1} & \multicolumn{2}{|c|}{ Factor 2} & \multicolumn{2}{|c|}{ Factor 3} & \multicolumn{2}{|c|}{ Factor 4} \\
\hline & $11-1$ & $11-2$ & $11-3$ & $11-4$ & $11-5$ & $11-6$ & $11-7$ & $11-8$ \\
\hline $\begin{array}{l}\text { SIGNED } \\
\text { STATEMENT } \\
\text { SURPRISE }\end{array}$ & $\begin{array}{l}4.75^{* *} \\
(4.80)\end{array}$ & & $\begin{array}{l}1.1 \\
(1.14)\end{array}$ & & $\begin{array}{l}0.5 \\
(1.11)\end{array}$ & & $\begin{array}{l}-1.12 \\
(-1.90)\end{array}$ & \\
\hline $\begin{array}{l}\text { SIGNED PATH } \\
\text { SURPRISE }\end{array}$ & & $\begin{array}{l}9.8 * * \\
(4.13)\end{array}$ & & $\begin{array}{l}-2.2 \\
(-1.01)\end{array}$ & & $\begin{array}{l}-6.3^{* *} \\
(-2.54)\end{array}$ & & $\begin{array}{l}-1.94 \\
(-1.45)\end{array}$ \\
\hline $\begin{array}{l}\text { SIGNED JGB } \\
\text { SURPRISE }\end{array}$ & & $\begin{array}{l}0.9 \\
(0.53)\end{array}$ & & $\begin{array}{l}-2.7 \\
(-1.64)\end{array}$ & & $\begin{array}{c}5.1 * * \\
(2.80)\end{array}$ & & $\begin{array}{l}-1.16 \\
(-1.17)\end{array}$ \\
\hline $\begin{array}{l}\text { SIGNED CAB } \\
\text { SURPRISE }^{\mathrm{b}}\end{array}$ & & $\begin{array}{c}0.4 \\
(0.26)\end{array}$ & & $\begin{array}{l}0.4 \\
(0.28)\end{array}$ & & $\begin{array}{l}-0.0 \\
(-0.02)\end{array}$ & & $\begin{array}{l}-1.70 * * \\
(-2.0)\end{array}$ \\
\hline Adjusted $R^{2}$ & .17 & .16 & .01 & .03 & .06 & .13 & .02 & .10 \\
\hline
\end{tabular}

Source: Authors' regressions.

a. Factors are as defined in table 9. Independent variables are defined in a manner analogous to the definitions in tables 2 and 3 for the United States. Numbers in parentheses are $t$ statistics; ** indicates statistical significance at the 95 percent level.

b. CAB, current account balances (at commercial banks).

central bank affect their yields. However, the estimated effect, although statistically significant, is not large (5 basis points) and is of necessity based on relatively few observations.

The results for the fourth factor, which is essentially the change in stock prices during the event window, are of interest. Columns 11-7 and 11-8 of table 11 show that the Japanese stock market index drops between 1 and 2 percent on average when the BOJ issues a surprisingly hawkish statement. The statistically strongest link is to BOJ announcements of new current account balance targets. Inspection of the data shows that, on three of the six occasions when the BOJ made surprise announcements of increases in its target for current account balances, the Nikkei 500 rose between 3 and 6 percent, including a 5.9 percent increase on the announcement of the quantitative easing policy. On one other such occasion the market rose nearly 2 percent. Thus, in the event study at least, quantitative easing appears to provide a positive impetus to the stock market, with both current and future interest rate expectations held constant.

Two general conclusions emerge from the BOJ event study. First, there is little evidence that the BOJ used its statements to influence nearterm policy expectations during this period. This contradicts the finding 
of other research that the ZIRP was effective; we revisit this issue below. Second, our findings provide some tentative support for the view that asset prices respond to quantitative easing and targeted asset purchases; specifically, we find statistically significant links between JGB purchases and JGB yields on the one hand, and between quantitative easing and stock prices on the other. Whether these latter effects were large enough to have a significant influence on the Japanese economy will be addressed next.

\section{A Benchmark Term Structure Model for Japan}

As a final exercise, we estimate a benchmark term structure model for Japan and compare the results with actual term structure behavior. As in the U.S. case, the model is a no-arbitrage affine term structure model driven by observable factors. The underlying factors are assumed to be the unemployment rate, the inflation rate (the twelve-month change in the consumer price index), the overnight call rate, and the year-ahead Euroyen futures rate. These variables are closely analogous to those used for the U.S. estimation, except that we do not have a monthly inflation expectations measure for Japan to include. The dynamics of the factors are determined by an estimated VAR with four lags, where the estimation uses monthly data over the sample period June 1982 to May 2004. ${ }^{88}$

With the estimated VAR in hand, we then fit the no-arbitrage term structure model using data from the JGB market. The data on JGB yields are month-average zero-coupon yields at maturities of six months and one, two, three, five, seven, and ten years, obtained from Bloomberg for the period since April 1989. The prices of risk are estimated using yield curve data from April 1989 to December 1997, based on the VAR dynamics estimated over the full sample. The fit of the model is quite good (figure 10). We show the fit of the model through 1997 only; as we will discuss next, for the period after 1997 we need to make an adjustment for the proximity of short-term yields to the ZLB.

When short-term interest rates fall to very low levels, the ZLB constraint begins to influence the shape of the yield curve. One effect is that

88. Data on the Euroyen futures rate are available only from June 1989; for earlier dates we regressed the futures rate on the five-year JGB yield and the call rate for the sample period June 1989 to May 1999 and used the fitted values from this regression as a proxy for the actual futures rate. 
Figure 10. Actual and Predicted Japanese Government Zero-Coupon Yields, 1989-97ª

Percent a year

\section{Two-year}

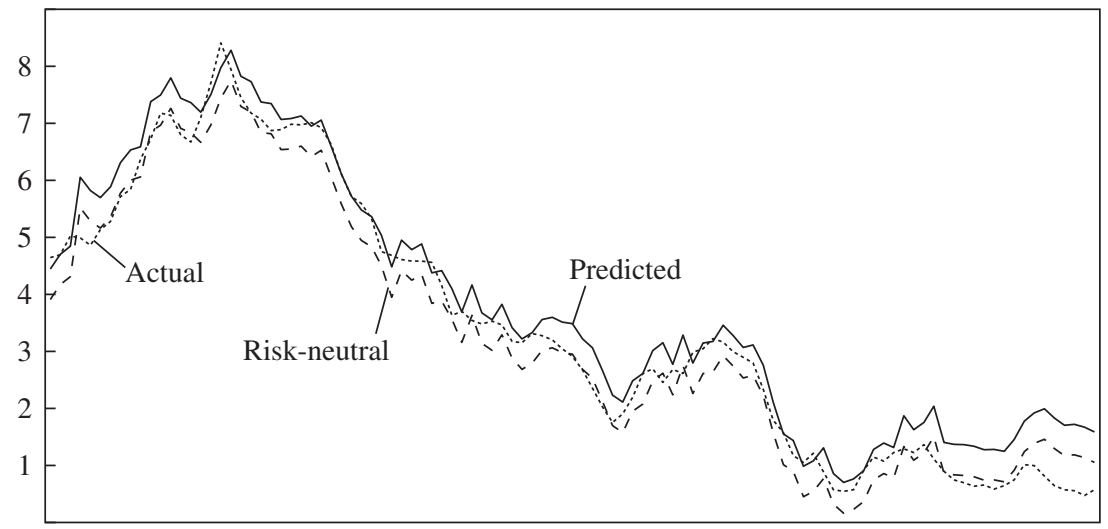

Ten-year

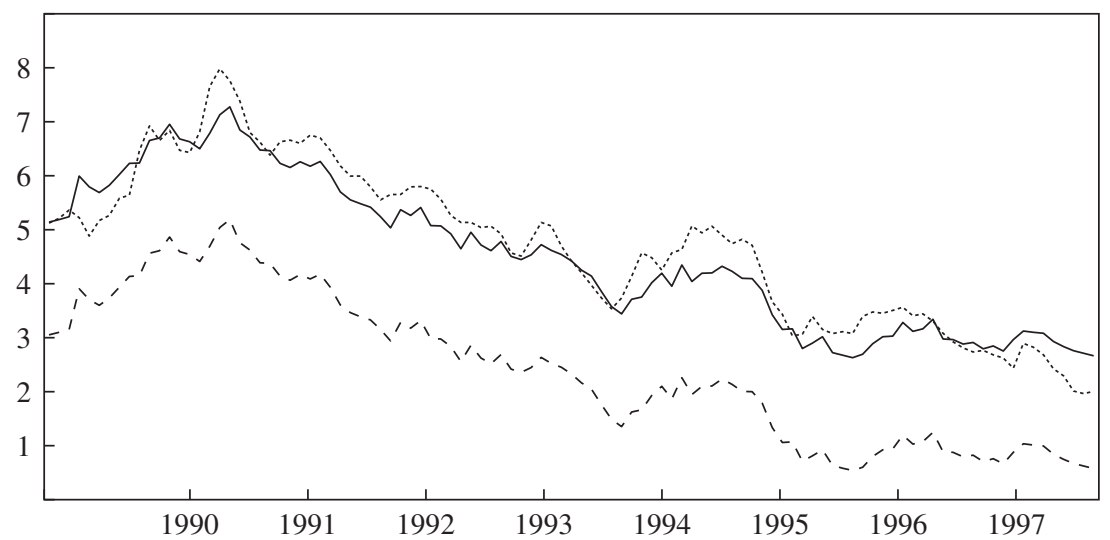

Source: Authors' calculations based on data from Datastream, the Chicago Mercantile Exchange, and Bloomberg.

a. The predicted yields are generated by the term structure model, as described in the text. The risk-neutral yields are generated by the same model, but with the prices of risk set equal to zero. 
the ZLB reduces the possibility of declines in interest rates (and obviously eliminates them at short-term maturities), which limits the scope for capital gains on fixed-income securities. To compensate for this, investors will demand higher yields on fixed-income assets, ${ }^{89}$ thereby steepening the yield curve.

We can account for this effect in our VAR model. The price of a twoyear note, for example, should equal the expected product of the pricing kernel over the next twenty-four months:

$$
P_{t}^{24}=E_{t}\left[m_{t+1} m_{t+2} m_{t+3} \ldots m_{t+24}\right] .
$$

We computed the bond price defined by equation 9 by performing 10,000 simulations of the model over the subsequent twenty-four months, determining the path of the pricing kernel in each iteration, and then taking the average of the product of the pricing kernel over all simulations. This exercise can be performed either ignoring the ZLB or imposing it.

If we perform the simulations without imposing the ZLB, the predicted bond prices will (asymptotically) be the same as those obtained directly from the VAR (such as those shown in figure 10), since the VAR dynamics do not recognize the presence of the ZLB constraint. To impose the ZLB, in each simulation we assume that, in any month that the policy rate would go negative, there is a shock to the policy rate sufficient to pull it back to zero. ${ }^{90}$ We can rigorously price fixed-income assets according to equation 9 under these alternative simulations, which then allows us to estimate the effects of the ZLB on the term structure. In this exercise we account for the fact that investors, in valuing bonds, take into account the effect of the ZLB on the future path of short-term interest rates, as well as its effects on all of the state variables that affect the prices of risk. ${ }^{91}$

89. As described in Bomfim (2003); see also Ruge-Murcia (2002).

90. The year-ahead futures rate is assumed to respond endogenously to these policy shocks, based on a Cholesky decomposition in which the policy rate is ordered second to last and the futures rate is ordered last. Without this endogenous response, the futures rate would often go negative.

91. This exercise seems to get us a long way toward properly accounting for the effects of the ZLB on the term structure of interest rates, but it still has some shortcomings. Specifically, the dynamics of the VAR and the relationship between risk prices and economic variables may change in important ways near the zero bound, so that their dynamics are not well captured by the VAR with policy shocks. A similar criticism applies to other work on the effects of the ZLB, such as that of Bomfim (2003). 
Figure 11. Yield Curve on Zero-Coupon Japanese Government Bonds before and after Bank of Japan Policy Announcements

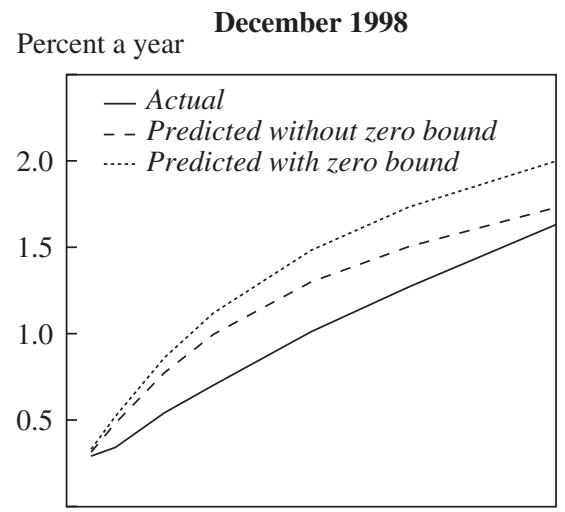

November 2000

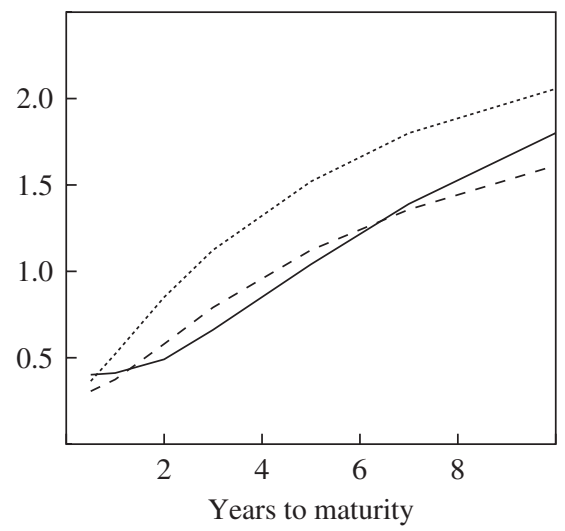

May 1999

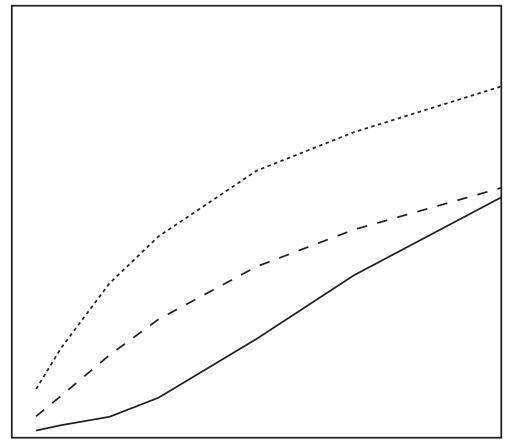

June 2001

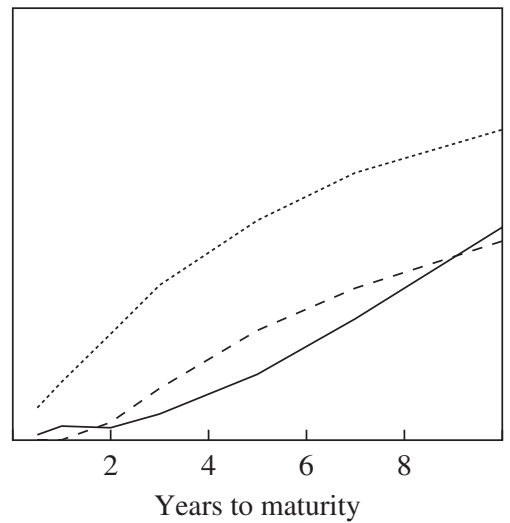

Source: Authors' calculations based on data from the sources listed in figure 10.

Figure 11 shows the results from this exercise for four representative months: December 1998 (several months before the introduction of the ZIRP), May 1999 (several months after its introduction), November 2000 (several months after the end of the ZIRP but before the introduction of the quantitative easing policy), and June 2001 (several months after the introduction of the quantitative easing policy). The influence of the ZLB (shown by the shift in the predicted yield curve) is to shift the yield curve upward in all cases, the magnitude of the shift depending on the proxim- 
ity of rates to the ZLB. More important, the predicted yield curves (considering the ZLB) tend to lie above the corresponding actual yield curves. In other words, the VAR term structure model has difficulty explaining the low JGB yields during this period.

This result holds even though the VAR offers a very pessimistic view of the Japanese economy over this period. For most of the period since 1998, the VAR predicts that deflation will persist for some time and that short-term interest rates will remain very low. This forecast, however, probably should be regarded with some skepticism. The VAR is estimated over a sample period in which unemployment was rising and inflation falling; as a result, it finds that these variables are very persistent and extrapolates these trends. One could presumably improve upon that forecast by taking into consideration additional information or a more detailed model. Nevertheless, the interesting finding for our purposes is that, even given the VAR's downbeat projections of short-term interest rates, actual longer-term JGB yields seem to have been even lower than projected by the model.

An interesting question, then, is whether the low level of JGB yields was associated with the policies of the BOJ. Figure 11 suggests that the ZIRP and the quantitative easing policy may have played some role: the deviation between the predicted yields (taking account of the ZLB) and actual yields widened after the introduction of the ZIRP, narrowed once the policy was abandoned, and widened again after the introduction of the quantitative easing policy. Also of interest is that, in May 1999, after the introduction of the ZIRP, the spread between actual and predicted yields is greatest at the short end of the maturity structure-a result consistent with earlier research on the ZIRP, as discussed above.

As noted earlier, assessing the effects of the ZIRP and especially the quantitative easing policy is in general difficult because of the problems of controlling for other factors that influenced yields over the periods when these policies were in effect. It is intriguing that, when we control (at least roughly) for macroeconomic conditions and the current stance of monetary policy, as well as for the effects on longer-term rates of the option created by the presence of the ZLB, we still find that the Japanese term structure has recently been lower than predicted. Moreover, the deviation of the actual term structure and the predicted pattern of yields increased immediately following the introduction of the ZIRP and later of the quantitative easing policy. This evidence, more than the event-study 
analysis described above, gives some reason to believe that nonstandard policies in Japan have been effective at lowering longer-term interest rates. Whether the lower rates led to a material strengthening of the economy is beyond the scope of our discussion.

\section{Conclusion}

This paper has developed new empirical evidence on the likely effects of nonstandard monetary policies when nominal interest rates are near their zero lower bound. Although the evidence is to some degree indirect, it generally supports the view that nonstandard policies would be effective when the policy rate is at zero. Notably, the Federal Reserve has successfully used its communications to affect expectations of future policies and thus longer-term yields. We also find some evidence that relative supplies of securities matter for yields in the United States, a necessary condition for achieving the desired effects from targeted asset purchases. The event studies for Japan provide only limited evidence that the Bank of Japan has been successful in using nonstandard policies, but the analysis based on an estimated model of the term structure for that country does suggest that longer-term yields have been lower than might have been expected in recent years. The latter result holds open the possibility that the zero-interest-rate policy and quantitative easing policies have had expansionary effects.

Despite finding evidence that alternative policy measures may prove effective, we remain cautious about relying on such approaches. We believe that our findings go some way toward refuting the strong hypothesis that nonstandard policy actions, including quantitative easing and targeted asset purchases, cannot be successful in a modern industrial economy. However, the effects of such policies remain quantitatively quite uncertain. Thus we believe that policymakers should continue to maintain an inflation buffer and to act preemptively against emerging deflationary risks..$^{92}$ There are trade-offs, of course, in that erring toward the side of ease when rates are low tends to create an inflation bias, but the goal of zero inflation seems unwise in any case. Moreover, a systematic tendency to err toward an easier policy when adverse shocks bulk large

92. Reifschneider and Williams (2000). 
and nominal interest rates are low can be offset by a willingness to unwind that accommodation quickly once the situation clears.

Shaping investor expectations through communication does appear to be a viable strategy, as suggested by Eggertsson and Woodford..$^{93}$ By persuading the public that the policy rate will remain low for a longer period than expected, central bankers can reduce long-term rates and provide some impetus to the economy, even if the short-term rate is close to zero. However, for credibility to be maintained, the central bank's commitments must be consistent with the public's understanding of the policymakers' objectives and outlook for the economy.

93. Eggertsson and Woodford (2003a, 2003b). 


\section{Comments and Discussion}

Benjamin M. Friedman: This paper by Ben Bernanke, Vincent Reinhart, and Brian Sack is a welcome contribution to the new line of literature that examines, in a far more eclectic way than used to be done, how monetary policy works and what effects it has on the financial markets and the nonfinancial economy. The paper is valuable both because the question it asks is important - whether what the authors call nonstandard policy measures can be effective when ordinary monetary policy actions are constrained by the zero lower bound on short-term nominal interest rates-and because the analysis it brings to bear on this question is largely empirical. The paper also reaches what I regard as a sensible conclusion: that the potential efficacy of these nonstandard measures notwithstanding, it is wise for monetary policy both to aim at an inflation rate distinctly above zero, so as to allow for a buffer against disinflationary shocks, and to ease policy preemptively when necessary to avoid significant risk of hitting the zero lower bound on interest rates. Finally, the paper is important also because of who wrote it, but more on that below.

The authors consider three conceptually distinct classes of nonstandard monetary policy measures: central bank communications, changes in the size of the central bank's balance sheet, and changes in the composition of the central bank's balance sheet. (The last of these is what would normally be called debt management policy if it were executed by a country's fiscal authority rather than by its central bank.) It is important to point out, however-and this is the focus of my one major concern about the paper - that even when the authors are addressing the effects of changes in the size or composition of the central bank's balance sheet, what they are actually analyzing in their empirical work is still communications. Most 
of their empirical exercises focus not on policy actions but on official statements regarding intended future actions. Even when they examine such episodes as the U.S. Treasury's buyback of Treasury securities, during the happy but all-too-brief period in the late 1990s when the U.S. government ran surprisingly large budget surpluses instead of shamefully large deficits, their attention is more on what the Treasury said than on what it did.

In principle, of course, credible statements about future actions should matter for the pricing of medium- and long-term assets in speculative markets. The ground for concern is rather in how this approach to addressing questions of monetary policy reinforces the increasingly exclusive focus in recent literature on what many economists engaged in this line of research (for example, Gauti Eggertsson and Michael Woodford in a Brookings Paper last year) ${ }^{1}$ call "expectations management."

Surely everyone today believes that expectations matter, and therefore that whatever influences the public's expectations, including communication from the central bank, matters as well. I am also sympathetic to the authors' presumption that, when an economy has reached the zero lower bound on short-term interest rates, central bank communications may be even more important than normally. But the net impression, delivered both by the authors' discussion and by the battery of empirical tests they perform, nonetheless resonates too strongly, at least for my taste, with the idea, which they attribute to Eggertsson and Woodford, that "shaping the interest rate expectations of the public is essentially the only tool that central bankers have-not only when the ZLB binds, but under normal conditions as well." (I will not repeat here my criticism of this view, but interested readers can refer to my remarks as a discussant of the Eggertsson-Woodford paper.)

This concern aside, I regard the authors' empirical analysis of the effect of Federal Reserve and Treasury statements on market interest rates as carefully crafted, and I find their conclusions easily credible. I especially admire their willingness to go beyond the standard event studies and use a multifactor term structure model to try to identify the role of "surprise" elements of Federal Reserve statements, as distinct from the policy actions that these statements accompanied. One might quibble with some of the details, and no doubt subsequent researchers will suggest alternative specifications, but that is not my purpose.

1. Eggertsson and Woodford (2003a). 
My only real regret about this part of the paper is that the authors never say what they think of the specifics of the two recent Federal Open Market Committee statements they examine: the August 2003 statement that "policy accommodation can be maintained for a considerable period" and the May 2004 statement that the committee intends to remove policy accommodation "at a pace that is likely to be measured." How do they think these statements measure up to the now-conventional mantra that central bank communications with the market (and the general public) should be clear and transparent? What are we to read into their highly quotable remark about "policymaking by thesaurus"? FOMC practice may perhaps require a certain opacity, but publication in the Brookings Papers presumably does not.

The authors' extended analysis of what amounts to debt management policy (actually, statements about debt management policy) is a further strength of the paper, and it, too, merits comment. The basic principle at work here is that the vector of market-clearing expected returns on all traded assets emerges as a consequence of the equilibrium of respective asset supplies and asset demands. Given the conditions underlying the public's asset demands-importantly including the risk properties of specific assets, investors' risk tolerance, and investors' assessment of the magnitudes of various risks and of the relationships among them-changes in the relative supplies of any "outside" assets (that is, assets supplied by issuers, such as government, whose portfolio behavior lies outside the model of market equilibrium) normally result in changes in the entire vector of market-clearing relative returns. Whether the degree of imperfect substitutability among the relevant assets (especially longer-term obligations that are likely to be closer substitutes to equities and other claims on capital) is sufficient to render policy interventions of this kind potentially important is then an empirical question.

The authors rightly question the familiar presumption that the Federal Reserve's "Operation Twist" effort in the early 1960s provides evidence against the effectiveness of debt management policy. Not only did the Treasury's choice of maturity for its new issues offset the Federal Reserve's policy of buying in long bonds and selling bills, as James Tobin often rightly pointed out; indeed, the situation was worse than that. Treasury data show that the early 1960s was a quite exceptional time. In the three decades immediately following World War II, during which the mean maturity of the outstanding Treasury debt declined from 
ten years to just two-and-a-half years, this was the only time when the mean maturity lengthened. Why should the yield curve have flattened during these few years?

The authors' empirical efforts show a modest impact on the yield curve from the Treasury's statements about its late-1990s buyback program. I find these estimates credible. Indeed, they are close to what I myself found some years ago, using a structural supply-demand model for different debt instruments to estimate the impact of debt management policy. Specifically, I used my estimated model to simulate the effects of a switch out of long-term Treasury bonds and into short-term Treasury bills, in a quantity that was fairly large back in the pre-Reagan days when there was not much debt outstanding. My estimates indicated that, in response, the Treasury bill rate would rise by 18 basis points, the rate on three- to five-year securities would rise by 7 basis points, the rate on six- to eight-year maturities would fall by 21 basis points, and the rate on thirty-year maturities would fall by 25 basis points. These higher bill rates and lower bond rates, in turn, would induce private borrowers to shift their debt issuance from the short toward the long end of the available maturity range. As a result, although the rate on long-term government bonds went down by 25 basis points in my estimates, the rate on long-term corporate bonds-which is presumably what matters more for real economic activity—went down by only 12 basis points.

My only reservation about this part of the paper concerns the framing of the analysis in terms of the zero lower bound on nominal interest rates. What the authors are investigating is debt management policy (or, to repeat, statements about debt management policy). There is no reason to believe that the effects of debt management policy are any larger at or near the zero lower bound, nor is it necessarily the case that debt management policy is uninteresting away from the zero lower bound.

My reaction to the authors' treatment of changes in the size of the central bank's balance sheet likewise focuses not on what they did or what they found, but on how they describe this inquiry. Although they are careful to use language that does not make the point explicit, the question they are really asking here is whether changes in the quantity of money matter - even for prices! And their answer is mostly no, or at least that they do not matter under the economic conditions they have in mind.

It is a mark of how far the economics profession has come in the last two decades that it is possible to ask this question, and to give this answer, 
in the totally innocuous way the authors do. Twenty years ago most economists (although not everyone around the Brookings Panel table) automatically assumed that increasing the money stock would lead, at the least, to rising prices. Changes in money were what monetary policy was about. The idea that, once interest rates fell low enough, money and shortterm securities became perfect substitutes, so that further increases in money no longer mattered and monetary policy became impotent-that policymakers could not "push on a string"-was anathema. Today the whole conversation about monetary policy is couched in terms of interest rates, and any notion that the central bank would seek to increase or decrease the quantity of money, or that such changes in money would have any effect, in the absence of changes in interest rates is labeled "nonstandard." Indeed, the whole discussion now takes place without requiring mention of the word "money." Who ever said there is no such thing as intellectual progress?

Two smaller matters also merit at least some comment: First, why does the definition of a "pure pegging policy" require that the central bank match purchases or sales of the pegged security with sales or purchases of some other security, rather than with changes in the monetary base? In a model with only one kind of bond, "pegging the interest rate" always means being willing to vary the monetary base for this purpose. Why preclude that usage in a world with two or more kinds of bonds? And second, although I understand the desire of policymakers to take credit for all sorts of benefits that follow from "greater stability in the economy and in policy," I suspect that a major contributor to the decline in long-horizon risk premiums over the last decade and more, to which the authors point, has been the improvement in the efficiency and availability of the market's hedging facilities.

Let me close by returning to my remark at the outset that one reason this paper is welcome is simply that the authors are who they are. I have always regretted a certain cultural difference between policymakers in different domains: It is de rigueur for former active participants in foreign policy, for example, to write after-the-fact accounts of how policies were made, typically including details of the push and pull of how their institution or organization went about reaching its decisions. The practice among monetary policymakers, by contrast, is far more close-mouthed (or empty-penned). One can cite Sherman Maisel's book of a generation ago, and more recently books by Alan Blinder and Laurence Meyer, as 
well as by John Crow in Canada. But the serious student of the subject longs for books that were never written-in the United States alone by William McChesney Martin, Allen Sproul, Alfred Hayes, or other key players of that day; by Paul Volcker, or Anthony Solomon, or Gerald Corrigan; or by Alan Greenspan (although his would still be premature). Such books might not have the same public appeal as the classics of diplomacy by George Kennan and Dean Acheson and Henry Kissinger, but for students of our discipline they would be invaluable. I hope Governor Bernanke continues to engage in written reflection and analysis of his and his colleagues' actions, and of the thinking and discussions behind those actions, and that the book he will write in time will add to a literature that still stands much in need of further contributions.

Lars E. O. Svensson: ${ }^{1}$ This paper by Ben Bernanke, Vincent Reinhart, and Brian Sack is an important and interesting one, with a good theoretical discussion of and new empirical results on monetary policy alternatives at the zero lower bound (ZLB) on nominal interest rates. The paper is important and interesting also for the obvious reason that two of its authors are important and influential insiders at the Federal Reserve System. Notwithstanding the qualification that the views expressed are not necessarily shared by anyone else in the organization, the paper reveals some aspects of the Federal Reserve's thinking about and preparation for the possibility that the ZLB might bind at some future time.

I have no disagreements with the substance of the paper or the empirical results that the authors find. However, I believe that the paper's focus and emphasis are not quite right.

Consider a liquidity trap-a situation when the ZLB is strictly binding, in the sense that it prevents the central bank from setting the interest rate that is its instrument rate (the federal funds rate, in the case of the Federal Reserve) at its optimal level. What is the problem in a liquidity trap? The problem is that, even though the instrument rate is at zero, the real (shortterm) interest rate is too high, and as a consequence the economy is in a recession or inflation is too low (perhaps even negative), or both. The central bank would prefer a lower real interest rate and a more expansionary monetary policy stance, if that were possible.

How can the problem be solved? The central bank can lower the real interest rate if it can induce the private sector to expect a higher price level in the future. If expected inflation increases, the real interest rate falls, even

1. I thank Kathleen Hurley for secretarial and editorial assistance. 
if the nominal interest rate is unchanged at zero. But how can the central bank induce such expectations of a higher future price level? Indeed, this is the real problem in a liquidity trap. Consequently, in assessing policy alternatives in a liquidity trap, the focus should be on how effective each of those alternatives is in affecting expectations of the future price level. In this paper, however, the focus is mostly on affecting expectations of future interest rates, which is likely to be much less effective. ${ }^{2}$

\section{Price-Level Expectations in a Liquidity Trap}

Let me illustrate with a simple New Keynesian model. Let $x_{t} \equiv y_{t}-\bar{y}_{t}$ denote the output gap in the current period $t$, where $y_{t}$ denotes (log) output and $\bar{y}_{t}(\log )$ potential output. Potential output is assumed to be an exogenous stochastic process. Let $r_{t}$ denote the (short-term) real interest rate:

$$
r_{t} \equiv i_{t}-\pi_{t+1 \mid t} \equiv i_{t}-\left(p_{t+1 \mid t}-p_{t}\right),
$$

where $i_{t}$ denotes the nominal interest rate (the instrument rate), $\pi_{t+1 \mid t}$ denotes private sector expectations of one-period-ahead inflation, $p_{t}$ denotes the $(\log )$ price level, and $p_{t+1 \mid t}$ denotes the expected one-periodahead $(\log )$ price level. Let $\bar{r}_{t}$ denote the neutral (real) interest rate-that is, the Wicksellian natural interest rate, the real interest rate that would arise in a hypothetical flexible-price economy with output equal to potential output. In the simplest case, the neutral interest rate is given by

$$
\bar{r}_{t} \equiv \rho_{t}+(1 / \sigma)\left(\bar{y}_{t+1 \mid t}-\bar{y}_{t}\right),
$$

where $\rho_{t}$ is the rate of time preference (an exogenous stochastic process) and the positive constant $\sigma$ is the intertemporal elasticity of substitution for consumption. Hence the neutral interest rate is determined by the rate of time preference and expected growth of potential output. The output gap depends positively on the expected future output gap, $x_{t+1 \mid t}$,

2. Although, in some cases, a particular path of future interest rates may induce desirable price-level expectations in equilibrium, this way of affecting price-level expectations is certainly very indirect and in practice fraught with many difficulties. Furthermore, an interest rate commitment alone may not be sufficient to uniquely determine the price level, as emphasized long ago by Sargent and Wallace (1975) and more recently-in the context of a liquidity trap-by Benhabib, Schmitt-Grohé, and Uribe (2002). 
and negatively on the real interest rate gap, $r_{t}-\bar{r}_{t}$, according to the following aggregate demand relation:

$$
x_{t}=x_{t+1 \mid t}-\sigma\left(r_{t}-\bar{r}_{t}\right),
$$

which follows from a first-order condition for optimal consumption choice. The aggregate demand relation can be solved forward to period $t+T$ :

$$
x_{t}=x_{t+T \mid t}-\sigma \sum_{\tau=0}^{T-1}\left(r_{t+\tau \mid t}-\bar{r}_{t+\tau \mid t}\right) .
$$

This expression shows that the current output gap depends positively on the expected output gap $T$ periods ahead, $x_{t+T \mid t}$, and negatively on the sum of the current and expected future real interest rate gaps, $r_{t+\tau \mid t}-\bar{r}_{t+\tau \mid t}$, for the next $T$ periods. I assume that the horizon $T$ is chosen such that the economy is expected to be back to normal by then, in the sense that the output gap is expected to be approximately equal to zero, $x_{t+\left.T\right|_{t}} \approx 0$. The current output gap then depends only on the sum of the current and expected future real interest rate gaps for the next $T$ periods. If the current output gap is negative (the economy is in recession), the reason is that the sum of the current and expected future real interest rate gaps is too large-that is, the current and expected real interest rates are too high relative to the corresponding neutral interest rates.

Under the assumption that the economy is expected to be back to normal $T$ periods ahead, the current output gap can be written as

$$
\begin{gathered}
x_{t} \approx-\sigma \sum_{\tau=0}^{T-1}\left(i_{t+\tau \mid t}-\pi_{t+1+\tau \mid t}-\bar{r}_{t+\tau \mid t}\right) \\
=-\sigma \sum_{\tau=0}^{T-1} i_{t+\tau \mid t}+\sigma\left(p_{t+T \mid t}-p_{t}\right)+\sigma \sum_{\tau=0}^{T-1} \bar{r}_{t+\tau \mid t},
\end{gathered}
$$

where the first equality uses the definition of the real interest rate, and the second equality uses the fact that the sum of future inflation equals the total change in the $(\log )$ price level. I also assume that the economy is expected to be in or close to a liquidity trap during the next $T$ periods, so that the expected instrument rates for that period are approximately zero, $i_{t+\tau \mid t} \approx 0(0 \leq \tau \leq T-1)$. Then the first term on the right-hand side is approximately zero. For a given current price level $p_{t}$ (I assume that the current price level is sticky), the output gap depends only on the ex- 
pected price level $T$ periods ahead, $p_{t+T \mid t}$, and the sum of the expected neutral interest rates during the next $T$ periods. If the output gap is negative, so that the economy is in a recession, this is for two reasons: the sum of the current and expected future neutral interest rates, $\sum_{\tau=0}^{T-1} \bar{r}_{t+\tau \mid t}$, is too small, and the sum of the current and expected future real interest rates, $\sum_{\tau=0}^{T-1} r_{t+\tau \mid t} \approx-\left(p_{t+\left.T\right|_{t}}-p_{t}\right)$, is too large. That is, the expected future price level, $p_{t+T \mid t}$, is too low. It follows that the real interest rate can be lowered and the negative output gap reduced or eliminated if the central bank can induce private sector expectations of a higher future price level.

However, this paper is mostly about reducing the negative output gap by inducing private sector expectations of lower future instrument rates. Thus, in the case when the expected future instrument rates during the next $T$ periods are not exactly zero but positive, they can perhaps be reduced further toward zero. However, these rates are already low, and therefore what can be gained from reducing them is small. Furthermore, it may be possible to induce the private sector to expect instrument rates close to zero after period $T$ as well, after the liquidity trap is over. In the above framework, this would amount to creating expectations of a positive rather than a zero output gap $T$ periods ahead, $x_{t+T \mid t}>0$, which would reduce the current negative output gap. It seems likely that any such attempt to lower expectations of future instrument rates toward zero, when these expectations are already low to start with, will have very small, second-order effects on the current output gap.

In contrast, there is potentially a large first-order effect on the output gap from increasing expectations of the future price level. This is where I wish the focus of this paper had been.

\section{How Can the Central Bank Affect Expectations of the}

Future Price Level?

The insight that the solution to the problem of a liquidity trap involves affecting private sector expectations of the future price level is due to Paul Krugman. ${ }^{3}$ Krugman also noted that this principal solution immediately encounters a practical problem, namely, a credibility problem, in that it is not easy for a central bank to purposely affect such expectations.

3. Krugman (1998). 
In particular, a central bank that has built a reputation for consistent low-inflation policy finds it difficult to convince the private sector that it has suddenly changed its mind and wants the price level to increase substantially.

EXPANDING THE MONEY SUPPLY. One possible way to affect expectations of the future price level is by increasing the money supply: what the paper refers to as increasing the size of the central bank's balance sheet. As Krugman noted, this is effective only if the private sector perceives the increase in the money supply to be permanent. Unfortunately, there is no mechanism through which a modern central bank can commit itself to a particular future money supply.

We can see this in the above framework. Let us assume that the horizon $T$ is chosen such that the liquidity trap is expected to be over and interest rates are expected to be positive beginning in period $t+T: i_{t+T \mid t}>0$. To a first approximation, we may take demand for the monetary base to be proportional to nominal GDP when interest rates are positive. This implies (disregarding any constant)

$$
p_{t+T \mid t} \approx m_{t+T \mid t}-y_{t+T \mid t},
$$

where $m_{t+T \mid t}$ denotes the expected $(\log )$ monetary base $T$ periods ahead. That is, as an approximation, the expected future price level is directly related positively to the expected future monetary base and negatively to the expected future output level. If the central bank could affect private sector expectations of the future monetary base, it would, all else equal, also affect private sector expectations of the future price level to the same extent.

Unfortunately, it is not easy for a central bank to directly affect expectations of the future monetary base. The Japanese liquidity trap and the Bank of Japan's response to it provide an unusually clear-cut example. In March 2001 the Bank of Japan instituted its new policy of "quantitative easing," which consisted of a dramatic expansion of the monetary base. By the summer of 2004, the monetary base had increased by more than 60 percent. Suppose that the private sector believes this expansion to be permanent. The private sector would then believe that, some time in the future (for concreteness, say, in four years) when the Japanese liquidity trap is over, nominal GDP will have risen by more than 60 percent. Suppose that the private sector believes that Japanese real GDP in the next four years will rise by only some 10 to 15 percent. The private sector would then believe that, four years hence, the price level will be some 
40 to 45 percent higher than today. If this were the case, either the yen would depreciate by some 40 to 45 percent, or Japanese long-term interest rates would rise substantially, or some combination of the two would occur. In fact, neither has occurred. The obvious conclusion is that the private sector does not believe that the expansion of the monetary base is permanent. The quantitative easing has not affected price-level expectations. It appears to be a dramatic failure.

AN INFLATION TARGET OR A PRICE-LEVEl TARGET. An inflation target or, better, a price-level target would be a fine solution, if it were credible. However, merely announcing the target would not be enough: the announcement would have to be combined with statements and actions that make it credible. This seems to be a particular problem for central banks like the Federal Reserve and the Bank of Japan, since they have clearly demonstrated over many years their notorious aversion to any numerical target or other explicit commitment.

FISCAL POLICY. A fiscal expansion-an increase in the fiscal deficitmay or may not be expansionary and increase aggregate demand, depending on the composition of the fiscal expenditure, the degree of Ricardian equivalence, and so forth. Typically, Ricardian equivalence does not seem to hold, and a fiscal deficit is expansionary; however, private sector behavior may be closer to Ricardian equivalence in a crisis, with a fiscal deficit that is perceived to be unsustainable and an expected imminent fiscal consolidation through increased taxes, reduced spending, or both. Japan has certainly tried to implement an expansionary fiscal policy, but this, too, has failed to free Japan from the liquidity trap, although it has certainly led to a dramatic deterioration of Japan's public finances.

A money-financed rather than debt-financed fiscal expansion is often proposed as a remedy for a liquidity trap. But often it is not understood that, for a given fiscal deficit, and aside from any debt-induced inflation incentives for government-controlled (rather than independent) central banks, both money and debt financing work through exactly the same mechanism discussed above in regard to expanding the money supply. Money financing of a fiscal expansion will affect expectations of the future price level only to the extent that it is interpreted as a permanent expansion of the money supply. Again, since there is no mechanism by which the central bank can commit to a future money supply, current money financing of a deficit does not exclude the possibility that the money supply will be reduced in the future. Money financing of a fiscal expansion hence 
provides no separate mechanism by which to affect expectations of the future price level.

EMPIRICAL ASSESSMENT OF POLICY ALTERNATIVES IN A LIQUIDITY TRAP. In line with the above discussion, the empirical assessment of alternative policies in a liquidity trap should focus on their impact on price-level expectations. An obvious problem is that there are very few examples of this approach being taken, and so a case study approach seems the only feasible one. The "Rooseveltian Resolve" of 1933-34 seems a good case to examine from this point of view, with its devaluation, its new commitment to end deflation and reflate the economy, and its associated impression of a regime change. ${ }^{4}$ An examination of price expectations data from this period would prove interesting. Generally, it seems more relevant and revealing to look at price expectations data than interest rate expectations data when assessing alternative policies in a liquidity trap. In particular, one may want to look at data on the effect of central bank communication on price-level expectations.

THE FOOLPROOF WAY. In several recent papers, ${ }^{5}$ I have promoted what I call the "Foolproof Way" as an effective policy to escape from a liquidity trap. The Foolproof Way involves, first, the announcement and implementation of a price-level target; second, a currency depreciation and peg consistent with the price-level target; and, third, an exit strategy, to be undertaken when the price-level target has been reached, in which the currency is floated and inflation targeting or price-level targeting is instituted.

In terms of the above framework, the idea is to induce private sector expectations of a higher future price level, such that the real interest rate falls and the economy expands out of the liquidity trap. Let the price-level target for period $t+T, \hat{p}_{t}$, be such that price-level expectations satisfying

$$
p_{t+T \mid t}=\hat{p}_{t+T \mid t},
$$

and zero instrument rates during the next $T-1$ periods would be adequate to achieve the desired fall in the real interest rate and increased stimulus of the economy. Price-level expectations and exchange rate expectations will be related according to

$$
p_{t+T \mid t}=s_{t+T \mid t}+p_{t+T \mid t}^{*}-q_{t+T \mid t}
$$

4. This episode is discussed by Bernanke (2000).

5. Svensson (2001, 2003, 2004); Jeanne and Svensson (2004). 
where $s_{t}$ denotes the $(\log )$ exchange rate, $p_{t}^{*}$ denotes the $(\log )$ foreign price level, and $q_{t}$ denotes the $(\log )$ real exchange rate. I assume that the horizon $T$ is chosen such that the economy is expected to be back to normal by then, and in particular that it is chosen such that the real exchange rate is expected to be back to its natural (neutral, potential) level, $\bar{q}_{t+T \mid t}$, and hence can be treated as exogenous from the perspective of current monetary policy. I also assume that the foreign price level can be taken as exogenous. Under these assumptions the expected future price level and the expected future exchange rate are directly related and move together.

By interest parity, the current exchange rate is related to the expected future exchange rate and the interest rate differential between the home and the foreign interest rate, $i_{t}-i_{t}^{*}$, by

$$
s_{t}=s_{t+1 \mid t}-\left(i_{t}-i_{t}^{*}\right)=s_{t+T \mid t}-\sum_{\tau=0}^{T-1} i_{t+\tau \mid t}+\sum_{\tau=0}^{T-1} i_{t+\tau \mid t}^{*}
$$

where the second equality follows from solving forward $T$ periods. By equation 2 , we get

$$
S_{t}=p_{t+T \mid t}-\sum_{\tau=0}^{T-1} i_{t+\tau \mid t}+\ldots,
$$

where the exogenous terms have been left out. The expectation that future instrument rates will approximately equal zero implies that the current exchange rate is directly related to and moves together with the expected future price level. An increase in the expected future price level corresponds to an equal current depreciation of the currency. The exchange rate peg of the Foolproof Way implements the exchange rate consistent with the future price-level target and the zero instrument rates. ${ }^{6}$ If the Foolproof Way and its price-level target are immediately credible, price-level expectations will rise to fulfill equation 1 , and the currency will, by equation 2 , depreciate by the same amount, and the peg will not be binding. Otherwise, the peg forces private sector price-level expectations to be consistent with the price-level target.

Many comments on the Foolproof Way, including in this paper, have suggested that a potential improvement in the trade balance due to currency depreciation under the peg may be problematic for the trading

6. The peg may need to incorporate a rate of crawl to be exactly consistent with a zero home instrument rate. A constant peg would imply a home instrument rate equal to the foreign short-term interest rate, but the practical difference is small. 
partners. However, any effects on the trade balance will be exactly the same as would result from a credible price-level target without any peg, or a lower instrument rate, if that were not prevented by the ZLB. The truth is that any expansionary monetary policy implies a real depreciation and thus a trade balance effect. Furthermore, any net effect on the trade balance from expansionary monetary policy will consist of income and substitution effects of opposite signs. In a liquidity trap and a deep recession, the income effect on the trade balance may be particularly strong and actually improve the trade balance for the trading partners. Finally, nothing prevents the trading partners from conducting their own expansionary monetary policy to counteract any contractionary effect from the Foolproof Way. In this way, an optimal world monetary expansion might be achieved. ${ }^{7}$

\section{Changing the Composition of the Central Bank Balance Sheet}

The paper also discusses changes in the composition of the central bank balance sheet as a policy alternative in the vicinity of the ZLB. ${ }^{8}$ The purpose of such a policy is to affect various risk premiums through portfolio balance effects. For example, consider the relation between the interest rate on a nominal discount bond with a maturity of $T$ periods, $i_{t}^{T}$, and the instrument rate,

$$
i_{t}^{T}=(1 / T) \sum_{\tau=0}^{T-1} i_{t+\tau \mid t}+\varphi_{t}^{T} .
$$

Here $\varphi_{t}^{T}$ denotes a term premium, which may depend on the relative supply of maturity- $T$ government bonds, denoted $B_{t}^{T}$. If initially $i_{t}^{T}$ is positive, by changing the composition of its assets so as to increase the proportion of maturity- $T$ bonds and reduce the proportion of Treasury bills,

7. See Svensson (2004) for an analysis of the international effects of the Foolproof Way. One possible problem with the Foolproof Way is that the central bank may have an incentive to renege in the future through an unanticipated currency appreciation, so as to achieve low inflation ex post. However, Jeanne and Svensson (2004) show-starting from the fact that a currency appreciation reduces the home-currency value of foreign exchange reserves, and given the strong aversion toward negative central bank capital revealed by central bank officials and noted by central bank commentators-that a central bank can manage its capital so as to create a commitment not to appreciate the currency in the future.

8. Note that the management of central bank capital so as to create a commitment not to appreciate the currency, discussed in Jeanne and Svensson (2004), is an example of a policy that changes the composition of central bank capital (see note 6). 
the central bank can reduce the relative supply of maturity- $T$ bonds and lower the term premium, thereby lowering $i_{t}^{T}$ toward zero. It is possible in principle for central banks to lower the interest rate on longer-term bond rates somewhat this way. The paper reports some very interesting empirical results on the Federal Reserve's attempts to affect long-term interest rates. But it is not clear that such attempts will have a substantial effect on the current output gap. The impact is probably one of a few basis points, or at most a few tens of basis points, on long-term bond rates that are probably already low. Compared with changes in price-level expectations, it seems to be a second-order effect. ${ }^{9}$ Although the paper's empirical results are very interesting and the analysis is well done, it seems clear that we are talking about rather small effects.

\section{Conclusion}

In conclusion, it seems obvious that, in the face of a liquidity trap, monetary policy should focus on policy alternatives that are capable of affecting expectations of the future price level rather than just affecting expectations of future interest rates. The effect of changing price-level expectations and related exchange rates seems much more powerful than that of changing long-term nominal interest rates or expectations of future short-term interest rates that are already close to zero. Obviously, there is no bound on prices or exchange rates similar to that on nominal interest rates. Therefore I would like to see more theoretical and empirical research on policies in a liquidity trap that focus on affecting pricelevel expectations.

General discussion: Robert Gordon agreed with Lars Svensson on the importance of distinguishing between the effects of monetary policy on expectations about future interest rates and its effects on expectations about the future price level. But he disagreed with the view that there is a direct connection between monetary policy statements or actions and expectations about the price level in an economy like the United States. In his view the output gap and supply shocks such as changes in oil prices or exchange rates are the major factors affecting inflation, and they do so

9. In the simple analytical framework used in this comment, it is not clear whether $i_{t}^{T}$ or $\sum_{\tau=0}^{T-1} i_{t+\tau \mid t}$ matters more for the output gap. A more elaborate model, one that does not use first-order approximations, is needed to answer that question. 
with long and variable lags. In order for statements or actions by the central bank to affect expectations of the future price level, they have to alter expectations of these variables. Even before the emergence of modern financial markets, the monetary base, the instrument directly controlled by policy, was not reliably related to either the money supply or nominal output and prices. The classic example is 1938-39, during the administration of Franklin Roosevelt, when the monetary base tripled in the United States as gold flowed in from Europe. Although the increase in the money supply was substantial, it was far less in percentage terms than the increase in the monetary base, and there was no jump in the price level. The Japanese experience in the face of a liquidity trap in 2001 was similar.

Lars Svensson agreed that a liquidity trap is an extreme situation and that in those circumstances it would be difficult for any central bank to affect expectations by announcing a price-level target. But, he argued, the exchange rate is a much more effective means of affecting price-level expectations. Furthermore, the exchange rate, unlike the nominal shortterm interest rate, has no zero bound. Olivier Blanchard remarked that a currency devaluation would increase costs for some firms, which would lead to an immediate increase in some prices and quickly affect expectations of the future price level. Gordon expressed his doubts, observing that, following the 1992 breakup of the European Exchange Rate Mechanism, the pass-through of the exchange rate change to domestic price levels was far from complete.

Several Panel participants pursued the question of whether communications are effective during a liquidity trap. Robert Lawrence found the evidence on the efficacy of such nonconventional monetary policy mechanisms in normal times quite compelling, but he thought it risky to assume the same results in the unusual circumstances of a liquidity trap. This could be why such policies have not worked very well in Japan. Adam Posen echoed Lawrence's concern that announcement effects may not work in a zero-interest-rate environment; he and Kenneth Kuttner had written a paper that reported little impact of statements by the Bank of Japan. William Nordhaus wondered whether one reason Japan has not had success is the lack of a unified central bank with a highly credible leader. John Leahy was also impressed with the evidence on the effectiveness of central bank communication, but he emphasized that the communications studied in the present paper were about monetary instruments over which the Federal Reserve has clear control. It is not obvious 
how much impact the Federal Reserve could have when commenting about variables, such as the inflation rate, that are not under its direct control. Posen, reminding the Panel that a fiscal expansion brought an end to the Great Depression, suggested analyzing the effects of coordinated monetary and fiscal actions near the zero lower bound. Statements about a coordinated monetary and fiscal policy in such circumstances were likely to be more effective than statements about either one separately. Nordhaus found the results on communications both interesting and persuasive. He thought they were consistent with a 2003 paper by Ray Fair in the Journal of International Money and Finance, which estimated the responses of stocks, bonds, and the exchange rate to unexpected announcements in official releases of various economic indicators. Of these "data shocks," those in employment reports had the largest effect on interest rates. However, Nordhaus questioned the authors' interpretation of the United States going off the gold standard as an example of quantitative easing, arguing that Roosevelt's action was essentially an exchange rate event. Ben Bernanke replied that that devaluation could indeed be interpreted as a case of quantitative easing, because it freed up the money supply rather than changing relative prices. 


\section{References}

Adam, Klaus, and Roberto M. Billi. 2004. "Optimal Monetary Policy under Commitment with a Zero Bound on Nominal Interest Rates." Working paper. Frankfurt: European Central Bank (May).

Akerlof, George A., William T. Dickens, and George L. Perry. 1996. "The Macroeconomics of Low Inflation." BPEA, no. 1: 1-59.

Andres, Javier, David Lopez-Salido, and Edward Nelson. 2003. "Tobin's Imperfect Asset Substitution in Optimizing General Equilibrium." Presented at the James Tobin Symposium, sponsored by the Journal of Money, Credit, and Banking and the Federal Reserve Bank of Chicago, November 14-15.

Ang, Andrew, and Monika Piazzesi. 2003. "A No-Arbitrage Vector Autoregression of Term Structure Dynamics with Macroeconomic and Latent Variables." Journal of Monetary Economics 50: 745-87.

Ang, Andrew, Monika Piazzesi, and Min Wei. 2003. "What Does the Yield Curve Tell Us about GDP Growth?" Working Paper 10672. Cambridge, Mass.: National Bureau of Economic Research (October).

Auerbach, Alan J., and William G. Gale. 2000. "Perspectives on the Budget Surplus." National Tax Journal 53, no. 3, part 1: 459-72.

Auerbach, Alan, and Maurice Obstfeld. 2004. "The Case for Open Market Purchases in a Liquidity Trap." Working paper. University of California, Berkeley (May).

Baba, Naohiko, and others. 2004. "Japan's Deflation, Problems in the Financial System, and Monetary Policy." Paper presented at a Bank for International Settlements conference on Understanding Low Inflation and Deflation, Brunnen, Switzerland, June 19.

Benhabib, Jess, Stephanie Schmitt-Grohé, and Martin Uribe. 2002. "Avoiding Liquidity Traps.” Journal of Political Economy 110, no. 3: 535-63.

Bernanke, Ben S. 2000. "Japanese Monetary Policy: A Case of Self-Induced Paralysis?" In Japan's Financial Crisis and Its Parallels to U.S. Experience, edited by Adam Posen and Ryoichi Mikitani. Special Report 13. Washington: Institute for International Economics.

2002. "Deflation: Making Sure 'It' Doesn't Happen Here." Remarks before the National Economists' Club, Washington, November 21 (www.federalreserve.gov/boarddocs/speeches/2002/20021121/default.htm).

. 2003. "Some Thoughts on Monetary Policy in Japan." Speech to the Japan Society of Monetary Economics, Tokyo, May 31 (www.federalreserve.gov/boarddocs/speeches/2003/20030531/default.htm).

Bernanke, Ben, and Kenneth Kuttner. Forthcoming. "Why Does Monetary Policy Affect the Stock Market?" Journal of Finance. 
Bernanke, Ben, and Vincent Reinhart. 2004. "Conducting Monetary Policy at Very Low Short-Term Interest Rates." American Economic Review 94, no. 2: 85-90.

Blinder, Alan. 2000. "Monetary Policy at the Zero Lower Bound: Balancing the Risks: Summary Panel." Journal of Money, Credit, and Banking 32, no. 4: 1093-99.

Bolder, David J. 2001. "Affine Term-Structure Models: Theory and Implementation." Working Paper 2001-15. Ottawa: Bank of Canada.

Bomfim, Antulio N. 2003. "Interest Rates as Options: Assessing the Markets' View of the Liquidity Trap." Working paper. Washington: Board of Governors of the Federal Reserve System (July).

Brainard, William C., and James Tobin. 1968. "Pitfalls in Financial ModelBuilding." American Economic Review 58, no. 2: 99-122.

Clouse, James, and others. 2003. "Monetary Policy When the Nominal ShortTerm Interest Rate Is Zero." Topics in Macroeconomics 3, no. 1, article 12 (www.bepress.com/bejm/topics/vol3/iss1/art12).

Coenen, Günter, Athanasios Orphanides, and Volker Wieland. 2004. "Price Stability and Monetary Policy Effectiveness When Nominal Interest Rates Are Bounded at Zero." Advances in Macroeconomics, 4, no. 1, article 1 (www. bepress.com/bejm/advances/vol4/iss1/art1).

Cox, John C., Jonathan E. Ingersoll, Jr., and Stephen A. Ross. 1985. "A Theory of the Term Structure of Interest Rates." Econometrica 53, no. 2: 385-407 (March).

Duffie, Darrell, and Rui Kan. 1996. "A Yield-Factor Model of Interest Rates." Mathematical Finance, 6, no. 4: 379-406.

Eggertsson, Gauti, and Michael Woodford. 2003a. "The Zero Bound on Interest Rates and Optimal Monetary Policy." BPEA, no. 1: 139-211.

2003b. "Optimal Monetary Policy in a Liquidity Trap." Working Paper 9968. Cambridge, Mass.: National Bureau of Economic Research (September).

Eichengreen, Barry J. 1992. Golden Fetters: The Gold Standard and the Great Depression, 1919-1939. New York: Oxford University Press.

Eichengreen, Barry, and Peter Garber. 1991. "Before the Accord: U.S. MonetaryFinancial Policy, 1945-51." In Financial Markets and Financial Crisis, edited by R. Glenn Hubbard. University of Chicago Press.

Feldstein, Martin. 1997. "The Costs and Benefits of Going from Low Inflation to Price Stability." In Reducing Inflation: Motivation and Strategy, edited by Christina Romer and David Romer. University of Chicago Press.

Fischer, Stanley. 1996. "Why Are Central Banks Pursuing Long-Run Price Stability?" In Achieving Price Stability. Kansas City: Federal Reserve Bank of Kansas City. 
Fisher, Mark, Douglas W. Nychka, and David Zervos. 1995. "Fitting the Term Structure of Interest Rates with Smoothing Splines." Finance and Economics Discussion Paper 95-1. Washington: Board of Governors of the Federal Reserve System.

Friedman, Benjamin M., and Kenneth N. Kuttner. 1998. "Indicator Properties of the Paper-Bill Spread: Lessons from Recent Experience." Review of Economics and Statistics 80, no. 1: 34-44.

Friedman, Milton. 1969. The Optimum Quantity of Money and Other Essays. Chicago: Aldine.

Fujiki, Hiroshi, and Shigenori Shiratsuka. 2002. "Policy Duration Effect under the Zero Interest Rate Policy in 1999-2000: Evidence from Japan's Money Market Data." Monetary and Economic Studies 20, no. 1: 1-31.

Gürkaynak, Refet, Brian Sack, and Eric Swanson. Forthcoming. "The Sensitivity of Long-Term Interest Rates to Economic News: Evidence and Implications for Macroeconomic Models." American Economic Review.

Hodrick, Robert J. 1992. "Dividend Yields and Expected Stock Returns: Alternative Procedures for Inference and Measurement." Review of Financial Studies 5, no. 3: 357-86.

Holland, Thomas E. 1969. “ 'Operation Twist' and the Movement of Interest Rates and Related Economic Time Series." International Economic Review 10, no. 3: 260-65.

Hutchinson, William K., and Mark Toma. 1991. "The Bond Price Support Program as a Change in Policy Regimes: Evidence from the Term Structure of Interest Rates." Journal of Money, Credit, and Banking 23, no. 3: 367-82.

Jeanne, Olivier, and Lars E. O. Svensson. 2004. "Credible Commitment to Optimal Escape from a Liquidity Trap: The Role of the Balance Sheet of an Independent Central Bank." Working paper. Princeton University (July). (www. princeton.edu/ svensson/papers/js.pdf).

Kimura, Takeshi, and others. 2002. "The Effect of the Increase in Monetary Base on Japan's Economy at Zero Interest Rates: An Empirical Analysis." IMES Discussion Paper Series 2002-E-22. Tokyo: Bank of Japan (December).

Kohn, Donald L., and Brian P. Sack. 2003. "Central Bank Talk: Does It Matter and Why?" Finance and Economics Discussion Series 2003-55. Washington: Board of Governors of the Federal Reserve System (August).

Krugman, Paul. 1998. “It's Baaack! Japan's Slump and the Return of the Liquidity Trap.” BPEA, no. 2: 137-87.

Kuttner, Kenneth N. 2001. "Monetary Policy Surprises and Interest Rates: Evidence from the Fed Funds Futures Market." Journal of Monetary Economics 47, no. 3: 523-44.

Longstaff, F. A., and E. S. Schwartz. 1992. "A Two-Factor Interest Rate Model and Contingent Claims Evaluation." Journal of Fixed Income 2, no. 3: $16-23$. 
Marumo, Kohei, and others. 2003. "Extracting Market Expectations on the Duration of the Zero Interest Rate Policy from Japan's Bond Prices." Financial Markets Department Working Paper 03-E-2. Tokyo: Bank of Japan (July).

Meltzer, Allan H. 1999. "Comments: What More Can the Bank of Japan Do?" Bank of Japan, Monetary and Economic Studies 17, no. 3: 189-91.

2001. "Monetary Transmission at Low Inflation: Some Clues from Japan in the 1990s." Bank of Japan, Monetary and Economic Studies 19, S-1: 13-34.

Modigliani, Franco, and Richard Sutch. 1966. "Innovations in Interest Rate Policy." American Economic Review 56, no. 1/2: 178-97.

1967. "Debt Management and the Term Structure of Interest Rates: An Empirical Analysis of Recent Experience.” Journal of Political Economy 75, no. 4, part 2: 569-89.

Nagayasu, Jun. 2004. "The Term Structure of Interest Rates and Monetary Policy during a Zero Interest Rate Period." Bank of Japan, Monetary and Economic Studies 22, no. 2: 19-43.

Okina, Kunio, and Shigenori Shiratsuka. 2004. "Policy Commitment and Expectation Formation: Japan's Experience under Zero Interest Rates." North American Journal of Economics and Finance 15, no. 1: 75-100.

Phelps, Edmund S. 1972. Inflation Policy and Unemployment Theory. London: Macmillan.

Reifschneider, David, and John C. Williams. 2000. "Three Lessons for Monetary Policy in a Low-Inflation Era." Journal of Money, Credit, and Banking 32, no. 4, part 2: 936-66.

Reinhart, Vincent, and Brian Sack. 2000. "The Economic Consequences of Disappearing Government Debt.” BPEA, no. 2: 163-209.

Roley, V. Vance. 1982. "The Effect of Federal Debt-Management Policy on Corporate Bond and Equity Yields." Quarterly Journal of Economics 97, no. 4: 645-68.

Romer, Christina D. 1992. "What Ended the Great Depression?" Journal of Economic History 52, no. 4: 757-84.

Rudebusch, Glenn D., and Tao Wu. 2003. "A Macro-Finance Model of the Term Structure, Monetary Policy, and the Economy.” Working Paper 2003-17. Federal Reserve Bank of San Francisco (September).

Ruge-Murcia, Francisco J. 2002. "Some Implications of the Zero Lower Bound on Interest Rates for the Term Structure and Monetary Policy." Cahier 062002. Université de Montreal.

Sargent, Thomas J., and Neil Wallace. 1975. " 'Rational' Expectations, the Optimal Monetary Instrument, and the Optimal Money Supply Rule." Journal of Political Economy 83, no. 2: 241-54.

Shirakawa, Masaaki. 2002. "One Year under 'Quantitative Easing.' " IMES Discussion Paper 2002-E-3. Tokyo: Bank of Japan (April). 
Summers, Lawrence. 1991. "Panel Discussion: How Should Long-Term Monetary Policy Be Determined?" Journal of Money, Credit, and Banking 23, no. 3, part 2: 625-31.

Svensson, Lars E. O. 2001. "The Zero Bound in an Open Economy: A Foolproof Way of Escaping from a Liquidity Trap." Bank of Japan, Monetary and Economic Studies 19, S-1: 277-312.

. 2003. "Escaping from a Liquidity Trap and Deflation: The Foolproof Way and Others." Journal of Economic Perspectives 17, no. 4: 145-66.

. 2004. "The Magic of the Exchange Rate: Optimal Escape from a Liquidity Trap in Small and Large Open Economies.” Working paper. Princeton University. (www.princeton.edu/ svensson/papers/mag.pdf[July].)

Takeda, Yosuke, and Yasuhide Yajima. 2002. "How the Japanese Government Bond Market Has Responded to the Zero Interest Rate Policy." Tokyo: NLI Research Institute (www.nli-research.co.jp/eng/resea/econo/eco020903.pdf [December 2004]).

Temin, Peter, and Barrie Wigmore. 1990. "The End of One Big Deflation." Explorations in Economic History 27 (October): 483-502.

Tobin, James. 1963. “An Essay on Principles of Debt Management.” In Commission on Money and Credit, Fiscal and Debt Management Policies (cowles.econ.yale.edu/P/cp/p01b/p0195.pdf). . 1969. "A General Equilibrium Approach to Monetary Theory." Journal of Money, Credit, and Banking 1, no. 1: 15-29. . 1974. The New Economics: One Decade Older. Princeton University Press.

Toma, Mark. 1992. "Interest Rate Controls: The United States in the 1940s." Journal of Economic History 52, no. 3: 631-50.

Vasicek, Oldrich. 1977. "An Equilibrium Characterization of the Term Structure." Journal of Financial Economics 5: 177-88.

Woodford, Michael. 2003. Interest and Prices: Foundations of a Theory of Monetary Policy. Princeton University Press. 